\title{
Aquisição de Conhecimento Utilizando Aprendizado de Máquina Relacional
}

\author{
Chandler Wellington Caulkins
}

Orientadora: Profa. Dra. Maria Carolina Monard

Dissertação apresentada ao Instituto de Ciências Matemáticas e de Computação - ICMC-USP, como parte dos requisitos para obtenção do título de Mestre em Ciências - Área: Ciências de Computação e Matemática Computacional.

USP - São Carlos

Julho de 2000 
Esta dissertação foi produzida utilizando o formatador de texto LaTeX. Para gerar a bibliografia foi utilizada uma ferramenta associada ao formatador chamada BibTeX, por isso pode haver algumas frases em inglês fora de lugar. 


\section{Agradecimentos}

À minha orientadora e professora, Maria Carolina Monard, por sua dedicação e perseverança e por tudo que me ensinou sobre Inteligência Artificial;

Aos meus pais, Donald e Marion, por seu amor e carinho que sempre me sustentaram;

Aos meus irmãos, Mateus, Caio e Bryan, por tudo pelo que passamos juntos e ainda haveremos de passar;

Aos amigos passados, presentes e futuros: Valéria, João, Dani, Ludimila, Mirla, Marisa, Júlio, ... são tantos que só quero agradecer pelos dias e noites de amizade e apoio;

A Solange, Naiara, Antônio e Vitor, pela amizade de tantos anos e o apoio que sempre me deram;

Ao pessoal do LABIC: Cris, Claudinha, Adriano, Jaque, Walter, Robson, Gustavo, Claudia, Augusto e todo o resto do povo pelo ambiente que compartilhamos;

Aos funcionários do meu querido ICMC: Paulinho, Marília, Laura, Beth, Jacques, Pedrão,

Sandrinha, Dri, Sandra, Maria e Rose da Biblioteca por tudo que fizeram por mim 


\section{Resumo}

Aprendizado de Máquina - AM - é uma área de Inteligência Artificial - IA - que estuda métodos computacionais para adquirir novos conhecimentos bem como meios de organizar o conhecimento já existente. Para isso, são necessárias linguagens de descrição de objetos e de conceitos aprendidos. Elas podem ser divididas em dois tipos: baseadas em atributos, ou proposicionais, e relacionais. Sistemas de AM proposicional tếm sido aplicados com relativo sucesso, utilizando dados no formato atributo-valor. No entanto, são incapazes de aprender relações em função da linguagem que utilizam. Programação Lógica Indutiva - PLI - é uma abordagem recente dentro de AM que faz uso de uma linguagem de descrição relacional baseada em lógica de primeira ordem, de modo que consegue aprender relaçōes entre os objetos.

Todo problema que pode ser resolvido por um sistema de aprendizado proposicional pode, em princípio, ser resolvido por um sistema de aprendizado relacional, desde que os dados estejam devidamente formatados. Uma série de ferramentas foi por nós implementada para converter os dados do formato atributo-valor para o formato relacional apropriado de dois sistemas de PLI, FOIL (Quinlan, 1990) e PROGOL (Muggleton, 1995). A partir dessas representações, tornou-se possível analisar o comportamento de cada um deles em bases de dados naturais com características diferentes.

Como estudo de caso do mundo real, utiliza-se uma base de dados disponibilizada pelo Programa de Melhoramento Genético da Raça Nelore - PMGRN - da Universidade de São Paulo em Ribeirão Preto (Lôbo et al., 1999). Utilizando os sistemas PLI, adquire-se um conhecimento sobre essa base de dados de gado. Para tanto segue-se uma metodologia baseada no processo KDD (Knowledge Discovery in Databases) descrito em (Fayyad, 1996). 


\begin{abstract}
Machine Learning - ML - is an area in Artificial Intelligence - AI - which studies computational methods for acquiring new knowledge along with ways to organize existing knowledge. To do this, descriptive languages are necessary for the objects being studied as well as the concepts that are learned. The languages can be divided into two types: languages based on attributes, or propositional languages, and relational languages. Propositional ML systems have been applied to several problemas with quite a bit of success, by using data in an attribute-value format. Yet they cannot learn relationships because of the propositional language they use. Inductive Logic Programming - ILP - is a recent ML approach which uses a relational description language based on first-order logic, so that it is able to learn relationships between objects.

Any problem that can be solved using propositional learning can, theoretically, be solved using a relational learning system, once the data has been put in the correct format. A series of tools have been implemented by us to convert data in attribute-value format to appropriate relational formats for two ILP systems, FOIL (Quinlan, 1990) and PROGOL (Muggleton, 1995). Using these representations, it is possible to analyze the behavior of each one in natural databases with different characteristics.

A database made available by the Program for the Genetic Improvement of the Nelore Breed - PMGRN - at the University of São Paulo in Ribeirão Preto is used as a realworld case study. Some knowledge is acquired about the cattle database, by using an ILP system and the results are discussed. A knowledge acquisition process based on the Knowledge Discovery in Databases - KDD - process described in (Fayyad, 1996) is used.
\end{abstract}




\section{Sumário}

1 Introdução 1

1.1 Linguagens de Representação . . . . . . . . . . . . . . . . 2

1.2 Organização do Trabalho . . . . . . . . . . . . . . . 5

2 Programação Lógica Indutiva $\quad 6$

2.1 Considerações Iniciais . . . . . . . . . . . . . . . . . . . 6

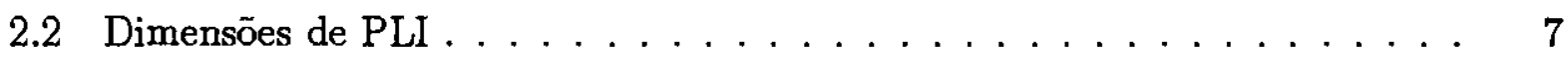

2.3 O Processo de Aprendizado em PLI . . . . . . . . . . . . . . 8

2.4 Completude e Consistência de uma Hipótese . . . . . . . . . . . 9

2.5 Um Exemplo de Aprendizado Relacional em PLI . . . . . . . . . . . . . . . 11

2.6 Considerações Finais . . . . . . . . . . . . . . . . . . . 12

3 Técnicas Básicas de PLI 13

3.1 Considerações Iniciais . . . . . . . . . . . . . . . . . . . 13

3.2 Terminologia Utilizada . . . . . . . . . . . . . . . . . . . . . 14

3.3 A Relação $\theta$-subsoma . . . . . . . . . . . . . . . . . . . . . . 16

3.4 Técnicas de Generalização . . . . . . . . . . . . . . . . 18

3.4 .1 Menor Generalização Geral $\ldots \ldots \ldots . \ldots 18$

3.4 .2 Menor Generalização Geral Relativa . . . . . . . . . . . . . 20

3.4 .3 Resolução Inversa . . . . . . . . . . . . . . . . . . . . 22

3.5 Técnicas de Especialização . . . . . . . . . . . . . . . 25

3.6 Modelos de $\operatorname{Regras} \ldots \ldots \ldots \ldots$. . . . . . . . . . . . 27 
3.7 Transformação de Problemas de PLI para a Forma Proposicional . . . . . . 28

3.8 Considerações Finais . . . . . . . . . . . . . . . . . . . . . 30

4 Alguns Sistemas de PLI

4.1 Considerações Iniciais . . . . . . . . . . . . . . . . . . . . . . . 31

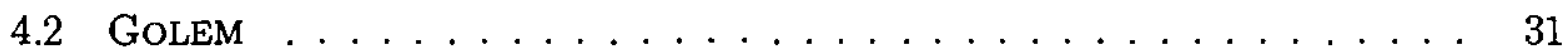

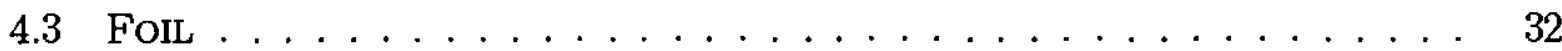

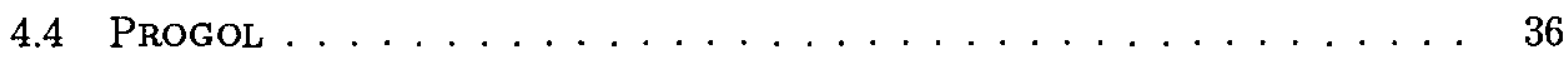

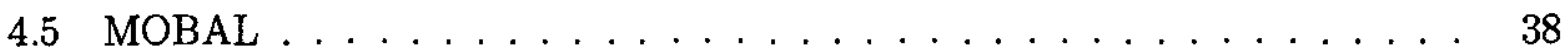

4.6 Consideraçōes Finais . . . . . . . . . . . . . . . . . . . . . 40

5 Ferramentas para Conversão de Dados no Formato Atributo-Valor para o Formato Relacional $\quad 41$

5.1 Considerações Iniciais . . . . . . . . . . . . . . . . . . . . . . . 41 4

5.2 Formato Atributo-Valor $\ldots \ldots \ldots \ldots 4 \ldots \ldots \ldots$

5.3 Método MB - Morik e Brockhausen . . . . . . . . . . . . . . . 42

5.4 Ferramentas para o Processo de Conversão . . . . . . . . . . . . . . . . 44

$5.4 .1 \quad \mathrm{De} \mathcal{C N} 2$ para $\mathcal{C} 4.5 \ldots \ldots \ldots \ldots \ldots \ldots$

5.4 .2 De $\mathcal{C} 4.5$ para Foll "Proposicional" $\ldots \ldots \ldots \ldots \ldots$

5.4.3 De Foll "Proposicional" para Progol "Proposicional" . . . . . . 51

5.4 .4 De Foll "Proposicional" para Progol MB . . . . . . . . . . . 56

5.4.5 De Foll "Proposicional" para Foll MB . . . . . . . . . . . . . . . 59

5.5 Consideraçōes Finais . . . . . . . . . . . . . . . . . . . . . 63

6 Comparaçāo Empírica de Foll e Progol Utilizando Dados no Formato Atributo-Valor $\quad 65$

6.1 Considerações Iniciais . . . . . . . . . . . . . . . . . . . 65

6.2 Conjuntos de Dados . . . . . . . . . . . . . . . 66

6.2.1 Descrição Geral dos Conjuntos de Dados . . . . . . . . . . . . 66

6.2.2 Características dos Conjuntos de Dados . . . . . . . . . . . 67

6.3 Descrição dos Experimentos . . . . . . . . . . . . . . . . 68 
6.4 Medidas Consideradas . . . . . . . . . . . . . . . . . . 69

6.5 Resultados Experimentais . . . . . . . . . . . . . . . . . . 72

6.6 Considerações Finais . . . . . . . . . . . . . . . . . 81

7 Estudo de Caso com uma Base de Dados sobre Gado Nelore 83

7.1 Considerações Iniciais . . . . . . . . . . . . . . . . . . 83

7.2 Histórico do PMGRN . . . . . . . . . . . . . . . . . . . 83

7.3 Contexto do Problema $\ldots \ldots \ldots \ldots$. . . . . . . . . . 84

7.4 Processo para Aquisição de Conhecimento . . . . . . . . . . . 87

7.4 .1 Definição do Problema . . . . . . . . . . . . . . 88

7.4 .2 Coleta, Limpeza e Preparação dos Dados . . . . . . . . . . . . 88

7.4 .3 Aquisição de Conhecimento . . . . . . . . . . . . 90

7.5 Experimentos Realizados e Resultados . . . . . . . . . . . . . . 91

7.5 .1 See5 . . . . . . . . . . . . . . . . . . 91

7.5.2 Transformação dos Dados de $\mathcal{S}$ ee5 para Progol . . . . . . . . 97

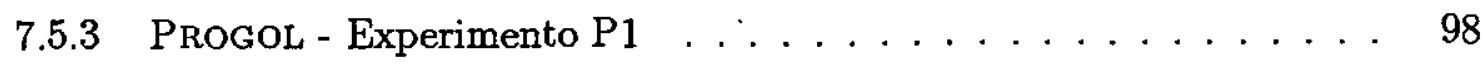

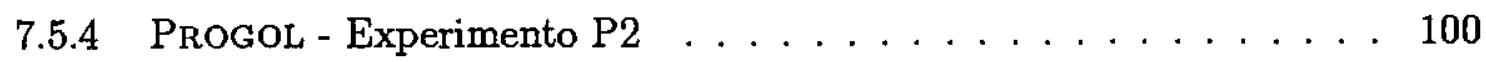

7.6 Considerações Finais . . . . . . . . . . . . . . . 101

8 Conclusões 102

$\begin{array}{lr}\text { A FoIL } & 105\end{array}$

A.1 Arquivo de Entrada . . . . . . . . . . . . . . . . . . 105

A.2 Parâmetros Configuráveis . . . . . . . . . . . . . . 107

$\begin{array}{lr}\text { B Progol } & 109\end{array}$

B.1 Arquivo de Entrada . . . . . . . . . . . . . . . . . 109

B.2 Declaraçôes de Modo . . . . . . . . . . . . . . . . 110

B.3 Parâmetros Configuráveis . . . . . . . . . . . . . . . 111

B.4 Comandos Disponíveis . . . . . . . . . . . . . . 113 


\section{Lista de Figuras}

2.1 Completeza e Consistência de uma Hipótese (Lavrač e Džeroski, 1994) . . 10

3.1 Algoritmo para Calcular lgg de Termos . . . . . . . . . . . . 18

3.2 Algoritmo para Calcular lgg de Literais . . . . . . . . . . . . . . . 19

3.3 Algoritmo para Calcular lgg de Cláusulas . . . . . . . . . . . . 20

3.4 Uma Árvore de Derivação Linear Inversa (Džeroski, 1996) . . . . . . . . 24

3.5 Parte do Grafo de Refinamento para Aprender a Relação filha/2 . . . . . 26

5.1 Uma Visão Geral do Processo de Conversão . . . . . . . . . . . . . . . 45

$5.2 \quad \mathrm{De} \mathcal{C N 2}$ para $C 4.5 \ldots \ldots \ldots \ldots \ldots \ldots \ldots \ldots$

5.3 Arquivo $\mathcal{C N} 2$ voyage att $\ldots \ldots \ldots \ldots \ldots \ldots \ldots$

5.4 Arquivo $C \mathcal{N} 2$ voyage. exs $\ldots \ldots \ldots \ldots \ldots \ldots$

5.5 Arquivo $\mathcal{C N 2}$ voyage.tst $\ldots \ldots \ldots \ldots \ldots \ldots \ldots$

5.6 Arquivo $C 4.5$ voyage names $\ldots \ldots \ldots \ldots \ldots \ldots \ldots$

5.7 Arquivo $C 4.5$ voyage data . . . . . . . . . . . . . . . 49

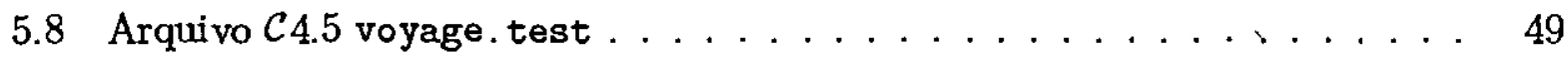

$5.9 \mathrm{De} C 4.5$ para Foll "Proposicional" $\ldots \ldots \ldots \ldots \ldots$

5.10 Arquivo $\mathcal{C} 4.5$ voyage . names Modificado para Uso com c45_to_foil . . . . . 50

5.11 Arquivo Foll "Proposicional" voyage.d . . . . . . . . . . . . . 51

5.12 De Forl "Proposicional" para Progol "Proposicional" . . . . . . . . . 52

5.13 Arquivo Progol "Proposicional" voyage_training.pl . . . . . . . . . . 53

5.14 Arquivo Progol "Proposicional" voyage_test.pl . . . . . . . . . . 55

5.15 Arquivo Progol "Proposicional" voyage_extra_bg_test.pl . . . . . . 56 
5.16 De Foll "Proposicional" para Progol MB . . . . . . . . . . . . 56

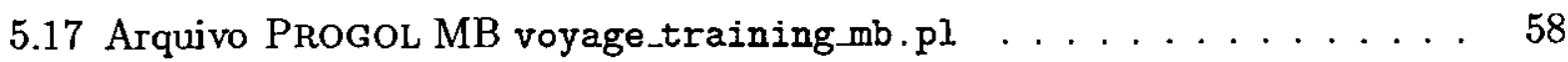

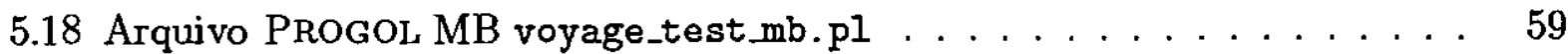

5.19 De Foll "Proposicional" para Foll MB . . . . . . . . . . . . 60

6.1 Dimensionalidade dos Conjuntos de Dados . . . . . . . . . . . . . 68

6.2 Verdadeiros Positivos, Falsos Positivos e Falsos Negativos . . . . . . . . . 71

6.3 Regras Geradas por Foll: Conjunto de Dados Breast e Método Prop, com $\mathrm{C} 1=$ recurrence $\ldots \ldots \ldots \ldots \ldots \ldots$

6.4 Regras Geradas por Progol: Conjunto de Dados Breast e Método Prop, com $\mathrm{C} 1=$ recurrence $\ldots \ldots \ldots \ldots \ldots \ldots$

6.5 Regras Geradas por Foll: Conjunto de Dados Breast e Método MB, com $\mathrm{C} 1=$ recurrence $\ldots \ldots \ldots \ldots \ldots \ldots \ldots \ldots \ldots$

6.6 Regras Geradas por Progol: Conjunto de Dados Breast e Método MB, com $\mathrm{C} 1=$ recurrence

6.7 Regras Geradas por Foll: Conjunto de Dados Breast e Método Prop, com $\mathrm{C} 2=$ no_recurrence

6.8 Regras Geradas por Progol: Conjunto de Dados Breast e Método Prop, com $\mathrm{C} 2=$ no recurrence $\ldots \ldots \ldots \ldots \ldots$

6.9 Regras Geradas por Foll: Conjunto de Dados Breast e Método MB, com $\mathrm{C} 2=$ no_recurrence $\ldots \ldots \ldots \ldots \ldots \ldots \ldots$

6.10 Regras Geradas por Progol: Conjunto de Dados Breast e Método MB, com $\mathrm{C} 2=$ no_recurrence $\ldots \ldots \ldots \ldots \ldots \ldots \ldots$

7.1 Célula Animal . . . . . . . . . . . . . . . . . . . . . . . . 85

7.2 Passos do Processo de Aquisiçāo de Conhecimento . . . . . . . . . . . 87

7.3 Quantidade de Progênie Gerada pelas Matrizes Mais Produtivas . . . . . . 92

7.4 .Algumas Regras Geradas no Experimento TipoMt_See5 . . . . . . . . . . 93

7.5 Alguns Touros que Determinam a Classe menoq0 na Sua Progênie . . . . . 94

7.6 Quantidade de Progênie Gerada pelos Touros Mais Produtivos . . . . . . 94

7.7 Alguns Touros que Determinam a Classe maioq0 na Sua Progênie . . . . 95

7.8 Alguns Touros em que o Atributo MGT Determina a Classe menoq0 na Progênie . . . . . . . . . . . . . . . . . 


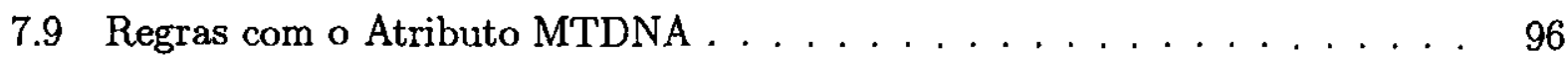




\section{Lista de Tabelas}

2.1 Um Exemplo de Aprendizado Utilizando PLI . . . . . . . . . . . . . . . 12

3.1 Exemplos de $\operatorname{lgg}$ de Termos $\ldots \ldots \ldots \ldots$

3.2 Exemplos de $\operatorname{lgg}$ de Literais $\ldots \ldots \ldots$

3.3 Forma Proposicional para Aprender a Relação filha/2 f . . . . . . . 29

5.1 Formato Atributo-Valor (ou Planilha) para Dados . . . . . . . . . . . . 42

5.2 Formato Atributo-Valor para Exemplos e Contra-exemplos de um Conceito 43

5.3 Condições Climáticas para uma Viagem . . . . . . . . . . . . . . 46

5.4 Arquivo Foll MB voyage mb.d . . . . . . . . . . . . 62

6.1 Resumo de Características dos Conjuntos de Dados . . . . . . . . . . 67

6.2 Desempenho de Classificação para Duas Classes . . . . . . . . . . 70

6.3 Breast - Descrição dos Atributos . . . . . . . . . . . . . . 73

6.4 Médias para o Conjunto de Dados Breast e Método "Proposicional", $(\mathrm{C} 1=$ recurrence e $\mathrm{C} 2=$ no_recurrence) $\ldots \ldots \ldots \ldots \ldots . \ldots . \ldots 74$

6.5 Médias para o Conjunto de Dados Breast e Método $\mathrm{MB},(\mathrm{C} 1=$ recurrence e $\mathrm{C} 2=$ no_recurrence) $\ldots \ldots \ldots \ldots \ldots \ldots \ldots$

6.6 Diferença em Desvios-Padrão dos Erros de Foll para Progol com Método

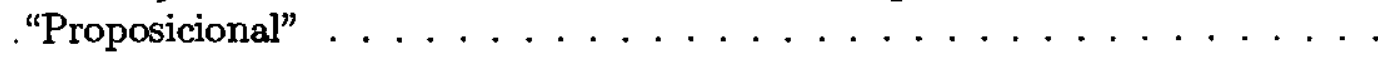

6.7 Diferença em Desvios-Padrão dos Erros de Foll para Progol com Método MB . . . . . . . . . . . . . . . .

6.8 Erro Aparente para o Conjunto de Dados Breast $(\mathrm{C} 1=$ recurrence e $\mathrm{C} 2=$ no_recurrence) . . . . . . . . . . . . . 
6.9 Número de Cláusulas, Regras e Tempo de Execução Utilizando Todo o Conjunto de Dados Breast $(\mathrm{Cl}=$ recurrence e $\mathrm{C} 2=$ no_recurrence $) \ldots \ldots 75$

6.10 Taxas Médias de Erro e Número Médio de Cláusulas e Regras . . . . . . 80

6.11 Diferenças em Desvios-Padrão dos Erros entre Foll e Progol . . . . . . . 81

7.1 Base de Dados Inicial e Reduzida: Descrição dos Atributos Considerados . $\quad 89$

7.2 Características do Conjunto de Dados para os Dois Problemas Tratados . . 89

7.3 Resumo dos Resultados Obtidos com See5 . . . . . . . . . . . . . . 92

7.4 EfMat_See5 - Quantidade de Regras por Classe e Atributos Considerados nessas Regras . . . . . . . . . . . . . . . . . . 93

7.5 Distribuição da Progênie de Alguns Touros na Base do PMGRN para a Classe menoq0 . . . . . . . . . . . . . . . 95

7.6 Distribuição da Progênie de Alguns Touros na Base do PMGRN para a Classe maioq0 . . . . . . . . . . . . . . . . . 96

7.7 Predicados Criados pelo Método MB e os Atributos Correspondentes para Cada Problema . . . . . . . . . . . . . . . . . . 97

7.8 Resumo dos Resultados Obtidos com Progol sem Conhecimento de Fundo Adicional . . . . . . . . . . . . . . . . . . . 


\section{Lista de Algoritmos}

4.1 Golem . . . . . . . . . . . . . . . . . . 33

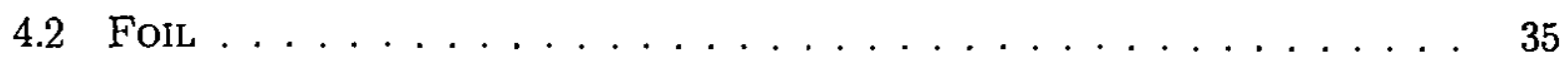

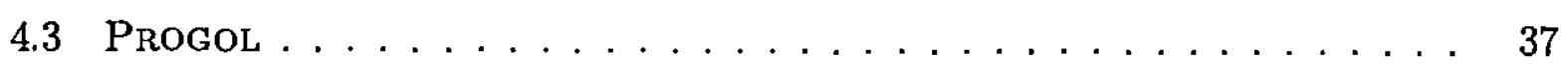




\section{Lista de Acrônimos}

$10 \mathrm{CV} \ldots \ldots \ldots \ldots \ldots \ldots \ldots \ldots \ldots$ " $\ldots \ldots \ldots$ fold cross-validation" $\mathrm{AM} \ldots \ldots \ldots \ldots \ldots \ldots \ldots \ldots \ldots \ldots \ldots \ldots \ldots$ Aprendizado de Máquina DEP . . . . . . . . . . . . . . . Diferença Esperada nas Progênies DGFM . . . . . . . . . Departamento de Genética da Faculdade de Medicina IA . . . . . . . . . . . . . . . . Inteligência Artificial KDD . . . . . . . . . . . . . . Knowledge Discovery in Databases LABIC . . . . . . . . . . . Laboratório de Inteligência Computacional MGT . . . . . . . . . . . . . . . Mérito Genético Total PLI . . . . . . . . . . . . . . . Programação Lógica Indutiva PMGRN . . . . . . . . . . . Programa de Melhoramento Genético da Raça Nelore USP . . . . . . . . . . . . . . . . . . Universidade de São Paulo 


\section{Capítulo 1}

\section{Introdução}

O interesse atual em Aprendizado de Máquina - AM, uma sub-área de Inteligência Artificial - IA, mostra-se grande por dois motivos: primeiro, embora não haja uma definiçāo universal da natureza de inteligência, há um consenso de que a capacidade de aprender é essencial para um comportamento inteligente (Russell e Norvig, 1995). Assim, AM se justifica do ponto de vista científico enquanto método para estudar a cognição humana. Por outro lado, ferramentas computacionais de aquisição de conhecimento têm utilizado com sucesso técnicas de AM, como por exemplo na construção de sistemas especialistas.

O objetivo de AM é desenvolver métodos, técnicas e ferramentas para construir máquinas inteligentes, que se modificam para realizar cada vez melhor suas tarefas. 'Melhor' nesse sentido pode ser trabalhar com mais eficiência ou precisão, ou ainda de forma a abranger uma classe maior de problemas.

De acordo com (Carbonell, 1989), há quatro grandes paradigmas de aprendizado de máquina:

- aprendizado analítico;

- aprendizado "genético", através de algoritmos genéticos;

- aprendizado conexionista, através de redes neurais; e

- aprendizado indutivo.

O foco desse trabalho é o aprendizado indutivo. A indução pode ser vista como um raciocínio do específico para o geral. Um problema pode ser formulado como uma tarefa 
de aprendizado de conceitos a partir de exemplos, conhecido como aprendizado indutivo de conceitos, no qual regras de classificação para um determinado conceito devem ser induzidas a partir de instâncias positivas e/ou negativas do mesmo. Neste caso, são dadas instâncias ou exemplos dos quais se deriva uma teoria ou regras gerais. Aprendizado indutivo tem sido aplicado com sucesso em vários problemas de classificação e previsão, como por exemplo no diagnóstico médico e botânico, ou na previsão de propriedades mecânicas do aço tendo por base suas características químicas.

\subsection{Linguagens de Representação}

Para a expressão de qualquer paradigma de aprendizado são necessárias linguagens que descrevam objetos assim como linguagens que descrevam os conceitos aprendidos. Vários formalismos lógicos têm sido utilizados em sistemas de aprendizado indutivo para a representação de exemplos e conceitos. Em geral, distinguem-se dois tipos de descrição:

1. descrição baseada em atributos $e$

2. descrição relacional.

Em uma descrição baseada em atributos, objetos são descritos em termos de atributos e valores desses atributos. Alguns dos algoritmos/sistemas de aprendizado indutivo que têm sido utilizados em uma série razoável de aplicações com relativo sucesso - tais como os da família TDIDT ${ }^{1}$ (Quinlan, 1986) e o CN2 (Boswell, 1990) - utilizam linguagens baseadas em atributos, equivalentes a linguagens proposicionais, para a representação de instâncias e conceitos. As linguagens de descrição de conceitos utilizadas por esses algoritmos para expressar as hipóteses induzidas, respectivamente árvores de decisão e regras de produção, podem ser tratadas como variantes de linguagens baseadas em atributos, i.e., linguagens proposicionais. Porém, apesar do relativo sucesso dos sistemas proposicionais de aprendizado, tais sistemas são fortemente limitados, em função de alguns problemas inerentes à linguagem usada na descrição de exemplos e conceitos, tais como:

- Representação restrita: não conseguem representar problemas de conhecimento relacional, ou que envolvam relacionamentos estruturais arbitrariamente complexos,

\footnotetext{
${ }^{1}$ Top Down Induction of Decision Trees
} 
como quando se lida com uma árvore genealógica, ou com um mapeamento de genes de DNA (Muggleton e Raedt, 1994);

- Não fazem uso de conhecimento prévio ${ }^{2}$ sobre o domínio: se restringem a utilizar informações sobre os atributos do objeto sendo estudado, quando muito combinandoos para encontrar novos atributos mais descritivos;

- "Bias" forte do vocabulário: fazem uso de um conjunto limitado de atributos proposicionais. No sentido de aliviar este problema, há uma grande área de pequisa em IA para encontrar maneiras de inventar símbolos de predicados auxiliares e complementar o conhecimento prévio quando este é insuficiente.

No caso de uma descrição relacional, ou estrutural, um objeto é descrito em termos de seus componentes e de relações entre eles e com outros objetos. Isso mclui domínios nos quais descrições relacionais necessitam ser expressas, como por exemplo num diagnóstico médico.

A adoção, por sistemas de aprendizado, de linguagens lógicas de primeira ordem como linguagens de representação, permite que relações ou predicados possam ser induzidos. Isto faz com que o espaço dos conceitos passíveis de serem aprendidos seja aumentado. Linguagens baseadas em lógica de primeira ordem são usadas há mais de 30 anos (Sammut, 1993). No entanto, aprendizado empírico de primeira ordem só começou a atrair atenção maciça no início dos anos 90 .

Programação Lógica Indutiva - PLI - é uma abordagem relativamente recente de aprendizado indutivo de máquina, que busca contornar algumas das limitações das abordagens anteriores através do uso de teoria do domínio, ou conhecimento prévio, e uma linguagem de descrição de conceitos baseada em lógica de primeira ordem.

Embora a adoção dessa linguagem viabilize o aprendizado de um conjunto muito maior de conceitos, traz também uma série de problemas relacionados à busca no espaço de hipóteses, uma vez que este é muito maior que no caso proposicional.(Estes problemas podem ser contornados impondo restriçōes às linguagens de descrição utilizadas no sistema. Para tanto, são utilizadas técnicas de generalização e especialização para construir a hipótese induzida de modo a adequá-la aos exemplos.

\footnotetext{
${ }^{2}$ também denominado conhecimento de fundo; neste urabalho os dois termos serão utilizados indistintamente
} 
Os sistemas de PLI podem ser divididos ainda em duas famílias de acordo com a forma como aprendem sobre os exemplos. A primeira família se baseia num método de revisão sucessiva. A cada exemplo tratado erroneamente por sua hipótese, faz-se uma revisão da mesma para consertar o que há de errado. A segunda família utiliza um método de "dividir-e-conquistar". A cada iteração do algoritmo, busca-se uma cláusula que cubra exemplos positivos sem cobrir exemplos negativos. A maioria dos sistemas atuais de PLI são dessa segunda familia.

Devido à importância de aprendizado relacional, diversas mudanças foram realizadas na especificação original de alguns sistemas de PLI, com a finalidade de poder também definir variáveis contínuas que possam ser comparadas com algum limite numérico. Sistemas de PLI que possuem essa facilidade podem ser utilizados para tentar extrair relações de conjuntos de dados na forma atributo-valor, os quais são comumente utilizados por sistemas proposicionais. Assim, é interessante verificar o comportamento de sistemas PLI, que manipulam variáveis contínuas, nesse tipo de problema.

Entretanto, para que esses sistemas de PLI possam induzir conhecimento a partir desses dados, é necessário um processo de conversão que permita passar os dados do formato atributo-valor para o formato relacional. Neste trabalho, esse processo foi implementado através de uma série de ferramentas, de modo a colocar os dados em dois formatos diferentes que podem ser utilizados por sistemas de aprendizado relacional: um desses formatos consiste em uma representação quase direta do formato atributo-valor e o outro formato permite representar os exemplos no formato relacional.

Com os conjuntos de dados devidamente formatados, torna-se possível comparar sistemas de PLI. Neste trabalho são apresentados diversos experimentos realizados com os sistemas de PLI FoIl e Progol, utilizando seis bases de dados naturais, com características diferentes.

Uma forma de explorar melhor as vantagens de sistemas PLI, é utilizá-los com dados que, em princípio, são propícios para a aplicação de tais sistemas, tais como dados nos quais está implícita a relação de parentesco. Neste trabalho é realizado um estudo de caso com uma base do mundo real que possui essas características.

A base de dados utilizada é um subconjunto da base de dados do Programa de Melhoramento Genético da Raça Nelore - PMGRN - criada a partir de uma iniciativa conjunta de criadores de gado Nelore e pesquisadores do Departamento de Genética da Faculdade de Medicina - DGFM - da USP em Ribeirão Preto. Essa base consiste de todos os 
animais, na base PMGRN, para os quais foi possível determinar o tipo mitocondrial. Esse tipo é herdado geneticamente pelo lado materno e pode ter influência nas características bovinas de produção de carne e de leite.

\subsection{Organização do Trabalho}

No Capítulo 2 é introduzida a área de PLI, objeto de estudo deste trabalho que trata de aprendizado de máquina relacional utilizando linguagens de descrição de lógica de primeira ordem.

No Capítulo 3 as técnicas mais conhecidas de PLI são abordadas, e são mostrados exemplos de como elas funcionam.

No Capítulo 4 alguns sistemas de PLI frequentemente utilizados pela comunidade são descritos, salientando seus algoritmos e aplicações no mundo real.

No Capítulo 5 são descritos dois processos de conversão de dados do formato atributo-valor para o formato relacional bem como as ferramentas por nós desenvolvidas para realizar esse processo.

No Capítulo 6 são descritos diversos experimentos realizados, com várias bases de dados naturais, originalmente no formato atributo-valor, utilizando os sistemas de PLI FoIL e PROGOL. Esses dados foram primeiramente transformados para o formato relacional, através das ferramentas de conversão por nós implementadas.

No Capítulo 7 é apresentado o estudo de caso realizado com o subconjunto de animais da base de dados do PMGRN, cujo tipo mitocondrial é conhecido.

Finalmente, no Capítulo 8 são apresentadas algumas conclusões e sugestōes para trabalhos futuros. 


\section{Capítulo 2}

\section{Programação Lógica Indutiva}

\subsection{Considerações Iniciais}

Programação Lógica Indutiva - PLI - inicialmente foi definida como a intersecção de aprendizado de máquina e programação lógica (Muggleton, 1991). Posteriormente, esta definição foi generalizada por Luc De Raedt, no prefácio de (Lavrač e Džeroski, 1994), como a interseç̧ão de indução com a programação lógica. Assim, PLI pode ser visto como a conjunção de aprendizado indutivo de máquina e a lógica computacional.

Do aprendizado de máquina indutivo, PLI herda os objetivos que são bastante práticos e incluem: desenvolver ferramentas e técnicas para induzir hipóteses a partir de exemplos, e sintetizar novos conhecimentos a partir de experiência (Muggleton e Raedt, 1994).

Da lógica computacional, PLI herda não somente seu formalismo representacional, mas também sua orientação semântica, e várias técnicas bem estabelecidas. Em contraste com outras abordagens de aprendizado indutivo, Programação Lógica Indutiva está interessada nas propriedades das regras de inferência, na convergência de algoritmos e na complexidade computacional dos procedimentos (Lavrač e Džeroski, 1994; Nicoletti e Monard, 1994; Batista, 1997).

Programação Lógica Indutiva estende a teoria e prática da lógica computacional através da investigação da indução, ao invés da dedução, como método básico de inferência. $\mathrm{Da}$ mesma forma que a teoria da lógica computacional descreve inferências dedutivas a partir de fórmulas lógicas, PLI estuda a inferência indutiva de programas lógicos a partir de 
exemplos e um conhecimento prévio do domínio (Bergadano e Gunetti, 1995; Pompe e Kononenko, 1998; Sammut, 1998).

\section{.2 Dimensões de PLI}

jistemas de PLI podem ser classificados em várias dimensões como descrito a seguir.

- Primeiro, eles podem aprender um único conceito ou múltiplos conceitos (predicados). No caso de aprender um único conceito, as observações são simplesmente exemplos desse conceito. A meta de um aprendizado de múltiplos conceitos é aprender um conjunto de definições de predicados, possivelmente inter-relacionados;

- Segundo, os sistemas podem necessitar que todos os exemplos sejam fornecidos antes de iniciar o processo de aprendizado (aprendizado em batch ou não-incremental) ou podem utilizar exemplos de treinamento individuais, fornecidos um a um, durante o processo de aprendizado (aprendizado incremental);

- Terceiro, durante o processo de aprendizado, o sistema pode precisar de um oráculo (um especialista ou o próprio usuário) para verificar a validade das generalizações e/ou classificar os exemplos gerados pelo sistema. Nesse caso, o sistema é chamado de interativo, senão é chamado de não-interativo. Interatividade implica incrementalidade mas pode ser encontrada também em alguns sistemas de aprendizado empírico que fazem uso de revisão de teoria;

- Quarto, o sistema pode inventar termos (predicados) novos. Isto amplia o vocabulário disponível na teoria do domínio e pode facilitar a tarefa de aprender um conceito. Sistemas que apresentam esta qualidade são chamados de sistemas de indução construtiva (Russell e Norvig, 1995);

- Quinto, a teoria do domínio utilizada pelo sistema pode ser intensional ou extensional. Uma teoria extensional é representada apenas por fatos "ground", enquanto que uma teoria intensional contém tanto fatos "ground" quanto cláusulas com variáveis, permitindo reduzir a descrição do conceito (Nicoletti e Monard, 1995a). A grande maioria dos sistemas de PLI restringem a teoria a exemplos "ground", mas existem atualmente vários sistemas que permitem descrever a teoria de forma intensional, tais como Progol (Muggleton, 1995) e Focl (Pazzani et al., 1991); 
- Finalmente, um conceito pode ser aprendido do zero, tendo como hipótese a cláusula vazia, ou pode ser aceita uma hipótese (teoria) inicial, a qual é revisada durante o processo de aprendizado. Sistemas que fazem este tipo de revisão são chamados de revisores de teoria.

Embora estas dimensōes sejam a princípio independentes, os sistemas atuais de PLI se situam em duas pontas de um espectro. Em uma ponta estão sistemas não-interativos de aprendizado não-incremental que aprendem um único predicado a partir do zero, e na outra ficam os sistemas interativos e revisores de teoria que aprendem múltiplos predicados. O primeiro tipo de sistema é denominado sistema empírico de PLI e o segundo sistema interativo de PLI.

Mis (Shapiro, 1983), Marvin (Sammut e Banerji, 1986) e Clint (De Raedt, 1992) são exemplos de sistemas de PLI interativos: aprendem definições de múltiplos predicados a partir de um conjunto pequeno de exemplos e consultas ao usuário.

Por outro lado, como já mencionado, sistemas empíricos de PLI tendem a aprender um único predicado utilizando uma grande coleção de exemplos. Esta classe de sistemas de PLI inclui Foll (Quinlan, 1990), Golem (Muggleton e Feng, 1990), LiNus (Džeroski et al., 1995) e Progol (Muggleton, 1995), para citar alguns dos mais conhecidos. Até o presente momento, os sistemas empíricos têm-se mostrado mais adequados para aplicaçōes práticas.

\subsection{O Processo de Aprendizado em PLI}

De uma forma geral, PLI pode ser descrita a partir de uma teoria de conhecimento de fundo inicial $\mathcal{K}$ e algum conjunto de exemplos $E=E^{+} \cup E^{-}$, onde $E^{+}$representa os exemplos positivos e $E^{-}$os exemplos negativos. O objetivo consiste em induzir uma hipótese $\mathcal{H}$ que juntamente com $\mathcal{K}$ explique os exemplos $E$.

No cáso geral, $\mathcal{H}, \mathcal{K}$ e $E$ podem ser qualquer conjunto de cláusulas. Entretanto, na maioria dos problemas a teoria de conhecimento prévio, os exemplos e a hipótese induzida têm qu satisfazer um conjunto de restrições sintáticas $\mathcal{B}$, chamado de bias. Bias define o espaç de fórmulas bem formadas usadas para representar hipóteses e pode ser considerada como parte do conhecimento prévio.

O aprendizado empírico de um único conceito - predicado - em PLI pode ser formulado 
então da seguinte forma (Muggleton, 1991; Lavrač e Džeroski, 1994):

Dados

- um conjunto de exemplos de treinamento $E$ descritos na linguagem $\mathcal{L}_{E}$ e consistindo de

- exemplos positivos, $E^{+} \mathrm{e}$

- exemplos negativos, $E^{-}$

- um predicado desconhecido $p$ - relação a ser aprendida (relação alvo ou meta)

- uma linguagem de descrição $\mathcal{L}_{\mathcal{H}}$, especificando as restriçōes sintáticas na definição do predicado $p$

- um bias de linguagem $\mathcal{B}$ que define o espaço de hipóteses

- teoria do domínio $\mathcal{K}$, descrita numa linguagem $\mathcal{L}_{\mathcal{K}}$, definindo predicados $q_{i}$ (diferentes de $p$ ) os quais podem ser usados na definição de $p$ e que podem fornecer informação adicional sobre argumentos dos exemplos da relação alvo

- um operador entre $\mathcal{L}_{E}$ e $\mathcal{L}_{\mathcal{H}}$, com relação a $\mathcal{L}_{\mathcal{K}}$ que determina se um exemplo é coberto por uma cláusula expressa em $\mathcal{L}_{\mathcal{H}}$

Encontrar

- uma definição $\mathcal{H}$ para $p$, expressa em $\mathcal{L}_{\mathcal{H}}$, tal que

- $\mathcal{H}$ é completa, i.e., $\mathcal{K} \wedge \mathcal{H} \models E^{+}$,

$-\mathcal{H}$ é consistente, i.e., $\mathcal{K} \wedge \mathcal{H} \nvdash E^{-}$

com relação aos exemplos.

\subsection{Completude e Consistência de uma Hipótese}

Diferentes situações podem ocorrer em relação à completude e consistência de uma hipótese como mostrado na Figura 2.1. Esta figura utiliza a função cobre, que pode ser definida assim: 
$\mathcal{H}$ : completa, consistente

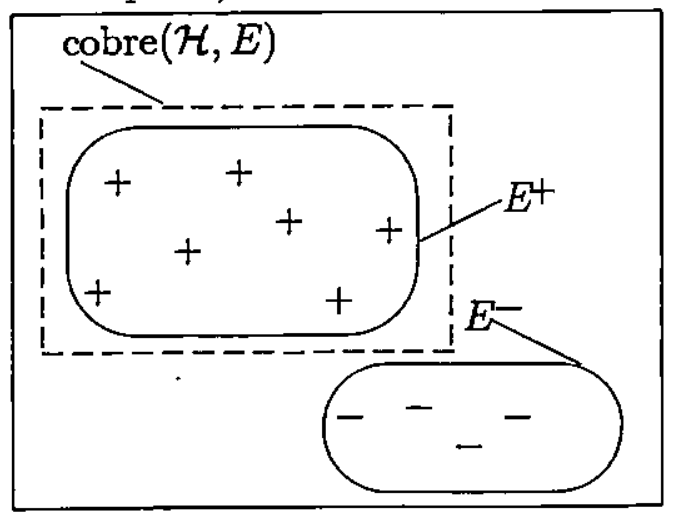

$\mathcal{H}$ : completa, inconsistente

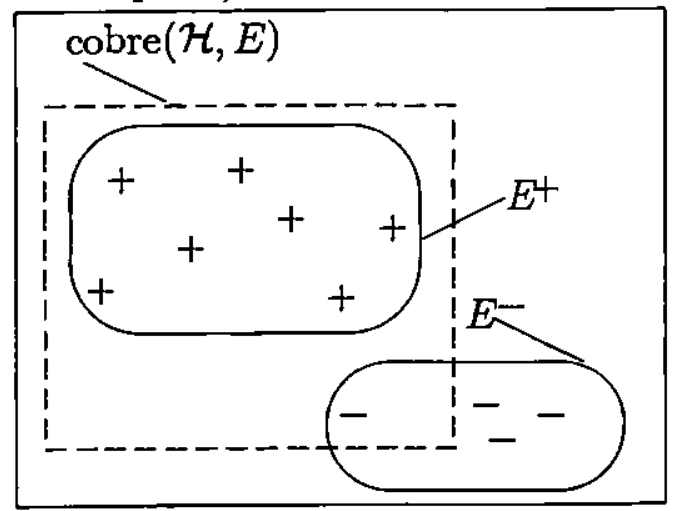

$\mathcal{H}$ : incompleta, consistente

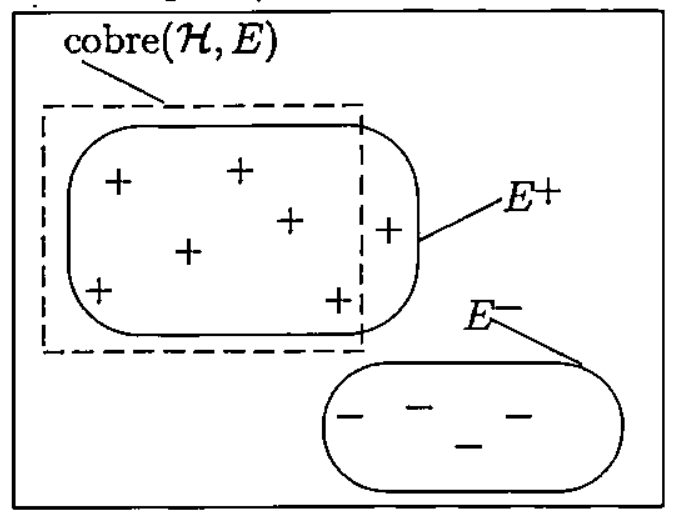

Figura 2.1: Completeza e Consistência de uma Hipótese (Lavrač e Džeroski, 1994) 


$$
\begin{aligned}
& \operatorname{cobre}(\mathcal{H}, e)=\text { verdade se } e \text { é coberto por } \mathcal{H} \\
& \operatorname{cobre}(\mathcal{H}, e)=\text { falso caso contrário }
\end{aligned}
$$

A função pode ser redefinida para conjuntos de exemplos da seguinte forma

$$
\operatorname{cobre}(\mathcal{H}, E)=\{e \in E \mid \operatorname{cobre}(\mathcal{H}, e)=\text { verdade }\}
$$

bem como pode ser redefinida para considerar a teoria de domínio:

$$
\operatorname{cobre}(\mathcal{H}, \mathcal{K}, E)=\operatorname{cobre}(\mathcal{H} \cup \mathcal{K}, E)
$$

Assim, quatro situações podem acontecer, dependendo de como a hipótese cobre os exemplos positivos e negativos:

1. $\mathcal{H}$ completa e consistente, cobre todos os exemplos positivos e não cobre exemplos negativos;

2. $\mathcal{H}$ incompleta e consistente, não cobre todos os exemplos positivos e não cobre exemplos negativos;

3. $\mathcal{H}$ completa e inconsistente, cobre todos os exemplos positivos e cobre alguns exemplos negativos;

4. $\mathcal{H}$ incompleta e inconsistente, não cobre todos os exemplos positivos e cobre alguns exemplos negativos.

\subsection{Um Exemplo de Aprendizado Relacional em PLI}

Uma tarefa de aprendizado relacional pode ser aprender uma relação filha $(X, Y)$, em que uma pessoa $X$ é filha de uma pessoa $Y$. Para isso, são usadas relações já conhecidas de mulher e progenitor. Estas relações são mostradas na base de conhecimento da Tabela 2.1. Nesta tabela há dois exemplos positivos e dois negativos da relação alvo (indicados com os símbolos $\oplus$ e $\ominus$ respectivamente). Há ainda, algum conhecimento prévio declarado de forma intensional.

$\mathrm{Na}$ linguagem de hipóteses de programas lógicos, podemos formular a seguinte definição da relação (conceito) desejada: 


$$
\text { filha }(X, Y) \leftarrow \text { mulher }(X), \text { progenitor }(Y, X) \text {. }
$$

a qual é consistente e completa com relação ao conhecimento prévio e os exemplos de treinamento. Dependendo do conhecimento prévio, a linguagem $\mathcal{L}_{\mathcal{H}}$ e a complexidade do conceito procurado, a definição da relação alvo pode consistir de um conjunto de cláusulas, tais como:

$$
\begin{gathered}
\text { filha }(X, Y) \leftarrow \text { mulher }(X), \text { mae }(Y, X) . \\
\text { filha }(X, Y) \leftarrow \text { mulher }(X), \text { progenitor }(Y, X) .
\end{gathered}
$$

\begin{tabular}{|c|c|c|c|}
\hline Exemplos de Treinamento & \multicolumn{3}{|c|}{ Conhecimento Prévio } \\
\hline 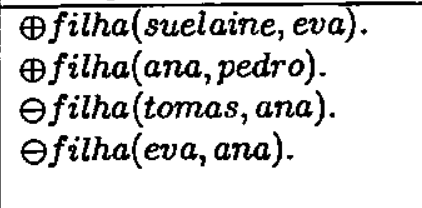 & $\begin{array}{l}\text { mae }(\text { eva, suelaine }) . \\
\text { mae }(\text { ana, tomas }) . \\
\text { pai (pedro, ana }) . \\
\text { pai (tomas, suelaine }) .\end{array}$ & $\begin{array}{l}\text { progenitor }(X, Y) \leftarrow \\
\text { mae }(X, Y) . \\
\text { progenitor }(X, Y) \leftarrow \\
\text { pai }(X, Y) .\end{array}$ & $\begin{array}{l}\text { mulher(ana). } \\
\text { mulher (suelaine). } \\
\text { mulher(eva). } \\
\text { homem(pedro). } \\
\text { homem(tomas). }\end{array}$ \\
\hline
\end{tabular}

Tabela 2.1: Um Exemplo de Aprendizado Utilizando PLI

\subsection{Considerações Finais}

Neste capítulo apresentou-se uma idéia geral do que constitui Programação Lógica Indutiva e das dimensões consideradas para classificar os sistemas existentes, dividindo-os entre sistemas interativos e empíricos. Estes últimos têm se mostrado bastante eficientes no tratamento de problemas de aprendizado no mundo real e serão enfocados no Capítulo 4 .

O processo de aprendizado empírico foi esboçado. A completeza e consistência de hipóteses foi discutida, mostrando como a cobertura de exemplos pode ocorrer, e estendendo esta noção para o uso de conhecimento prévio do domínio. Por fim, um exemplo foi dado no âmbito de aprendizado relacional, que será retomado e reaproveitado no Capítulo 3 .

A seguir serão vistas algumas das técnicas mais comumente utilizadas em PLI. 


\section{Capítulo 3}

\section{Técnicas Básicas de PLI}

\subsection{Considerações Iniciais}

Técnicas de PLI procuram por cláusulas na linguagem de hipóteses que sejam consistentes com os exemplos de treinamento. Para reduzir a busca, o espaço de cláusulas é estruturado por uma relação de generalidade entre cláusulas, chamada de relação $\theta-s u b s o m a$.

Sistemas de PLI podem ser agrupados em duas famílias. A primeira utiliza uma estratégia de revisão sucessiva e a outra faz uso de uma estratégia de "dividir-e-conquistar".

Muitos dos sistemas iniciais tais como Mis (Shapiro, 1983), MARvin (Sammut e Banerji, 1986) e Cigol (Muggleton e Buntine, 1988) se baseiam num método de revisão sucessiva. Uma teoria com falhas é muito geral se ela cobre um exemplo negativo, e muito específica se não cobre um exemplo positivo. A cada exemplo tratado erroneamente, faz-se um exame para descobrir o defeito, talvez com a ajuda de um oráculo ou especialista, e se tenta consertá-lo. Na prática, esta família de algoritmos demanda muito em termos computacionais, ficando limitada a tarefas que envolvem um número pequeno de exemplos cuidadosamente escolhidos.

A outra família utiliza uma estratégia de "dividir-e-conquistar", cujo pioneiro foi Michalski (Michalski, 1980). Todos os exemplos de treinamento são consideradas em conjunto e, a cada iteração, uma cláusula da teoria que cobre alguns exemplos positivos e nenhum exemplo negativo é encontrada. Ós exemplos cobertos pela cláusula são descartados e o processo é repetido até que todos os exemplos positivos sejam cobertos por pelo menos 
uma cláusula.

Levando-se em consideração a busca realizada para encontrar cláusulas da teoria, esta família pode ser sub-dividida ainda em "top-down" e "bottom-up". Sistemas "top-down", tais como Forl (Quinlan, 1990), começam com a cabeça da cláusula mais geral contendo apenas o literal da relação meta e adicionam literais ao seu corpo até que todos os exemplos negativos sejam excluídos. Sistemas "bottom-up", exemplificados por GoLEM (Muggleton e Feng, 1990), formam a generalização mais específica ou menos geral - lgg - de um subconjunto pequeno dos exemplos positivos, e em seguida a generalizam mais, descartando liter ais enquanto a cláusula não cobre algum exemplo negativo. Ambos os métodos têmse mostrado muito mais rápido que os sistemas baseados em revisão sucessiva, obtendo também resultados bastante expressivos.

As técnicas básicas de PLI que serão consideradas neste capítulo são utilizadas em sistemas de PLI empíricos, mas se aplicam também a sistemas interativos. A seguir são dadas algumas definições de termos que serão utilizados no decorrer do trabalho e é dada uma definição da relação $\theta$-subsoma. Em seguida, são vistas algumas técnicas utilizadas em sistemas de PLI: menor generalização geral, menor generalização geral relativa, resolução inversa, busca em grafos de refinamento e modelos de regras.

\subsection{Terminologia Utilizada}

Nesta seção é introduzida a terminologia básica de lógica formal que será usada no decorrer deste trabalho.

Toda expressão é composta de constantes (por ex., maria, 23, joao), variáveis ( $X, Y$, $Z)$, símbolos de predicados (maior_que, como em maior-que(elefante, rato), mulher, como em mulher(maria)) e símbolos de função (idade, como em maior_que(idade(maria), 24)). A diferença entre predicados e funções é que predicados assumem o valor verdadeiro ou falso, enquanto que funções podem assumir qualquer constante como seu valor. Na nossa representação, variáveis são representadas por sequências de caracteres começando com letra maiúscula, enquanto que funçōes, constantes e predicado são sequências de caracteres começando com letra minúscula.

Utilizando esses símbolos, expressōes podem ser construídas da seguinte forma: um termo pode ser uma constante ou variável ou pode ser uma função aplicada a uma constante ou 
a uma variável, por exemplo maria, $X$, idade(maria), idade $(X)$.

Um literal é qualquer predicado (ou sua negação) aplicado a um conjunto de termos. Ex: mulher (maria), $\neg$ mulher $(x)$, maior_que(idade(maria), 20). Um literal pode ser chamado de "ground" se não contiver variáveis (por exemplo, homem(joao)). Pode ser visto também como uma tupla composta de constantes. Se um literal contiver um símbolo de negação (como por exemplo $\neg$ mulher (joao)) é chamado de literal negativo, se não é chamado de literal positivo.

Uma cláusula é uma disjunção de literais, cujas variáveis estão universalmente quantificadas. Uma cláusula de Horn é uma expressão contendo no máximo um literal positivo, como por exemplo:

$$
H \vee \neg L_{1} \vee \ldots \vee \neg L_{n}
$$

em que $H$ é o literal positivo e $\neg L_{1} \ldots \neg L_{n}$ são literais negativos. Por causa das igualdades $(B \vee \neg A)=(B \leftarrow A)$ e $\neg(A \wedge B)=(\neg A \vee \neg B)$, a cláusula de Horn (eq. 3.1) pode ser escrita da seguinte forma:

$$
H \leftarrow\left(L_{1} \wedge \ldots \wedge L_{n}\right)
$$

ou, na notação equivalente de regras

$$
\text { se }\left(L_{1} \wedge \ldots \wedge L_{n}\right) \text { então } H
$$

Seja qual for a notação de cláusula (eq. 3.1, eq. 3.2 ou eq. 3.3), $H$ é chamada de cabeça ou consequente da cláusula de Horn e a conjunção de literais $\left(L_{1} \wedge \ldots \wedge L_{n}\right)$ é chamada de corpo ou antecedentes da cláusula de Horn.

Uma cláusula $A$ é mais geral que uma cláusula $B$ se e somente se $A \vDash B$ e $B \nvdash A$. Uma cláusula $A$ é mais geral que uma cláusula $B$ relativa a uma cláusula $C$ se e somente se $C \wedge A \vDash B$ e $C \wedge B \forall \forall A$. 
Uma substituição é uma função que troca variáveis por termos em uma expressão. Por exemplo, a substituição $\{X / 3, Y / Z\}$ troca a variável $X$ pelo termo 3 e troca a variável $Y$ pelo termo Z. Dada uma substituição $\theta$ e um literal $L$, escreve-se $L \theta$ para indicar o resultado da aplicação da substituição $\theta$ em $L$.

Uma substituição unificadora de dois literais $L_{1}$ e $L_{2}$ é uma substituiçāo $\theta$ tal que $L_{1} \theta=$ $L_{2} \theta$.

\subsection{A Relação $\theta$-subsoma}

A maioria das técnicas disponíveis de aprendizado de conceitos pode ser vista como técnicas de busca (Mitchell, 1982). Para que uma busca seja efetiva, é fundamental que ela seja conduzida de maneira sistemática. No caso particular de PLI, para sistematizar a busca no espaço de hipóteses é imprescindível que esse espaço seja estruturado através do estabelecimento de uma ordenação de seus elementos. A relação $\theta$ - subsoma, aqui tratada, permite fazer isto.

Uma substituição $\theta=X_{1} / t_{1}, \ldots, X_{k} / t_{k}$ é uma função de variáveis para termos. A aplicação $W \theta$ de uma substituição $\theta$ a uma fórmula $W$ é obtida trocando todas as ocorrências de uma variável $X_{j}$ em $W$ pelo termo $t_{j}$ correspondente (Lloyd, 1987) - $^{\theta-s u b s o m a}$ constitui uma relação de generalidade entre cláusulas: Sejam $C_{1}$ e $C_{2}$ duas cláusulas (de programa). Uma cláusula $C_{1} \theta-$ subsoma uma cláusula $C_{2}$ se existe uma substituição $\theta$, tal que $C_{1} \theta \subseteq C_{2}$ (Plotkin, 1970). No exemplo a seguir, a cláusula $C_{1}$ é mais geral que $C_{2}$ :

$$
\begin{aligned}
& C_{1}: \text { filh }(X, Y) \leftarrow \text { mulher }(X) \\
& C_{2}: \text { filha }(a n a, Y) \leftarrow \text { mulher }(\text { ana }), \text { pai }(Y, a n a)
\end{aligned}
$$

Para verificar isto, as duas cláusulas precisam ser escritas como conjuntos de literais, que estão relacionados entre si por disjunção. Lembrando que dadas duas cláusulas $A$ e $B$, $(A \leftarrow B)$ equivale a $(A \wedge \neg B)$, as cláusulas podem ser escritas como os seguintes conjuntos de literais, nos quais todas as variáveis estão universalmente quantificadas e a disjunção está implícita

$$
\begin{aligned}
& S_{C_{1}}:\{f i l h a(X, Y), \neg \text { mulher }(X)\} \\
& S_{C_{2}}:\{\text { filha }(\text { ana }, Y), \neg \text { mulher }(\text { ana }), \neg \text { pai }(Y, \text { ana })\}
\end{aligned}
$$


Através da substituição $\theta=\{X / a n a\}$, tem-se

$$
S_{C_{1}} \theta=\{\text { filha }(\text { ana }, Y), \neg \text { mulher }(a n a)\}
$$

$S_{C_{1}} \theta$ passa a ser um subconjunto de $S_{C_{2}}$, o que satisfaz a condição de $\theta-$ subsoma, isto é, $C_{1} \theta \subseteq C_{2}$.

$\theta$ - subsoma introduz uma noção sintática de generalidade que estrutura o espaço de hipóteses e ajuda a eliminar buscas em grandes partes do espaço de busca pois (Lavrač e Džeroski, 1994)

- generalizações de uma cláusula que inclui um exemplo negativo também o incluem, logo não precisam ser testadas;

- especializações de uma cláusula que não cobre um exemplo positivo também não irão incluí-lo, e assim também não precisam ser testadas.

$\theta-$ subsoma possui duas propriedades importantes:

1. Se $C_{1} \theta-$ subsoma $C_{2}$ então $C_{1}$ também implica $C_{2}, C_{1} \vDash C_{2}$. O inverso nem sempre é verdadeiro.

2. Introduz um reticulado no conjunto de todas as cláusulas. Isto quer dizer que duas cláusulas nesse conjunto têm sempre uma cláusula que serve como limite superior mínimo delas e outra que funciona como limite inferior máximo.

Com o espaço de hipóteses estruturado pela introduçāo de uma ordem parcial, buscas nesse espaço tornam-se factíveis e podem ser realizadas sistematicamente, de maneira "bottomup" ou "top-down".

Técnicas que implementam busca "top-down" são conhecidas como técnicas de especialização. Consistem basicamente na aplicação de operadores de maneira a obter, a partir de uma descrição geral do conceito, descrições mais específicas. Por outro lado, técnica: de generalização realizam a busca no espaço de hipóteses de uma maneira "bottom-up" inicializando a busca a partir dos exemplos de treinamento - hipóteses mais específicas e generalizando os exemplos através de operadores.

A seguir são discutidas alguns dos operadores mais utilizados por sistemas de PLI em suas buscas, mais especificamente dentro das chamadas técnicas "bottom-up". 


\subsection{Técnicas de Generalização}

As técnicas de generalização mais utilizadas em PLI são: a menor generalização geral, a menor generalização geral relativa e a resolução inversa, vistas a seguir.

\subsubsection{Menor Generalização Geral}

A noção de menor generalização geral $-l g g^{1}$, apresentada primeiro em (Plotkin, 1970), é importante para PLI pois forma a base da generalização "cautelosa". Este tipo de generalização assume que se duas cláusulas $C_{1}$ e $C_{2}$ são verdadeiras, é bem provável que sua generalização mais específica também seja verdadeira. Define-se a lgg de duas cláusulas $C_{1}$ e $C_{2}$ como sendo o mínimo limite superior de $C_{1}$ e $C_{2}$ no reticulado introduzido por $\theta-$ subsoma.

Uma característica que faz com que uma $l g g$ sob $\theta-s u b s o m a$ seja especialmente adequada para PLI, é o fato de ser facilmente calculada. A seguir são apresentados algoritmos para calcular a lgg de termos, literais e cláusulas (Lavrač e Džeroski, 1994). O Algoritmo para calcular a lgg de termos é mostrado na Figura 3.1 e exemplos de lgg de alguns termos são mostrados na Tabela 3.1 .

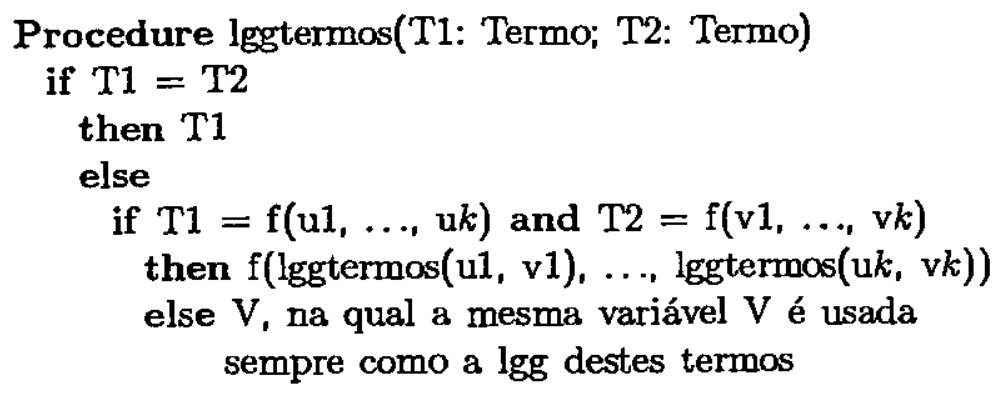

Figura 3.1: Algoritmo para Calcular lgg de Termos

Nos dois últimos exemplos da Tabela 3.1 são utilizadas listas, as quais podem ser consideradas termos, uma vez que estas podem ser escritas utilizando o funtor ".". Desta forma esses exemplos podem ser entendidos como:

$$
\operatorname{lgg}(.(1, .(2, .(3, .()))), .(1, .(4, .(5, .()))))=.(1, .(A, .(B, .())))
$$

\footnotetext{
${ }^{1}$ do inglès, Least Genenal Generalization; será mantida essa notação por ser mais comumente utilizado na comunidade de Aprendizado de Máquina
} 


$$
\operatorname{lgg}(.(r, .(s, .(t, .(u, .())))), .(r, .(s, .(t, .()))))=.(r, .(A, .(B, C)))
$$

\begin{tabular}{||l|l|l||}
\hline \hline$T_{1}$ & $T_{2}$ & $\lg g\left(T_{1}, \overline{T_{2}}\right)$ \\
\hline$f(r, s, t, u)$ & $f(v, x, y, z)$ & $f(A, B, C, D)$ \\
$f(r, s, t, s)$ & $f(v, x, x, x)$ & $f(A, B, C, B)$ \\
$f(r, s, t, u)$ & $g(r, s, t, u)$ & $A$ \\
{$[1,2,3]$} & {$[1,4,5]$} & {$[1, \mathrm{~A}, \mathrm{~B}]$} \\
{$[\mathrm{r}, \mathrm{s}, \mathrm{t}, \mathrm{u}]$} & {$[\mathrm{r}, \mathrm{t}, \mathrm{s}]$} & {$[\mathrm{r}, \mathrm{A}, \mathrm{B} \mid \mathrm{C}]$} \\
\hline \hline
\end{tabular}

Tabela 3.1: Exemplos de lgg de Termos

O algoritmo responsável por calcular a lgg de literais é apresentada na Figura 3.2.

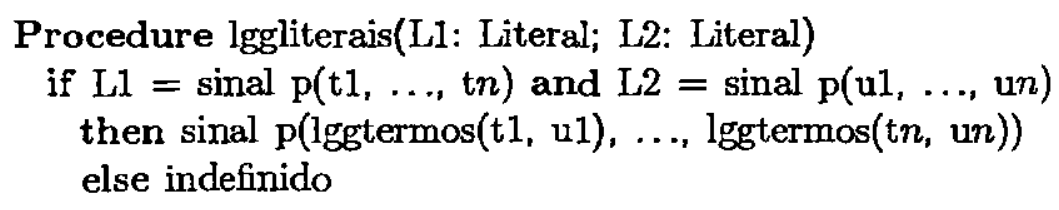

Figura 3.2: Algoritmo para Calcular lgg de Literais

O algoritmo pode ser entendido assim: a $l g g$ de dois literais é calculada comparando os termos que estão na mesma posição em cada literal. Se forem iguais, o valor do termo é mantido na $l g g$; se não, são substituídos por uma variável. Exemplos de lggs de alguns literais são mostrados na Tabela 3.2.

\begin{tabular}{||l|l|l||}
\hline \hline$L_{1}$ & $L_{2}$ & $\operatorname{lgg}\left(L_{1}, L_{2}\right)$ \\
\hline$p(r, s)$ & $p(v, x)$ & $p(A, B)$ \\
$\neg p(r, s)$ & $p(r, s)$ & indefinido \\
append([1,2], [3,4], [1,2,3,4]) & append([r] $,[\mathrm{s}],[\mathrm{r}, \mathrm{s}])$ & append([A]B], [C]D], [A, E|F]) \\
\hline \hline
\end{tabular}

Tabela 3.2: Exemplos de lgg de Literais

A $l g g$ de duas cláusulas é calculada através da lgg de cada par de literais na cabeça e corpo das mesmas. O algoritmo para encontrar a $l g g$ de duas cláusulas é um pouco diferente, podendo ser entendido da seguinte forma (Batista, 1997)

- Dadas duas cláusulas $C_{1}$ e $C_{2}$ entendidas na forma de conjuntos de literais, nos quais as literais se relacionam através de disjunções;

- $\lg g\left(C_{1}, C_{2}\right)$ é representado pelo conjunto de literais, $U$, formado da seguinte forma 
1. É calculado a $l g g$ de cada literal $L_{i}$ do conjunto $C_{1}$ com cada literal $K_{j}$ do conjunto $C_{2}$;

2. Se $\lg g\left(L_{i}, K_{j}\right)$ não é indefinido, o literal resultante desta operação é inserido no conjunto de resposta $U$.

A Figura 3.3 apresenta o algoritmo responsável por calcular lgg de cláusulas.

Procedure lggclausulas(C1: Clausula; C2: Clausula)

if $\mathrm{C} 1=\{L 1, \ldots, L n\}$ and $\mathrm{C} 2=\{K 1, \ldots, K m\}$

then $\{U i \mid U i=\operatorname{lggliterais}(L j, K k)$ para $1<=j<=n$ and $1<=k<=m$ and $\operatorname{lgg}(L j, K k)<>$ indefinido\}

Figura 3.3: Algoritmo para Calcular lgg de Cláusulas

Para mostrar esse procedimento, um exemplo é colocado utilizando a base do problema na Seção 2.5 .

- $C_{1}=$ filha $($ sara, eva $) \leftarrow$ mulher $($ sara $)$, progenitor $($ eva, sara $)$

$$
\left.S_{C_{1}}=\{\text { filha (sara, eva), } \neg \text { mulher (sara), } \neg \text { progenitor (eva, sara })\right\}
$$

- $C_{2}=$ filha $($ ana,pedro $) \leftarrow$ mulher $(a n a), \operatorname{progenitor}($ pedro, ana)

$S_{C_{2}}=\{$ filha(ana,pedro $), \neg$ mulher (ana), $\neg$ progenitor (pedro, ana $\left.)\right\}$

- $\operatorname{lgg}\left(S_{C_{1}}, S_{C_{2}}\right)=\{$ filha $(X, Y), \neg$ mulher $(Y), \neg$ progenitor $(Y, X)\}$

$$
\operatorname{lgg}\left(C_{1}, C_{2}\right)=\operatorname{filha}(X, Y) \leftarrow \operatorname{mulher}(Y), \operatorname{progenitor}(Y, X)
$$

Pode ser observado que a lgg não leva em consideração a teoria (ou conhecimento prévio) do domínio. Plotkin estendeu o conceito de lgg para a menor generalização geral relativa, descrita a seguir, na qual a teoria do domínio é considerada (Plotkin, 1971).

\subsubsection{Menor Generalização Geral Relativa}

A menor generalização geral relativa $-r l g g^{2}-$ de duas cláusulas $C_{1}$ e $C_{2}$ é a menor generalização geral, $\operatorname{lgg}\left(C_{1}, C_{2}\right)$, relativa ao conhecimento de fundo $\mathcal{K}$ (Plotkin, 1971). Em

\footnotetext{
${ }^{2}$ do inglês, Relative Least General Generalization; novamente esta notação será mantida por ser mais comumente utilizado na comunidade de Aprendizado de Máquina
} 
outras palavras, se o conhecimento prévio do domínio consiste de átomos "ground" e $\mathcal{K}$ denota a conjunção de todos esses fatos, a rlgg de dois exemplos de treinamento positivos $e_{1}$ e $e_{2}$, relativo a $\mathcal{K}$ é definido como:

$$
r \lg g\left(e_{1}, e_{2}\right)=\operatorname{lgg}\left(\left(e_{1} \leftarrow Q\right),\left(e_{2} \leftarrow Q\right)\right)
$$

Considerando os exemplos e conhecimento prévio definidos na Tabela 2.1, pág. 12, a seguir é computada a rlgg dos dois exemplos positivos $e_{1}=$ filha(sara, eva) e $e_{2}=$ filha(ana,pedro).

$\mathcal{K}$ é a conjunção das literais progenitor(eva, sara), progenitor(ana, tomas), progenitor(pedro, ana), progenitor(tomas, sara), mulher(ana), mulher(sara), mulher(eva). Para simplificar a representação no exemplo, as seguintes abreviações são utilizadas: f-filha, g-progenitor, m-mulher, a-ana, e-eva, s-sara, t-tomas, p-pedro. A conjunção dos fatos do conhecimento prévio ("," significa conjunção) pode ser escrito como

$$
\mathcal{K}=g(e, s), g(a, t), g(p, a), g(t, s), m(a), m(s), m(e) .
$$

O cálculo da $r l g g\left(e_{1}, e_{2}\right)$ produz a seguinte cláusula

$$
\begin{gathered}
f\left(V_{s, a}, V_{e, p}\right) \leftarrow g(e, s), g(a, t), g(p, a), g(t, s), m(a), m(s), m(e), \\
g\left(V_{e, a}, V_{s, t}\right), g\left(V_{e, p}, V_{s, a}\right), g\left(V_{e, t}, s\right), g\left(V_{a, p}, V_{t, a}\right), \\
g\left(V_{a, t}, V_{t, s}\right), g\left(V_{p, t}, V_{a, s}\right), m\left(V_{a, s}\right), m\left(V_{a, e}\right), m\left(V_{s, e}\right)
\end{gathered}
$$

em que $V_{x, y}$ representa $r l g g(x, y)$ para cada $x$ e $y$.

Uma rlgg possui muitos literais redundantes que podem ser removidos, por exemplo, todos os literais que são fatos podem ser retirados, pois são conhecidamente verdadeiros e, portanto, não influenciam no significado da cláusula. Cada rlgg pode ser substituída por uma variável distinta, por exemplo, $V_{s, a}$ passa a ser $X, V_{e, p}$ passa a ser $Y$, e assim por diante. Com a remoção dos literais que são fatos existentes no conhecimento prévio do domínio e as substituiçōes mencionadas, obtém-se:

$$
f(X, Y) \leftarrow g(Z, W), g(Y, X), g(V, s), g(U, T), g(T, W), g(S, X), m(X), m(Z), m(R)
$$

Outra simplificação que pode ser feita é retirar todos os literais que introduzem novas variáveis, isto é, variáveis que não estão presentes na cabeça da cláusula. Cláusulas deste 
tipo são chamadas de cláusulas restringidas (Nicoletti e Monard, 1994). Com mais esta simplificação, obtém-se:

$$
f(X, Y) \leftarrow g(Y, X), m(X)
$$

o que equivale a

$$
\text { filha }(X, Y) \leftarrow \text { progenitor }(Y, X), \text { mulher }(X) \text {. }
$$

Um sistema que utiliza essa técnica como base para seu aprendizado, o GoLEM (Muggleton e Feng, 1990), será visto no Capítulo 4. A seguir, é descrita outra técnica de generalização, a resolução inversa.

\subsubsection{Resolução Inversa}

A idéia básica de resolução inversa, introduzida como uma técnica de generalização para PLI em (Muggleton e Buntine, 1988), é inverter a regra de resolução da inferência dedutiva (Robinson, 1965). Um passo básico de resolução aplicado em lógica proposicional deriva a proposição $p \vee r$ dadas as premissas $p \vee \neg q$ e $q \vee r$. Em lógica de primeira ordem, resolução é mais complicada, pois envolve substituições. A conclusão obtida de duas cláusulas $C_{1} \mathrm{e}$ $C_{2}$ através de um passo de inferência por resolução é denotada por res $\left(C_{1}, C_{2}\right)$ e é chamado de resolvente de $C_{1}$ e $C_{2}$.

Para ilustrar resolução em lógica de primeira ordem, será utilizado o exemplo da Seção 2.5, página 12. Suponha que o conhecimento prévio $\mathcal{K}$ consista das cláusulas $b_{1}=$ mulher (sara) e $b_{2}=$ progenitor $($ eva, sara $)$ e $\mathcal{H}=\{C\}=\{$ filha $(X, Y) \leftarrow$ mulher $(X)$, progenitor $(Y, X)\}$. Seja $\mathcal{T}=\mathcal{H} \cup \mathcal{B}$. Supondo que queiramos derivar o fato filha(sara, eva) de $\mathcal{T}$, procede-se da seguinte maneira:

- Primeiro, o resolvente $C_{1}=\operatorname{res}\left(C, b_{1}\right)$ é calculado com a substituição $\theta_{1}=\{X /$ sara $\}$. Com isso, a substituição $\theta_{1}$ é primeiro aplicada a $C$ para obter filha(sara, $\left.Y\right) \leftarrow$ mulher(sara), progenitor $(Y$, sara $)$ o que é resolvido junto com $b_{1}$ como no caso proposicional. O resolvente de $f i l h a(X, Y) \leftarrow$ mulher $(X)$, progenitor $(Y, X)$ e mulher(sara) é portanto $C_{1}=\operatorname{res}\left(C, b_{1}\right)=f i l h a($ sara,$Y) \leftarrow$ mulher (sara), progeni$\operatorname{tor}(Y$, sara $)$. 
- O próximo resolvente $C_{2}=\operatorname{res}\left(C_{1}, b_{2}\right)$ é calculado com a substituição $\theta_{2}=\{Y /$ eva $\}$. As cláusulas filha(sara, $Y) \leftarrow$ mulher (sara), progenitor $(Y$, sara) e progenitor(eva, sara) resolvem em $C_{2}=\operatorname{res}\left(C_{1}, b_{2}\right)=$ filha(sara, eva $)$.

Resolução Inversa, como foi implementada em (Muggleton e Buntine, 1988), utiliza um operador de generalização baseado no inverso de substituição (Buntine, 1988). Dada uma cláusula $W$, uma substituição inversa $\theta^{-1}$ de uma substituição $\theta$ é uma função que mapeia termos em $W \theta$ para variáveis, de modo que $W \theta \theta^{-1}=W$.

Seja $C=f i l h a(X, Y) \leftarrow$ mulher $(X), \operatorname{progenitor}(Y, X)$ e a substituição $\theta=\{X /$ sara, $Y / e v a\}$ :

$$
C^{\prime}=C \theta=f i l h a(\operatorname{sar} a, e v a) \leftarrow \text { mulher }(e v a), \operatorname{progenitor}(e v a, \text { sara }) .
$$

Aplicando a substituição inversa $\theta^{-1}=\{\operatorname{sara} / X, e v a / Y\}$, é possível obter a cláusula original:

$$
C=C^{\prime} \theta^{-1}=f i l h a(X, Y) \leftarrow \text { mulher }(X), \operatorname{progenitor}(Y, X) \text {. }
$$

No caso geral, substituição inversa se torna mais complexa. Envolve as posições dos termos para assegurar que as variáveis da cláusula inicial $W$ sejam restauradas a seus lugares apropriados em $W \theta \theta^{-1}$.

Seja o conhecimento de fundo $\mathcal{K}$ os dois fatos (cláusulas) $b_{1}=$ mulher(sara) e $b_{2}=$ progenitor (eva,sara). Seja a hipótese $\mathcal{H}=\emptyset$ e suponha que o sistema de aprendizado encontre o exemplo positi vo $e_{1}=f i l h a(s a r a, e v a)$. O processo de resolução inversa poderia ser o seguinte:

- Primeiro, procura-se uma cláusula $C_{1}$ que, junto com $b_{2}$, implique $e_{1}$ e possa ser adicionada à hipótese atual $\mathcal{H}$ no lugar de $e_{1}$. Através da substituição inversa $\theta_{2}^{-1}=\{e v a / Y\}$, um passo de resolução inversa gera a cláusula $C_{1}=i r e s\left(b_{2}, e_{1}\right)=$ filha $($ sara,$Y) \leftarrow \operatorname{progenitor}(Y$, sara $)$. Com isso, a cláusula $C_{1}$ se torna a hipótese atual $\mathcal{H}$, tal que $\left\{b_{2}\right\} \cup \mathcal{H} \models e_{1}$.

- Num passo seguinte, a resolução inversa tomaria $b_{1}=$ mulher(sara) e a hipótese atual $\mathcal{H}=\left\{C_{1}\right\}=\{$ filha $($ sara,$Y) \leftarrow \operatorname{progenitor}(Y$, sara $)\}$. Calculando $C_{2}$, com 
a substituição inversa $\theta_{1}^{-1}=\{\operatorname{sara} / X\}$, a cláusula pode ser generalizada com relação ao conhecimento de fundo $\mathcal{K}$, resultando na cláusula $C_{2}=$ filha $(X, Y) \leftarrow$ mulher $(X)$, progenitor $(Y, X)$. Assim, $C_{1}$ pode ser substitúda na hipótese atual $\mathcal{H}$ pela cláusula mais geral $C_{2}$ que junto com $\mathcal{K}$ implica o exemplo $e_{1}$. A hipótese induzida é $\mathcal{H}=\{$ filha $(X, Y) \leftarrow$ mulher $(X)$, progenitor $(Y, X)\}$

A Figura 3.4 mostra a árvore de derivação linear inversa correspondente a esse processo.

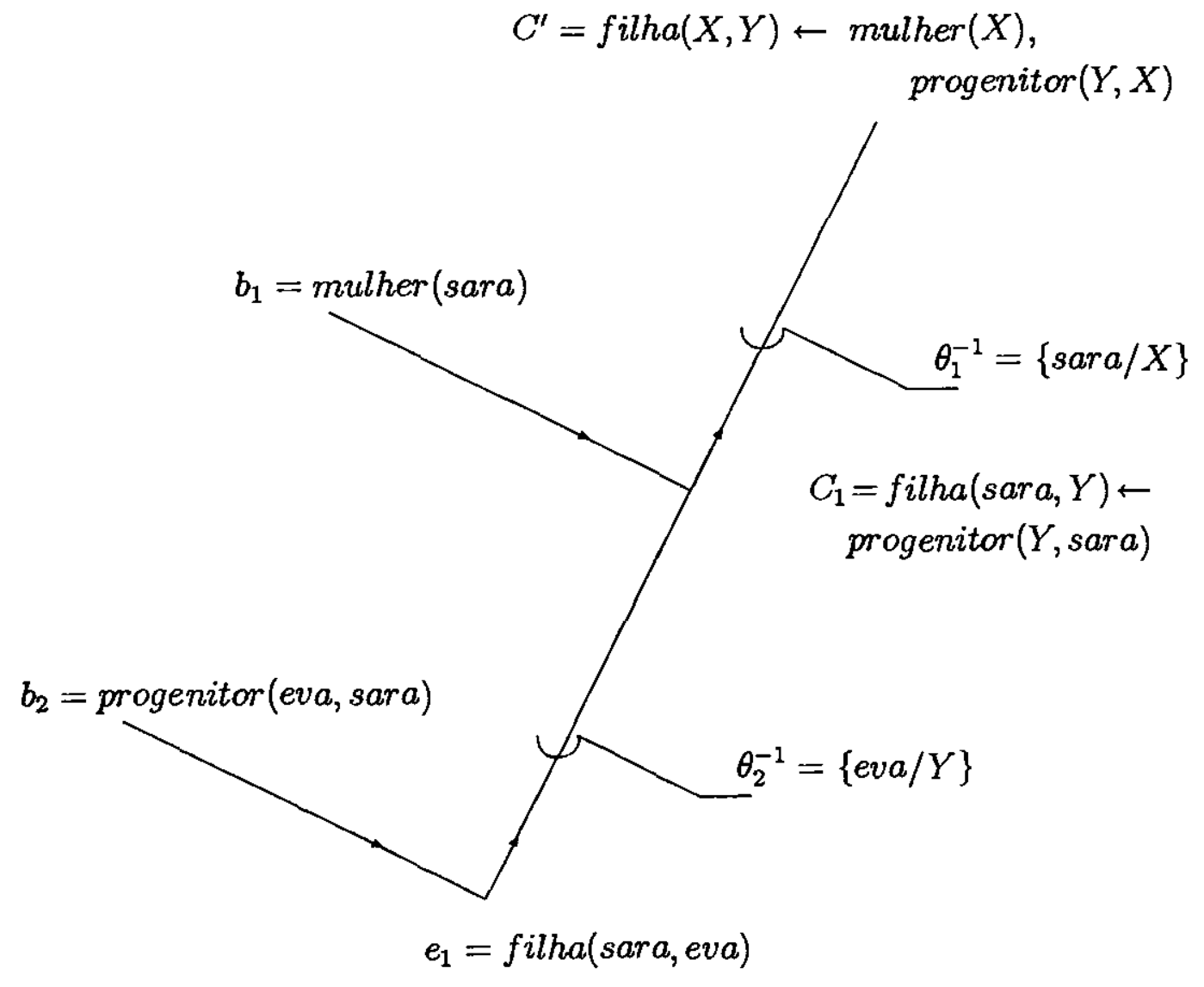

Figura 3.4: Uma Árvore de Derivação Linear Inversa (Džeroski, 1996)

O operador de generalização mostrado no exemplo acima é chamado de operador de $a b$ sorção (ou operador V). É um dos operadores utilizados no sistema CIGOL (Muggleton e Buntine, 1988). Outro operador importante é o de intra-construção, também chamado de operador $\mathbf{W}$, que combina dois operadores $\mathbf{V}$. Ele permite gerar cláusulas que utilizam predicados que não estão disponíveis no vocabulário inicial do programa de aprendizado. Esta habilidade de introduzir predicados novos é conhecida como invençāo de predicados. 


\subsection{Técnicas de Especialização}

Como mencionado anteriormente, técnicas que implementam busca "top-down" são denominadas técnicas de especialização. Sistemas de aprendizado "top-down" começam com a cláusula mais geral e a refinam repetidamente, especializando-a até que não cubra mais exemplos negativos. Durante a busca asseguram que a cláusula considerada cobre pelo menos um exemplo positivo. A técnica de especialização básica em PLI é a busca "topdown" em grafos de refinamento. Esta técnica foi introduzida no sistema de PLI interativo MIS (Model Inference System (Shapiro, 1983)). Também é utilizada no sistema empírico FOIL (Quinlan, 1990), e seus derivados, como mFOIL (Džeroski e Bratko, 1992) e FOCL (Pazzani e Kibler, 1991).

Dada uma linguagem de hipóteses $\mathcal{L}_{\mathcal{H}}$ e conhecimento de fundo $\mathcal{K}$, o espaço de hipóteses de cláusulas de programa forma um reticulado, estruturado através da ordenação de generalidade da relação $\theta$ - subsoma, como visto na Seçao 3.3. Neste reticulado, um grafo de refinamento pode ser definido como um grafo acíclico e dirigido no qual nós são cláusulas de programa e arcos correspondem às operações básicas de refinamento: substituir uma variável por um termo e adicionar um literal ao corpo de uma cláusula.

Parte do grafo de refinamento para o problema de relações familiares é mostrado na Figura 3.5. A busca pela cláusula é iniciada com a cláusula $f i l h a(X, Y) \leftarrow$, a qual cobre dois exemplos negativos. Os refinamentos da cláusula são considerados em seguida, dos quais $f i l h a(X, Y) \leftarrow$ mulher $(X)$ e $f i l h a(X, Y) \leftarrow$ pai $(Y, X)$ cobrem apenas um exemplo negativo. As duas cláusulas tem um refinamento em comum

$$
\text { filha }(X, Y) \leftarrow \text { mulher }(X), \operatorname{pai}(Y, X)
$$

a qual não cobre os exemplos negativos. A busca no reticulado de refinamento é em geral heurística, como as buscas realizadas em Progol (Muggleton, 1995) e FOIL (Quinlan, 1990). A seguir são consideradas outras técnicas utilizadas nos sistemas MOBAL e LINUS. 


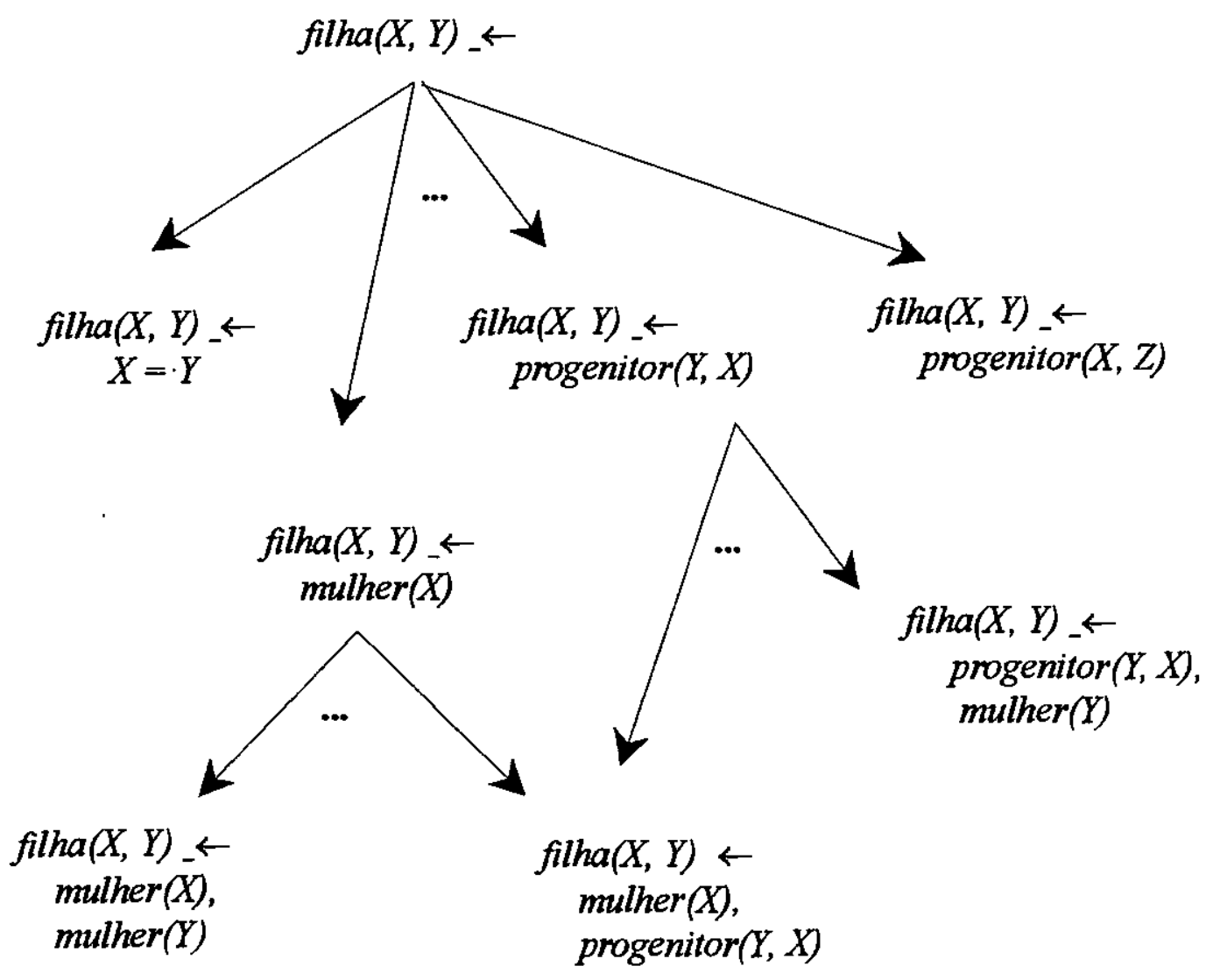

Figura 3.5: Parte do Grafo de Refinamento para Aprender a Relação filha/2 


\subsection{Modelos de Regras}

O sistema MOBAL (Morik et al., 1993) contém um módulo de aprendizado baseado no uso de modelos de regras. Estes modelos são uma forma de "bias" declarativo, ou mais especificamente, um "bias" declarativo de linguagem. Eles especificam a forma das cláusulas que podem aparecer na hipótese e são usados como "templates" para a construção de hipóteses. Os modelos de regras são fornecidos pelo usuário ou podem ser derivados a partir de regras já aprendidas, utilizando uma ferramenta de aquisição de modelos que é parte de MOBAL.

Um modelo de regra $R$ tem a forma $T \leftarrow L_{1}, \ldots, L_{m}$ onde $T$ e $L_{i}$ são esquemas de literais. Esquemas de literais têm a forma $Q_{i}\left(Y_{1}, \ldots, Y_{n_{i}}\right)$ ou not $Q_{j}\left(Y_{1}, \ldots, Y_{n_{j}}\right)$ nos quais todas as variáveis não-predicados $Y_{k}$ estão, implicitamente, universalmente quantificadas. A variável de predicado $Q_{i}$ somente pode ser instanciada com símbolos de predicado que possuem a aridade $n_{i}$ ou $n_{j}$ especificada.

A busca por hipóteses em MOBAL é guiada pelos modelos de regras. O espaço de hipóteses em que é realizada a busca é o conjunto de instanciações das variáveis de predicado com predicados do conhecimento prévio do domínio $\mathcal{K}$. Uma instanciação $\Theta$ é uma substituição de segunda ordem, isto é, um conjunto finito de pares $P / p$ onde $P$ é uma variável de predicado e $p$ é um símbolo de predicado. Uma instanciação de um modelo de regra $R$ (indicada por $R \Theta$ ) é obtida substituindo cada variável de predicado em $R$ com o correspondente símbolo de predicado do conjunto $\Theta$. Um modelo de regra de segunda ordem $R$ é chamado de "ground" se todas as suas variáveis estão instanciadas; nesse caso, $R$ se torna uma regra de primeira ordem (cláusula).

Para aprender a relação filha do nosso problema corrente de relações familiares, o usuário teria que definir o seguinte modelo:

$$
P(X, Y) \leftarrow R(X), Q(Y, X)
$$

Nesse caso, a cláusula correta filha $(X, Y) \leftarrow$ mulher $(X)$, pai $(Y, X)$ pode ser induzida a partir dos exemplos. Note que o modelo também poderia ser instanciado com filho $(X, Y) \leftarrow \operatorname{homem}(X), \operatorname{pai}(Y, X)$, desde que existisse os predicados filho/2 e homem $/ 1$ nos exemplos e conhecimento prévio do domínio, respectivamente. Assim, um modelo de regra pode ser útil para resolver vários problemas de aprendizado.

O espaço de cláusulas especificado pelos modelos de regras é muito grande. Para cada modelo de regra, todas as instanciações possíveis de variáveis de predicado devem ser 
provadas sistematicamente e as cláusulas resultantes testadas com relação aos exemplos e ao conhecimento de fundo. Uma ordem hierárquica de modelos de regras, baseada numa extensāo de $\theta$ - subsoma para representações de segunda ordem, permite que MOBAL elimine certas partes do espaço de busca.

\subsection{Transformação de Problemas de PLI para a For- ma Proposicional}

O sistema de PLI, LINUS (Lavrač e Džeroski, 1994), se baseia na seguinte idéia: conhecimento prévio do domínio pode ajudar na criação de novos atributos para o aprendizado proposicional. Um problema de PLI pode ser transformado de uma forma relacional para uma forma atributo-valor (proposicional) e resolvido por um programa de aprendizado atributo-valor. Vale ressaltar que esta abordagem somente é praticável numa classe restrita de problemas de.PLI. Por isso, a linguagem de hipóteses é restrita a cláusulas de programa sem funções e tipadas (cada variável é associada com um conjunto pré-determinado de valores), restringidas (todas as variáveis no corpo da cláusula também aparecem na cabeça dela) e näo-recursivas (o símbolo do predicado da cabeça não aparece em nenhum dos literais no corpo da cláusula).

O algoritmo de LINUS consiste de três passos:

- O problema de aprendizado é transformado da forma relacional para a forma atributovalor.

- O problema transformado é resolvido por um programa de aprendizado atributovalor.

- A hipótese induzida é transformada para a forma relacional.

O algoritmo acima permite que uma variedade de métodos desenvolvidos para problemas proposicionais, inclusive técnicas para tratar ruídos nos dados de algoritmos atributovalor, tais como ASSISTANT (Cestnik et al., 1987) e CN2 (Clark e Niblett, 1989), sejam utilizados para aprender relações. Ilustra-se isto com o problema simples de PLI para aprender relações familiares da Seção 2.5 na Tabela 2.1, página 12. Ali a tarefa consiste em definir a relação filh $a(X, Y)$, isto é, que pessoa $X$ é filha de pessoa $Y$, em termos do 
conhecimento prévio das relações mulher $/ 1$, homem/1 e progenitor $/ 2$. Todas as variáveis são do tipo pessoa, definido como pessoa $=\{a n a$, sara, eva, pedro, tomas $\}$. Há dois exemplos positivos e dois negativos da relação meta.

O primeiro passo do algoritmo, isto é, a transformação do problema de PLI para a forma atributo-valor, é realizada da seguinte maneira: as aplicações possíveis dos predicados que representam o conhecimento prévio do domínio aos argumentos da relação meta são determinadas, levando em conta os tipos dos argumentos. Cada aplicação destas introduz um novo atributo. No exemplo, todas as variáveis são do mesmo tipo pessoa. O problema correspondente de aprendizado atributo-valor é mostrado na Tabela 3.3, onde $m$ representa mulher, $h$ representa homem e $g$ representa progenitor. As tuplas de atributos e valores são generalizações (relativas ao conhecimento prévio) dos fatos individuais em cima da relação meta.

\begin{tabular}{|l|l|l|l|l|l|l|l|l|l|l|}
\hline \hline Classe & \multicolumn{2}{|c|}{ Variáveis } & \multicolumn{9}{c|}{ Características Proposicionais } \\
\hline & $X$ & $Y$ & $m(X)$ & $m(Y)$ & $h(\bar{X})$ & $\bar{h}(Y)$ & $g(X, X)$ & $g(X, Y)$ & $g(Y, X)$ & $g(Y, Y)$ \\
\hline$\oplus$ & sara & eva & verdade & verdade & falso & falso & falso & falso & verdade & falso \\
$\oplus$ & ana & pedro & verdade & falso & falso & verdade & falso & falso & verdade & falso \\
$\ominus$ & tomas & ana & falso & verdade & verdade & falso & falso & falso & verdade & falso \\
$\ominus$ & eva & ana & verdade & verdade & falso & falso & falso & falso & falso & falso \\
\hline \hline
\end{tabular}

Tabela 3.3: Forma Proposicional para Aprender a Relação filha/2

Na Tabela 3.3, a coluna Variáveis representa os argumentos da relação meta, e as colunas debaixo de Características Proposicionais representam os atributos novos construídos para a tarefa de aprendizado proposicional. Quando cláusulas livres de funções estão sendo aprendidas, somente os novos atributos são considerados para o aprendizado.

O segundo passo envolve induzir a seguinte regra se-então com um programa de aprendizado atributo-valor utilizando as tuplas na Tabela 3.3:

$$
\text { Classe }=\oplus \text { se }[\text { mulher }(X)=\text { verdadeiro }] \wedge[\text { progenitor }(Y, X)=\text { verdadeiro }]
$$

No último passo, as regras se-então induzidas são transformadas para cláusulas de Horn. No exemplo considerado obtém-se a cláusula

$$
\text { filha }(X, Y) \leftarrow \text { mulher }(X) \text {, progenitor }(Y, X) \text {. }
$$


LINUS já foi aplicado com sucesso ao problema de aprender regras para o diagnóstico de reumatismo em uma base de dados médicos (Lavrač et al., 1993). DINUS (Lavrač e Džeroski, 1994) é uma extensão de LINUS que aprende cláusulas determinadas, a mesma classe de claúsulas aprendida por GOLEM (Muggleton e Feng, 1990). Foi aplicado a um problema de clonagem comportamental, isto é, para aprender regras de controle para sistemas dinâmicos (Džeroski et al., 1995).

\subsection{Considerações Finais}

Neste capítulo foram vistas várias técnicas utilizadas nos sistemas empíricos de PLI. Duas categorias importantes são as técnicas de especialização, ou "top-down", e as técnicas de generalização, ou "bottom-up". Em ambos os casos, se refere à direção geral que é tomada pela busca por cláusulas.

Técnicas diferentes podem ser combinadas e empregadas dentro de um mesmo sistema de PLI. Por exemplo, modelos de regra em MOBAL sāo utilizados em conjunto com a busca "top-down" em grafos de refinamento. Muitas vezes, pode acontecer de precisar inverter esta direção para corrigir uma generalização muito geral ou uma especialização mütto específica. Busca bi-direcional, combinando buscas "top-down" e "bottom-up" por cláusulas, pode ser usada nesse caso (Siou, 1994).

No capítulo seguinte serão descritos alguns sistemas empíricos de PLI que incorporam a maioria das técnicas aqui tratadas. 


\section{Capítulo 4}

\section{Alguns Sistemas de PLI}

\subsection{Considerações Iniciais}

Atualmente há muitos sistemas de Programação Lógica Indutiva prontos e em desenvolvimento. Muitos deles estão disponíveis, para serem pesquisados e aproveitados, em projetos tanto do meio acadêmico quanto para fins comẹrciais. Existem aplicações diversas, com variados níveis de sucesso, espalhadas por inúmeras áreas. Quatro sistemas estão entre os mais proeminentes em termos de relatos de aplicação, principalmente no meio acadêmico: Foll (Quinlan, 1990), Golem (Muggleton e Feng, 1990), Progol (Muggleton, 1995) e MOBAL (Morik et al., 1993). A seguir estes quatro sistemas serão vistos com mais detalhes.

\subsection{Golem}

Este sistema aprende um predicado de cada vez, de modo não-interativo e não-incremental, a partir de uma busca "bottom-up", ou de generalização. Para restringir sua busca utiliza o conceito de $i j$-determinação que restringe a profundidade das variáveis consideradas na avaliação de literais (Nicoletti, 1994; Nicoletti e Monard, 1995b). O GoLEM está disponível para "download" no seguinte endereço na Internet

http://www.comlab.ox.ac.uk/oucl/groups/machlearn/golem.html 
O algoritmo do sistema funciona assim: para gerar uma única cláusula, o GOLEM escolhe um número (pré-determinado pelo usuário) de pares de exemplos positivos de forma aleatória, e calcula a rlgg de cada par. É escolhida aquela rlgg que cobre o maior número de exemplos positivos, ou seja, que tem a maior cobertura.

Esta cláusula é generalizada ainda mais ao escolher aleatoriamente novos exemplos positivos e calcular as rlggs da cláusula com cada um dos exemplos. Novamente é escolhida a rlgg que tem a maior cobertura, sem cobrir algum exemplo negativo. Esse processo de generalização é repetido até que a cobertura da melhor cláusula pare de aumentar. Numa fase de pósprocessamento da cláusula, o número de literais é reduzido eliminando literais irrelevantes, desde que isso não faça com que a cláusula cubra exemplos negativos.

Construída a cláusula, verifica-se o número de exemplos positivos cobertos por ela. Estes são removidos do conjunto de treinamento, e repete-se o processo até que todos os exemplos positivos estejam cobertos por alguma cláusula da hipótese. O Algoritmo 4.1 apresenta uma representação do algoritmo básico de GolEM.

GolEM tem sido utilizado com sucesso em diversas áreas de aplicação, tais como: construção de modelos qualitativos para tubos ligando recipientes de água, previsão de estruturas secundárias em proteínas (Muggleton et al., 1992) e modelos temporais para cálculo das necessidades de energia em satélites (Muggleton, 1991). Uma explicação mais detalhada deste sistema encontra-se em (Monard et al., 1998).

Deve ser observado que o mesmo grupo que desenvolveu GOLEM também desenvolveu Progol e, durante algum tempo, ambos algoritmos continuaram a ser utilizados. Porém, devido à explosão da busca no espaço de candidatos que se apresenta em determinadas situações, mostrou-se a impossibilidade de utilizar o GoLEM em alguns problemas práticos. Assim, o grupo de ML de Oxford descontinuou suas pesquisas com esse sistema, preferindo se concentrar em Progol. Por esses motivos, também desconsideramos a utilização de GOLEM em nosso trabalho.

\subsection{FOIL}

É um sistema que lê especificações extensionais de um conjunto de relações e produz hipóteses compostas de cláusulas de Horn para uma ou mais delas (Quinlan, 1990). O sistema aprende um predicado por vez, de uma forma não-interativa e não-incremental, 


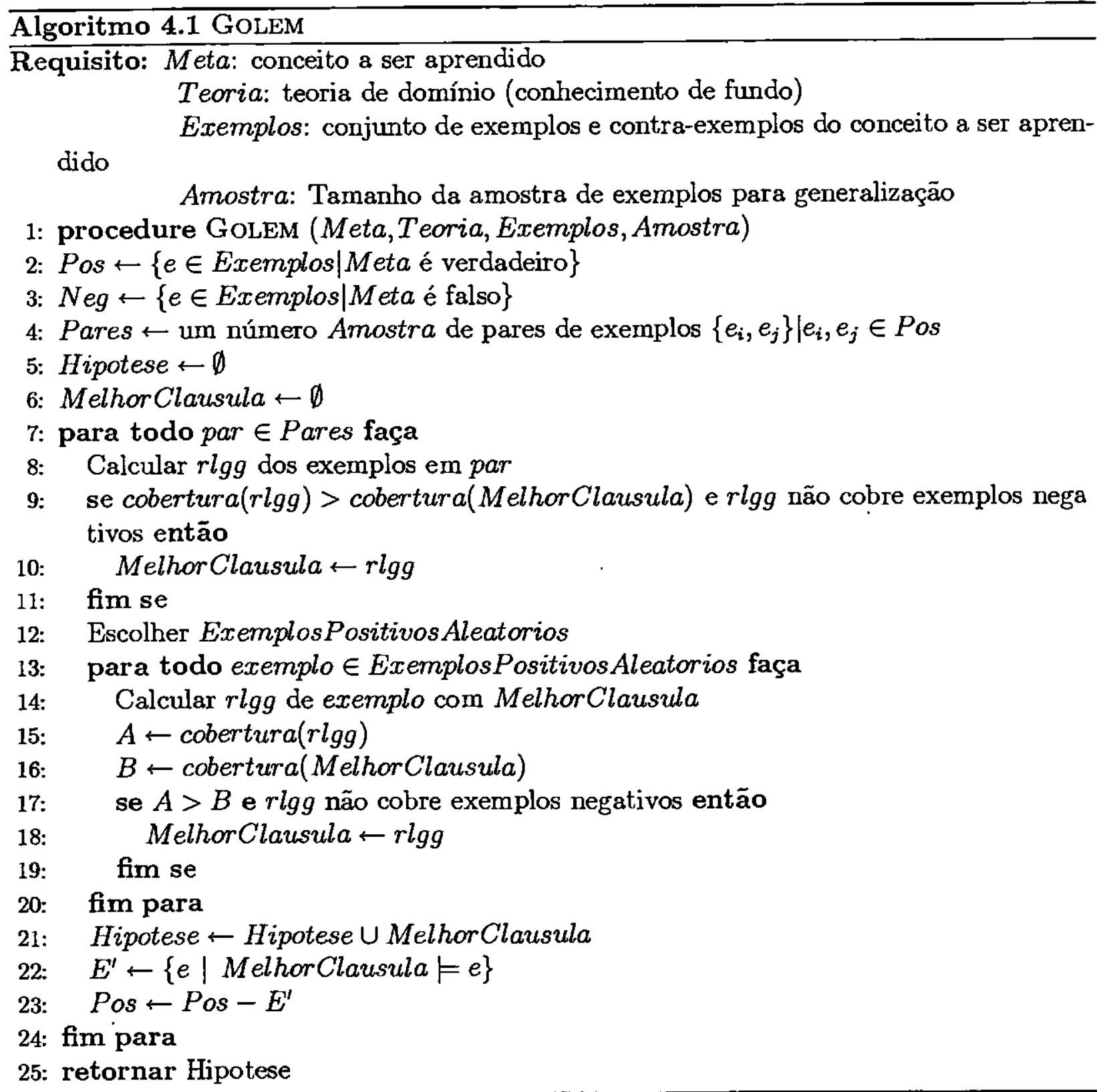


fazendo uma busca "top-down" no espaço de hipóteses. Atualmente encontra-se na versão 6.4. O "download" do sistema pode ser feito na Internet a partir do endereço

$$
\text { http://www.cse.unsw.edu.au/ quinlan/ }
$$

Foll aproveita algumas idéias do paradigma de aprendizado baseado em atributo-valor, utilizando um método de cobertura semelhante ao de AQ (Michalski, 1983) e uma heurística baseada em informaçāo semelhante ao de ID3 (Quinlan, 1986). Além disso, herda a idéia de busca "top-down" em grafos de refinamento do MIS (Shapiro, 1983).

A linguagem de hipóteses em Foll é restrita a cláusulas de programa livres de funções. Uma versão recente de Foll, chamada de FFoll, trata programas com funções (Quinlan, 1996). Constantes e termos compostos não podem aparecer nas cláusulas induzidas. $O$ corpo de uma cláusula é uma conjunção de literais $A$ e not $A$, onde $A$ é um átomo. Literais no corpo têm ou um símbolo de predicado $q_{i}$, tirado do conhecimento de fundo $\mathcal{K}$, ou o símbolo do predicado alvo, que faz com que seja possível aprender cláusulas recursivas. Pelo menos uma das variáveis nos argumentos de um literal do corpo deve aparecer na cabeça da cláusula ou em um dos literais à sua esquerda.

Os exemplos de treinamento bem como o conhecimento de fundo $\mathcal{K}$ consistem de definições extensionais de predicados. Exemplos negativos podem ser colocados explicitamente ou derivados do "mundo fechado".

Inicialmente procura-se uma cláusula que cubra o maior número de exemplos possível sem cobrir algum exemplo negativo. Para isso, inicia-se o algoritmo com a cláusula tendo o predicado alvo como cabeça e nenhum literal no corpo. Para eliminar exemplos negativos da cobertura, especializa-se a cláusula, adicionando literais e/ou comparações ao corpo com base em uma medida de ganho de informação. Esta medida leva em conta o número de exemplos positivos que serão cobertos pela inclusāo da nova cláusula, procurando assim maximizar a cobertura da cláusula a ser gerada.

Tendo gerado a cláusula, uma fase de pós-processamento é realizada pois, durante o processo de geração, há sempre a possibilidade de ficar literais irrelevantes no corpo da cláusula. Literais são retirados se a cláusula cobrir mais exemplos positivos sem eles e desde que continue sem cobrir exemplos negativos.

Versōes posteriores de FoIL, como mFOIL (Džeroski e Bratko, 1992), possuem capacidades de tratamento de ruídos nos exemplos, que podem ter informaçöes incompletas e/ou 
incorretas sobre o domínio sendo estudado. A partir da versão 6.0 , melhorias têm sido feitas no sentido de levar em consideração informação que está fora da visão de "mundo fechado" geralmente aplicada aos exemplos, e para tornar as cláusulas mais compreensíveis (Quinlan e Cameron-Jones, 1995).

O algoritmo básico de Foll é mostrado no Algoritmo 4.2:

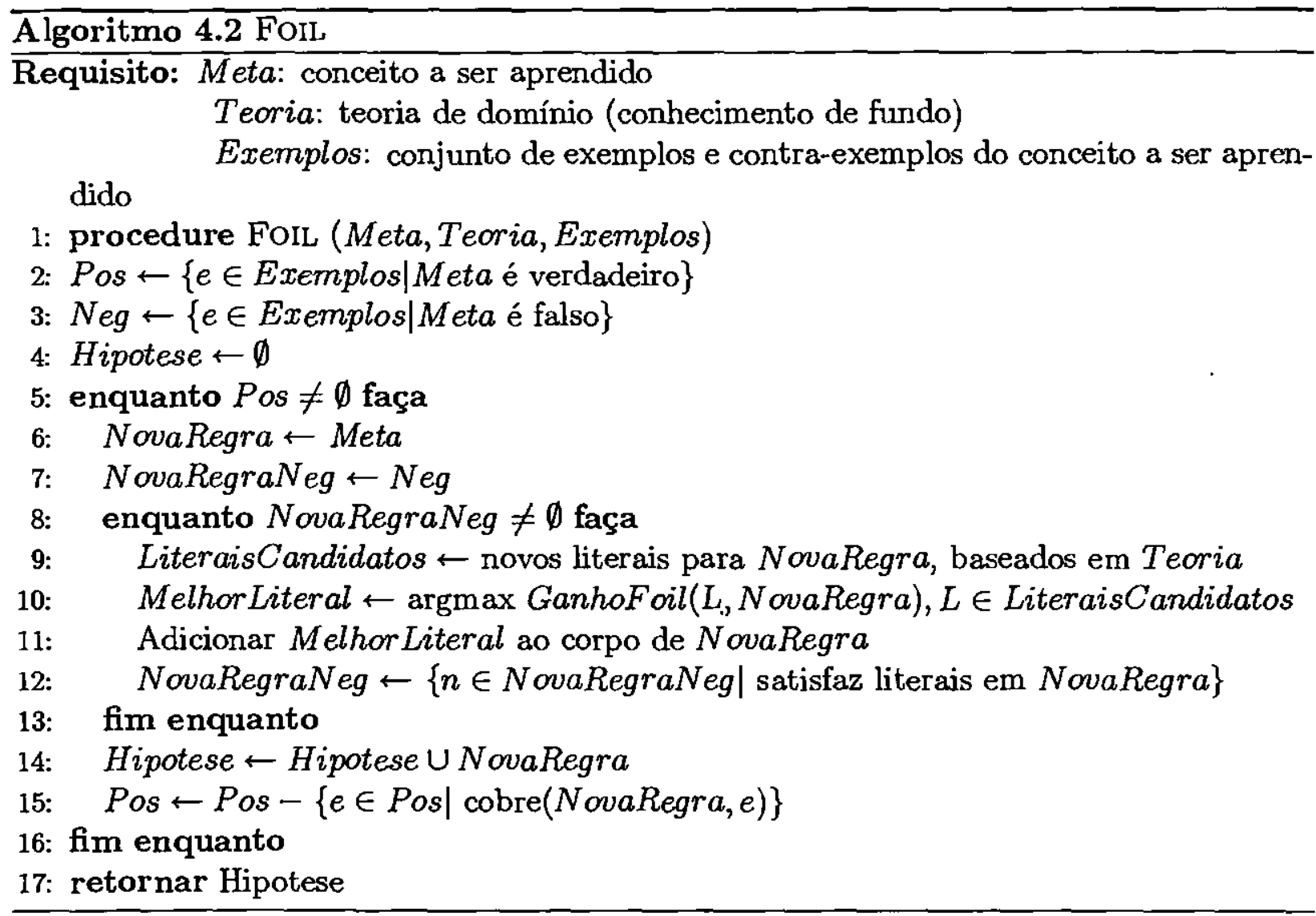

Foll tem sido aplicado e experimentado em conjuntos de dados de domínios diversos, das quais vale a pena citar: aprendizado de funções aritméticas; estratégias vencedoras em um jogo de xadrez, dadas as posições das peças no tabuleiro; e identificação de componentes em um documento (Quinlan e Cameron-Jones, 1995).

Esse sistema de PLI é utilizado neste trabalho. Maiores detalhes sobre sua execução podem ser encontrados no Apêndice A. 


\subsection{Progol}

Embora resolução inversa seja um método interessante para gerar hipóteses candidatas, na prática pode levar facilmente a uma explosão combinatória de candidatas. Uma forma alternativa de busca pode ser gerar uma hipótese única e mais específica que, junto com as informações (relaçōes) já conhecidas, implique os dados observados (exemplos). Esta hipótese mais específica pode ser usada então para limitar uma busca do geral ao específico através do grafo de refinamento de cláusulas semelhante àquela usada em Foll, mas com a restrição adicional que as hipóteses consideradas são hipóteses mais gerais que o limite estabelecido. Esse método é utilizado no sistema de PLI empírico PROGoL.

Progol aprende múltiplos predicados, de forma não-interativa (em 'batch') e empírica. Inicialmente procura uma hipótese menos geral para servir de limite inferior do reticulado de hipóteses. Faz uma busca do geral ao específico através de um grafo de refinamento das cláusulas, ou seja, de uma forma "top-down" (Muggleton, 1995). Pode ser obtido a partir do seguinte endereço na Internet

\section{http://www.cs.york.ac.uk/“ stephen/progol.htm!}

O algoritmo básico de Progol, mostrado no Algoritmo 4.3, pode ser descrito da seguinte forma:

- O usuário especifica uma linguagem restrita de expressões escritas em lógica de primeira ordem, chamadas de declaraçoes de modo, para servir de espaço de hipóteses $H$. Através destas restrições o usuário pode especificar os símbolos de predicado e função a serem consider ados, além dos tipos e formatos dos argumentos de cada um.

- Progol utiliza um algoritmo de cobertura sequencial para aprender um conjunto de expressóes de $H$ que cobrem os dados. Para cada exemplo $\left\{x_{i}, f\left(x_{i}\right)\right\}$ que ainda não é coberto por estas expressões aprendidas, primeiro procura-se a hipótese menos geral $h_{i}$ dentro de $H$ tal que (Modos $\left.\wedge h_{i} \wedge x_{i}\right) \vDash f\left(x_{i}\right)$. Para ser mais preciso, isto é aproximado calculando-se a hipótese menos geral dentre aquelas que implicam $f\left(x_{i}\right)$ a partir de $k$ aplicações da regra de resolução (onde $k$ é um parâmetro especificado pelo usuário).

- Em seguida uma busca do geral ao específico é empreendida no espaço de hipóteses limitado pela hipótese mais geral possível e pelo limite específico $h_{i}$ calculado no 


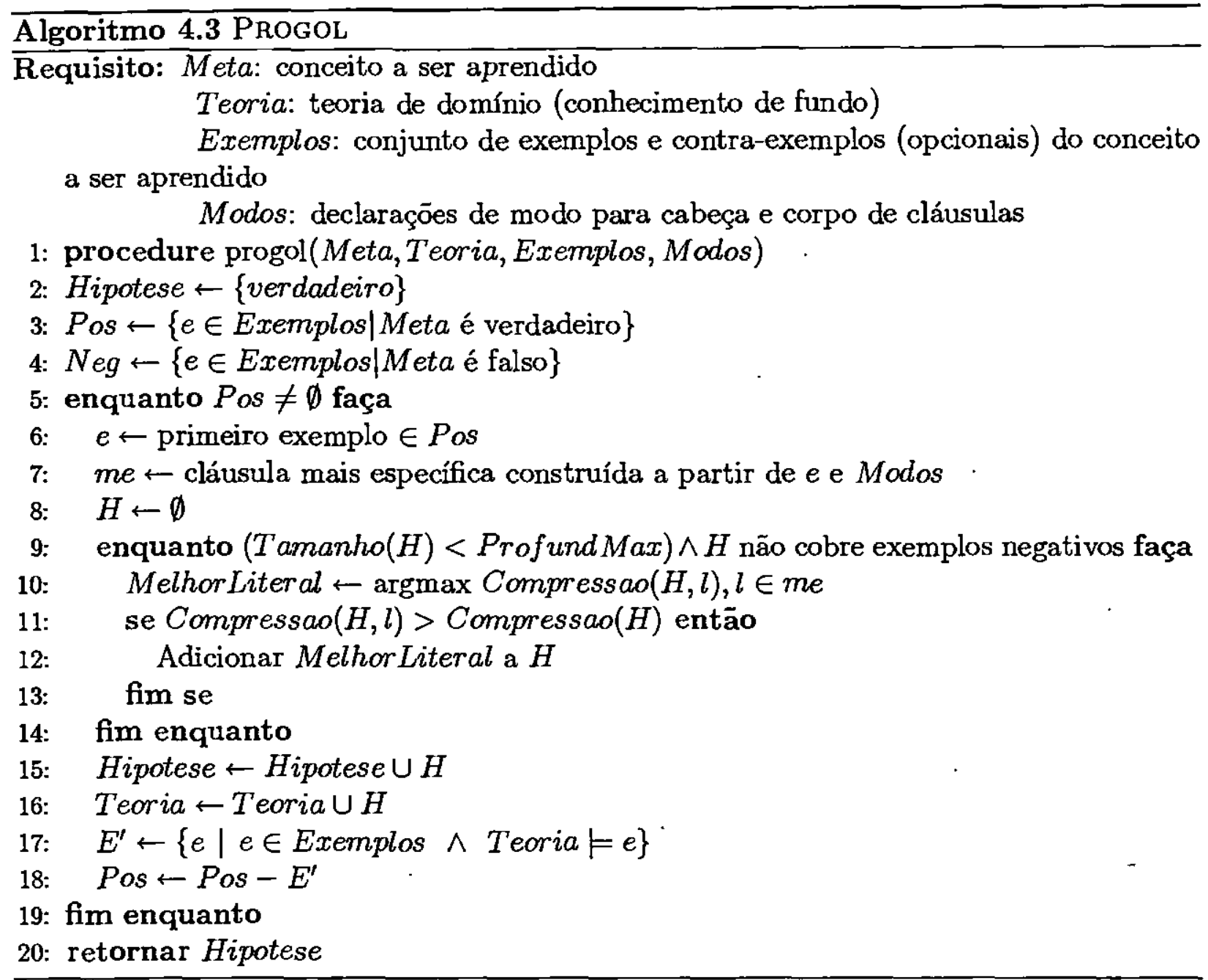

passo anterior. Neste conjunto de hipóteses, procura-se uma hipótese que tenha um comprimento mínimo de descrição (medido pelo número de literais). Esta parte da busca é guiada por uma heurística tipo $A^{*}$ que permite fazer poda sem correr o risco de eliminar a hipótese mais curta.

- A medida Compressao é calculada com relação ao número de exemplos positivos e negativos que sāo cobertos pela hipótese $H$. Além disso, leva-se em conta o número de literais necessários para ligar variáveis na cabeça através dos literais existentes em $m e$ (a cláusula mais específica construída a partir do exemplo $e$ sendo considerado e de Modos).

O sistema Progol tem sido aplicado a diversos domínios, dos quais alguns do mundo real que valem a pena citar: mutagenicidade de compostos químicos (Srinivasan et al., 1994); 
processamento de linguagem natural; posições ilegais num tabuleiro de xadrez (Muggleton, 1997) e outros.

Neste trabalho, um dos sistemas utilizados para extração de conhecimento é o Progol. Há uma explicação mais detalhada das opçōes do sistema no Apêndice B.

\subsection{MOBAL}

Ainda que sistemas de PLI consigam aprender conceitos mais poderosos que os sistemas proposicionais, isso não é suficiente para o processo de Aquisição de Conhecimento (Morik et al., 1993; Wrobel, 1994). A criação de uma base de conhecimento baseada em procedimentos de aprendizado de máquina constitui apenas uma parte do processo; é também necessário que o Engenheiro de Conhecimento possa adicionar e modificar regras por conta própria. Por isso, ao invés de concentrar-se somente no desenvolvimento de técnicas de aprendizado de máquina, deve ser dada também uma grande importância para a integração de técnicas de aquisição de conhecimento manual (editores de conhecimento, sistemas de elicitação de conhecimento, sistemas de manutenção de conhecimento) com métodos automatizados de aquisição de conhecimento. Em muitos casos, somente a integração dos resultados do aprendizado do usuário é que habilita o sistema a apoiar o processo geral de modelagem do domínio. O método de modelagem cooperativa e balanceada (Morik, 1993) permite dividir o trabalho de forma flexível entre sistema e usuário e é a base do sistema MOBAL.

MOBAL (Sommer et al., 1996) é um sistema para aquisição e inspeção de conhecimento que integra várias ferramentas com algoritmos de aprendizado, visando auxiliar o Engenheiro de Conhecimento a construir um modelo de um domínio de aplicação incrementalmente, inspecionando e refinando esse modelo. Para isso, utiliza-se de técnicas de aprendizado de máquina indutivo e relacional para procurar novas informaçöes sobre o conteúdo de uma base de conhecimento. Cada ferramenta auxilia num aspecto importante do processo de aquisição, e integra seus resultados com os das outras ferramentas, através de representações em lógica de primeira ordem, de modo a oferecer ao usuário uma visão geral e completa da base de conhecimento.

Através de uma interface gráfica amigável, o usuário pode interagir com o MOBAL, incluindo novos fatos e/ou regras, eliminando inconsistências e até mesmo modificando as 
representaçōes existentes na base para acomodar novos conhecimentos. O sistema é composto de sete ferramentas:

1. RDT, para descobrimento de regras. O espaço de hipóteses de RDT pode ser determinado não somente pelo seu formalismo de representação, mas também por restrições especificadas pelos usuários de acordo com a aplicação;

2. CLT, para descobrimento de conceitos;

3. KRT, para revisāo do conhecimento obtido e já existente;

4. STT, para organizar as classes de argumentos utilizados nos predicados em hierarquias;

5. MAT, para adquirir modelos de regras a partir de cláusulas (regras) já existentes na base de conhecimento;

6. PST, para facilitar a construção de um reticulado que mostre a precedência dos predicados contidos na base de conhecimento;

7. RRT, para reestruturar a hipótese obtida, procurando facilitar a compreensão dela, expandindo partes da hipótese ou condensando outras.

Além dessas sete ferramentas citadas possui ainda algumas ferramentas para mostrar informaçōes úteis para a compreensāo da base de conhecimento, como por exemplo o número de instâncias positivas e negativas cobertas por uma regra.

O resultado dos algoritmos de PLI mais comuns é uma descrição intensional do conceito aprendido utilizando a base de dados (exemplos) com que foram alimentados. Essa descrição em geral não distingue regras que são especializações e/ou generalizações umas das outras, de modo que há uma certa redundância entre elas. Além disso, certos conceitos podem ser expandidos para cobrir outros, após alguma manipulação lógica. Para melhorar a representação, podem ser utilizadas ferramentas como as que se encontram em MOBAL. A utilização de MOBAL é também facilitada pela sintaxe da linguagem de representação utilizada pelas diversas ferramentas, que é uma sintaxe simples de lógica de primeira ordem. Com isso, resultados obtidos a partir dos sistemas de PLI podem ser facilmente incorporados à base de MOBAL a fim de ser analisados e manuseados diretamente no sistema. Ao mesmo tempo, permite que o trabalho de procura por cláusulas iniciais (hipóteses), 
que cobrem os exemplos, seja realizado utilizando outros algoritmos de PLI mais eficientes. Embora MOB $\Lambda \mathrm{L}$ possua ferramentas próprias para realizar esta tarefa, elas consomem mais tempo e seu uso, nessa fase inicial de aquisição de conhecimento, é mais complexo que outros sistemas de PLI.

Algumas aplicações do mundo real de MOBAL que podem ser citadas são: regras para multas no trânsito, segurança em redes de telecomunicaçōes e falhas em motores de caminhões (Morik et al., 1993; Sommer et al., 1994; Morik e Brockhausen, 1997).

\subsection{Considerações Finais}

Foram vistos alguns sistemas de PLI, procurando mostrar o funcionamento de cada um e sua utilidade no sentido de aquisição de conhecimento em diversos domínios. Alguns utilizam técnicas de especializaçāo como método principal de busca, por exemplo FoIl. Este sistema consegue também tratar ruídos nos exemplos. Outros as utilizam em conjunto com métodos de generalização para tornar a busca no espaço de hipóteses mais compreensiva, como no caso de Progol. Existem também sistemas que procuram cláusulas construindoas a partir dos exemplos, aproveitando técnicas de generalização para isso, como é o caso de Golem. Por fim, há sistemas que podem, além de gerar cláusulas, também moldar estas cláusulas, eliminando redundâncias e reordenando literais, por exemplo, de modo a facilitar a compreensão do usuário. MOBAL, que pode ser considerado um desses sistemas, consegue então auxiliar tanto o usuário quanto outros sistemas através de suas ferramentas.

Cada sistema tem sido aplicado com sucesso nos mais diversos domínios, desde processamento de linguagem natural (Mooney, 1996) até a bioquímica (Muggleton, 1997), passando por aplicações aeroespaciais (Muggleton, 1991). Com isso, a utilidade prática deles fica comprovada, o que motiva o estudo de outras áreas em que possam ser aproveitados. Neste trabalho utilizou-se especificamente os sistemas de PLI, Foll e Progol. 


\section{Capítulo 5}

\section{Ferramentas para Conversão de Dados no Formato Atributo-Valor para o Formato Relacional}

\subsection{Considerações Iniciais}

O formato atributo-valor é o mais utilizado para os dados de entrada de um problema em AM proposicional. Objetos são descritos em termos de atributos e valores desses atributos, através de um vetor contendo valores para os atributos de um determinado exemplo. Um problema representado no formato atributo-valor também pode ser resolvido com AM relacional, desde que os dados representando os objetos no formato atributo-valor sejam transformados para o formato relacional. Neste capítulo, é descrita uma metodologia para essa transformação, inicialmente proposta por Katarina Morik e Peter Brockhausen (Morik e Brockhausen, 1997). A metodologia foi implementada através de ferramentas criadas para a conversão de dados de entrada dos algoritmos de AM proposicional $\mathcal{C N} 2$ (Clark e Boswell, 1991) e C 4.5 (Quinlan, 1993) para os algoritmos de AM relacional FoIL e Progol. Maiores detalhes sobre a implementação podem ser encontrados em (Caulkins e Monard, $2000 \mathrm{~b}$ ). 


\subsection{Formato Atributo-Valor}

Em aprendizado de máquina proposicional, um conjunto de exemplos de treinamento é apresentado ao sistema de indução. Cada exemplo, ou instância, é descrito por um vetor contendo valores de atributos e um rótulo que atribui uma classe ao exemplo. A Tabela 5.1 mostra o formato geral de um conjunto de dados com $n$ instâncias e $m$ atributos. Nessa tabela uma linha $i$ refere-se ao $i$-ésimo exemplo ou instância $(i=1,2, \ldots, n)$ e as entradas de coluna $x_{i, j}$ referem-se ao valor do $j$-ésimo atributo $X_{j}(j=1,2, \ldots, m)$ da instância $i$.

\begin{tabular}{|cccc|c|}
\hline$a_{1}$ & $a_{2}$ & $\cdots$ & $a_{m}$ & classe \\
\hline$x_{1,1}$ & $x_{1,2}$ & $\cdots$ & $x_{1, m}$ & $y_{1}$ \\
$x_{2,1}$ & $x_{2,2}$ & $\cdots$ & $x_{2, m}$ & $y_{2}$ \\
$\cdots$ & $\cdots$ & $\cdots$ & $\cdots$ & $\cdots$ \\
$x_{n, 1}$ & $x_{n, 2}$ & $\cdots$ & $x_{n, m}$ & $y_{n}$ \\
\hline
\end{tabular}

Tabela 5.1: Formato Atributo-Valor (ou Planilha) para Dados

Pode ser observado que instâncias são tuplas $\left(x_{i, 1}, x_{i, 2}, \ldots, x_{i, m}, y_{i}\right)=\left(\mathbf{x}_{i}, y_{i}\right)$ também denominadas ( $\mathrm{X}$, classe $(\mathrm{X}))$ ou $(\mathrm{X}, Y)$ onde o último atributo, $Y$, é o que se deseja predizer dados os outros atributos $\mathbf{X}$ i.e., $Y=f(\mathbf{X})$.

Esse formato é bastante utilizado por sistemas de aprendizado proposicional (Baranauskas e Monard, 2000b). A seguir é descrito um método para converter esse formato para uma representação mais próxima da utilizada por sistemas de Programação Lógica Indutiva.

\subsection{Método MB - Morik e Brockhausen}

Em princípio, todo problema que possa ser resolvido com um sistema de aprendizado proposicional pode ser resolvido também com um sistema de PLI (Cameron-Jones e Quinlan, 1993). Para isso, exemplos em formato atributo-valor podem ser considerados como fatos relacionados a um único predicado exemplo/n. Esse predicado se torna entāo o conceito procurado e faz parte da cabeça de cláusulas induzidas por um sistema de aprendizado de máquina relacional.

Por exemplo, considerando os exemplos da Tabela 5.2, semelhante à Tabela 5.1, para exemplos (classe + ) e contra-exemplos (classe - ) de um conceito, o predicado exemplo/n seria representado da seguinte forma: 


\begin{tabular}{|c|cccc|c|}
\hline$\# i d$ & $a_{1}$ & $a_{2}$ & $\cdots$ & $a_{m}$ & classe \\
\hline \hline 1 & $x_{1,1}$ & $x_{1,2}$ & $\cdots$ & $x_{1, m}$ & + \\
2 & $x_{2,1}$ & $x_{2,2}$ & $\cdots$ & $x_{2, m}$ & - \\
$\vdots$ & $\cdots$ & $\cdots$ & $\cdots$ & $\cdots$ & $\cdots$ \\
$i$ & $x_{i, 1}$ & $x_{i, 2}$ & $\cdots$ & $x_{i, m}$ & + \\
$\vdots$ & $\cdots$ & $\cdots$ & $\cdots$ & $\cdots$ & $\cdots$ \\
$n$ & $x_{n, 1}$ & $x_{n, 2}$ & $\cdots$ & $x_{n, m}$ & - \\
\hline
\end{tabular}

Tabela 5.2: Formato Atributo-Valor para Exemplos e Contra-exemplos de um Conceito

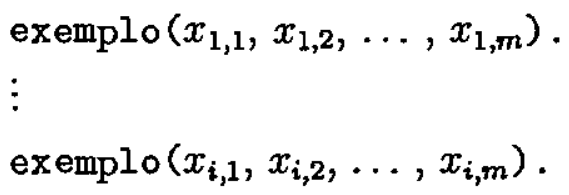

Cláusulas obtidas utilizando esse predicado como cabeça provavelmente conterão variáveis universalmente quantificadas, pois alguns atributos podem assumir qualquer valor sem afetar a hipótese sendo induzida para o conceito procurado. Ou seja, o valor desses atributos pode não influir na descrição do conceito. Quando essas variáveis não estão restringidas pelo corpo da cláusula, esta se torna muito geral. Mapeando cada atributo da relação a um predicado separado, aumenta-se o número de predicados e, ao mesmo tempo, evita-se a inclusão de variáveis universalmente quantificadas e irrestritas (Morik e Brockhausen, 1997). Ou seja, o conhecimento de fundo é enriquecido ao mesmo tempo em que se elimina uma parte do espaço de hipóteses a ser pesquisado. Com isso, obtém-se uma representaçāo direta de um exemplo em formato atributo-valor, através de uma representação relacional para os valores dos atributos de um exemplo, e ainda de uma forma que pode evitar variáveis universalmente quantificadas.

$\mathrm{Na}$ sua forma mais simples, e utilizando o nome dos atributos como os nomes das relações respectivas, os exemplos na Tabela 5.2 poderiam ser representados da seguinte forma:

$$
\begin{aligned}
& \operatorname{ex}(1) \cdot a 1\left(1, x_{1,1}\right) \cdot a 2\left(1, x_{1,2}\right) \ldots . a m\left(1, x_{1, m}\right) . \\
& \operatorname{ex}(2) \cdot a 1\left(2, x_{2,1}\right) \cdot a 2\left(2, x_{2,2}\right) . \ldots a m\left(2, x_{2, m}\right) .
\end{aligned}
$$


$\operatorname{ex}(i)$. a1 $\left(i, x_{i, 1}\right)$. a2 $\left(i, x_{i, 2}\right) . \ldots$ am $\left(i, x_{i, m}\right)$.

$\operatorname{ex}(n) . \mathrm{a} 1\left(n, x_{n, 1}\right) . \mathrm{a} 2\left(n, x_{n, 2}\right) . \ldots$ am $\left(n, x_{n, m}\right)$.

onde $\operatorname{ex}(1) \ldots$, ex $(i)$. são exemplos positivos e ex (2) . . , ex $(n)$. são exemplos negativos. O conhecimento representado através dos predicados a1 $/ 2, a 2 / 2, \ldots$, am $/ 2$, torna-se simplesmente o conhecimento de fundo.

Tendo em vista essas duas representações, uma baseada no formato proposicional (atributovalor) e outra relacional, é possível imaginar um processo de conversão de dados para as duas formas. Nas seções seguintes deste capítulo, considera-se esse processo especificamente voltado para dois sistemas de aprendizado proposicional e dois sistemas de Programação Lógica Indutiva, Foll e Progol. Os dois sistemas de aprendizado proposicional considerados, $\mathcal{C N} 2$ e $\mathcal{C} 4.5$, induzem regras de decisão e árvores de decisão, respectivamente. Maiores detalhes sobre esses dois sistemas podem ser encontrados em (Baranauskas e Monard, 2000a).

\subsection{Ferramentas para o Processo de Conversão}

A Figura 5.1 ilustra o processo, por nós implementado, de conversão dos dados utilizados pelos sistemas de aprendizado $\mathcal{C N} 2, \mathcal{C} 4.5$, FOIL e Progol.

Inicialmente os dados encontram-se em três arquivos na sintaxe requerida por $\mathcal{C N} 2$. A ferramenta denominada cn2_to_c45 é responsável pela transformação desses dados para a sintaxe de $\mathcal{C} 4.5$, colocando-os em outros três arquivos. Em seguida, a ferramenta c45_to_foil transforma esses dados para a sintaxe que Forl admite, gerando um único arquivo de dados. O conteúdo desse arquivo pode ser transformado para a sintaxe utilizada por PROGOL, através da ferramenta foil2progol. Pode ainda ser transformado para uma sintaxe de entrada voltada para aprendizado relacional através do "método MB". A ferramenta foil2progolmb é responsável pela transformação para a sintaxe de Progol, enquanto foil2foilmb realiza a transformação para a sintaxe de Forl. A seguir serão descritas cada uma dessas transformaçōes.

A fim de exemplificar melhor o processo de conversāo e as ferramentas implementadas, será utilizado um sub-conjunto de um conjunto de dados originalmente proposto por Quinlan 


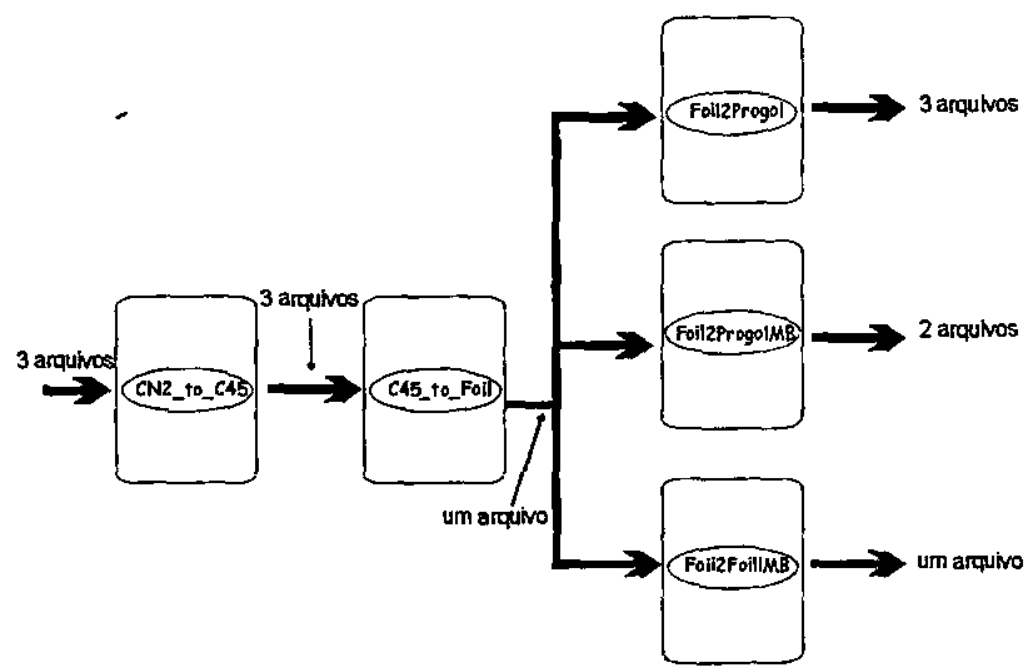

Figura 5.1: Uma Visão Geral do Processo de Conversão

(Quinlan, 1993), contendo medidas de condições climáticas para um período de 15 dias.

Cada instância (Tabela 5.3) é composta dos seguintes atributos:

- outlook: assume um dos valores discretos "sunny", "overcast" ou "rain", para os casos da previsão do tempo ser ensolarado, nublado ou chuvoso, respectivamente;

- temperature: um valor numérico indicando a temperatura em graus Celsius;

- humidity: um valor numérico que indica a porcentagem de umidade no ar;

- windy: assume um dos valores discretos "yes" ou "no", indicando se está ventando ou não no dia em questão.

Cada dia (ou instância) é rotulado como "go" se o tempo estiver bom para se fazer uma viagem à fazenda, ou "dont_go", se o tempo não estiver bom - coluna "Travel?" na Tabela 5.3.

\subsubsection{De $\mathcal{C N} 2$ para $\mathcal{C} 4.5$}

O processo de conversāo começa pela transformação dos arquivos utilizados por $\mathcal{C N} 2$ para os arquivos na sintaxe utilizada por $\mathcal{C} 4.5$. O utilitário que realiza esse passo inicial é chamado cn2_to_c45 (Figura 5.2). 
Capítulo 5 - Ferramentas para Conversão de Dados no Formato Atributo-Valor para o Formato Relacional

\begin{tabular}{lrrrrr}
\hline No. da Inst. & outlook & Temperature & Humidity & Windy & Travel? \\
\hline$T_{1}$ & sunny & 25 & 72 & yes & go \\
$T_{2}$ & sunny & 28 & 91 & yes & dont_go \\
$T_{3}$ & sunny & 22 & 70 & no & go \\
$T_{4}$ & sunny & 23 & 95 & no & dont_go \\
$T_{5}$ & sunny & 30 & 85 & no & dont_go \\
$T_{6}$ & overcast & 23 & 90 & yes & go \\
$T_{7}$ & overcast & 29 & 78 & no & go \\
$T_{8}$ & overcast & 19 & 65 & yes & dont_go \\
$T_{9}$ & overcast & 26 & 75 & no & go \\
$T_{10}$ & overcast & 20 & 87 & yes & go \\
$T_{11}$ & rain & 22 & 95 & no & go \\
$T_{12}$ & rain & 19 & 70 & yes & dont_go \\
$T_{13}$ & rain & 23 & 80 & yes & dont_go \\
$T_{14}$ & rain & 25 & 81 & no & go \\
$T_{15}$ & rain & 21 & 80 & no & go \\
\hline
\end{tabular}

Tabela 5.3: Condições Climáticas para uma Viagem

A entrada para cṇ2_to_c45 consiste dos três arquivos padrão utilizados por $\mathcal{C N} 2$, cujo conteúdo é descrito a seguir.

1. voyage.att (Figura 5.3) contendo os nomes das classes positiva (go) e negativa (dont_go) e dos atributos que compõem os exemplos, enumerando seus possíveis valores quando os atributos são discretos. Sua primeira linha deve ser ** ATTRIBUTE FILE **;

2. voyage exs (Figura 5.4) contendo os exemplos de treinamento utilizados por $\mathcal{C N} 2$ para induzir a hipótese. Sua primeira linha deve ser ** EXAMPLE FILE **;

3. voyage.tst (Figura 5.5) contendo os exemplos de teste para avaliar a precisão da hipótese induzida. Sua primeira linha também deve ser ** EXAMPLE FILE **.

É importante lembrar que o símbolo de comentário em $\mathcal{C N} 2$ é o símbolo \%. Assim, no arquivo exemplo voyage.att há duas linhas de comentário que indicam a posição das informações sobre atributos e sobre as classes.

Após a execução de cn2_to_c45, cada um desses arquivos é transformado, respectivamente, para os três arquivos padrão de entrada utilizados por $\mathcal{C} 4.5$ :

1. voyage .names (Figura 5.6) contendo as descriçōes dos tipos de dados dos atributos e das classes positiva (go) e negativa (dont_go); 


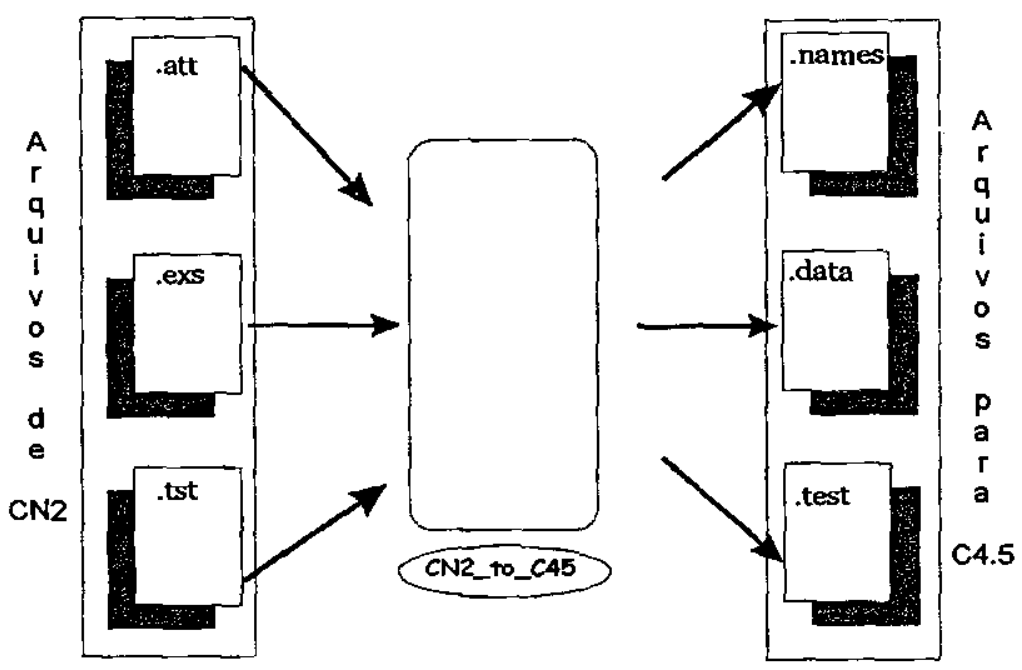

Figura 5.2: De $\mathcal{C N} 2$ para $C 4.5$

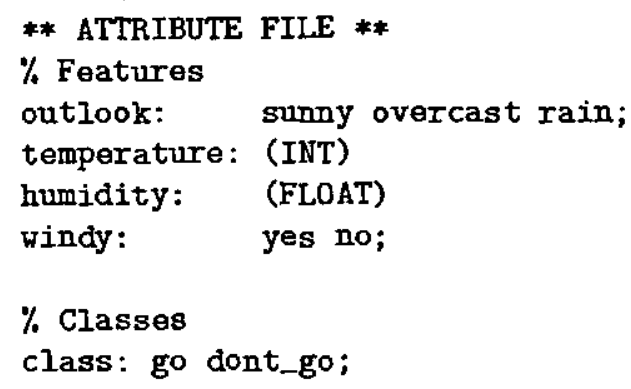

Figura 5.3: Arquivo $\mathcal{C N} 2$ voyage. att

2. voyage data (Figura 5.7) contendo os exemplos de treinamento;

3. voyage.test (Figura 5.8) contendo os exemplos de teste.

Deve ser observado que os tipos de dados numéricos em $\mathcal{C N} 2$, (INT) e (FLOAT), são representados por um único tipo de dados, continuous, no arquivo de descrição de atributos do C4.5. O símbolo de comentário, representado pelo símbolo \% na sintaxe do $\mathcal{C N} 2$, é equivalente ao símbolo I no $\mathcal{C} 4.5$. Tudo o que estiver escrito a partir desse símbolo até o final de uma linha é removido no processo de conversão realizado pela ferramenta cn2_to_c45. 
Capítulo 5 - Ferramentas para Conversão de Dados no Formato Atributo-Valor para o Formato Relacional

\begin{tabular}{|c|c|c|}
\hline * EXAMP & LE FILE ** & \\
\hline sumny & 2572 yes & go \\
\hline sunny & 2395 no & dont_go \\
\hline sunny & 3085 no & dont_go \\
\hline overcast & 2390 yes & go \\
\hline overcast & 2978 no & go \\
\hline overcast & 2675 no & go \\
\hline rain & 2295 no & go \\
\hline rain & 70 yes & dont_go \\
\hline rain & 80 yes & dont_go \\
\hline rain & $2180 \mathrm{no}$ & go \\
\hline
\end{tabular}

Figura 5.4: Arquivo $\mathcal{C N 2}$ voyage. exs

** EXAMPLE FILE **

sunny 2891 yes dont_go

sunny 2270 no go

overcast 1965 yes go

overcast 2087 yes dont_go

rain 2581 no go

Figura 5.5: Arquivo $\mathcal{C N} 2$ voyage.tst

\subsubsection{De $\mathcal{C} 4.5$ para FoIL "Proposicional"}

O processo de conversão dos dados na sintaxe de $\mathcal{C} 4.5$ para a de Foll, com os dados em um formato por nós denominado "proposicional", é realizado pelo utilitário c45_to_foil (Figura 5.9).

Esse utilitário foi implementado por Quinlan e Cameron-Jones (autores de Foll) e acompanha a distribuição da versão 6.4 de Foll. Antes de efetuar a conversão dos três arquivos na sintaxe de $\mathcal{C} 4.5$, algumas informações, descritas a seguir, devem ser acrescentadas manualmente ao arquivo voyage. names. Cada linha contendo informação sobre um atributo deve indicar o nome do tipo de dado utilizado pelo atributo. Isto deve ser acrescentado

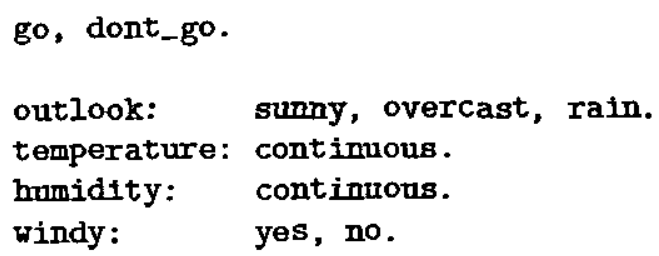

Figura 5.6: Arquivo $\mathcal{C} 4.5$ voyage. names 


sunny, 25,72, yes, go
sunny, 23,95, no, dont_go
sunny, 30,85, no, dont_go
overcast, 23,90, yes, go
overcast, 29,78, no, go
overcast, 26,75, no, go
rain, 22,95, no, go
rain, 19,70, yes, dont_go
rain, 23,80, yes, dont_go
rain, 21,80, no, go

Figura 5.7: Arquivo $\mathcal{C} 4.5$ voyage data

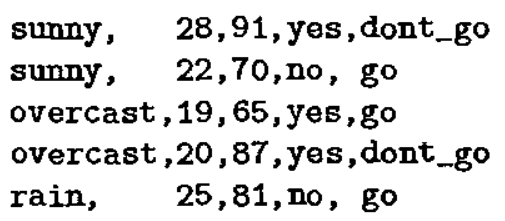

Figura 5.8: Arquivo $\mathcal{C} 4.5$ voyage. test

pelo usuário, como se fosse um comentário em $\mathcal{C} 4.5$, da seguinte forma:

$$
\text { (informação do atributo em } \mathcal{C} 4.5 \text { ) | type: nome_tipo }
$$

onde nome_tipo é o nome do tipo desse atributo. Um nome distinto deve ser dado a cada tipo de dados distinto, pois será prefixado a cada valor possível do tipo pelo utilitário implementado por Quinlan e Cameron-Jones. Esse nome pode ser o próprio nome do atributo que irá fazer uso do tipo, ou pode ser uma abreviação. Para o conjunto de dados voyage utilizado como exemplo, o arquivo .names acrescido dessas informaçōes é mostrado na Figura 5.10. Deve ser destacado que os atributos temperature e humidity foram "ligados" pelo tipo real, já que ambos atributos possuem o mesmo tipo de dados. Dois nomes diferentes, o e w, foram utilizados para os atributos outlook e windy, pois eles assumem valores diferentes. No caso de assumirem os mesmos valores, é conveniente que esses nomes sejam idênticos, já que fornecem uma informação importante aos sistemas de PLI..

Com estas modificações, os três arquivos na sintaxe de $\mathcal{C} 4.5$ podem ser fornecidos como entrada ao c45_to_foil. A saída de c45_to_foil é um arquivo cujo nome é o próprio nome do conjunto de dados concatenado com a extensão .d, i.e. para o exemplo de viagem o nome é voyage.d (Figura 5.11). 


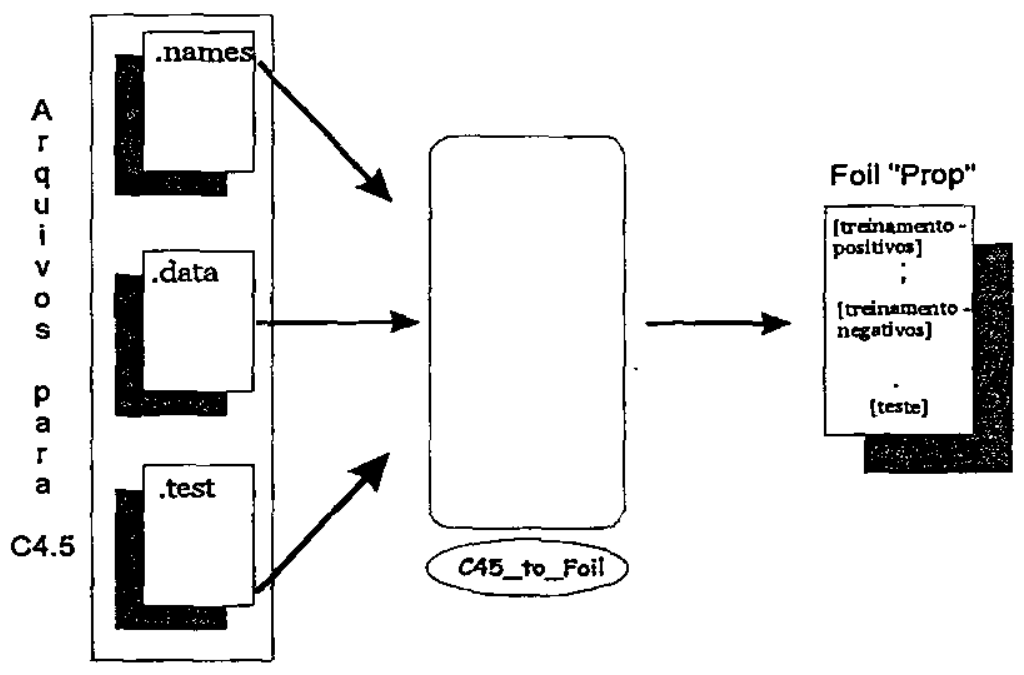

Figura 5.9: De $\mathcal{C} 4.5$ para Foll "Proposicional"

go, dont_go.

outlook: sunny, overcast, rain. I type: o

temperature: continuous. I type: real

humidity: continuous. I type: real

windy:

yes, no. I type: w

Figura 5.10: Arquivo $\mathcal{C} 4.5$ voyage . names Modificado para Uso com c45_to_foil

No início desse arquivo encontram-se descritos os tipos de dados que compõem os atributos dos exemplos. Para tipos de dados com valores discretos, o símbolo \# precede o nome do tipo. Cada valor possível do tipo é então listado, sendo prefixado pelo símbolo *. O tipo pré-definido continuous indica um tipo de dados numérico, podendo assumir qualquer valor do conjunto dos números reais, assim como na sintaxe de $\mathcal{C} 4.5$.

O predicado meta - is_go(o, real, real, w) na Figura 5.11 - que irá representar o conceito a ser aprendido é descrito em seguida. O nome do predicado é composto pelo nome do conceito procurado (no exemplo considerado, go) acrescentado de is_. Assim, no exemplo o nome do predicado meta é is_go. Nesse predicado encontra-se também descrito o tipo de dado de cada um dos seus argumentos.

Depois da descrição dos tipos de dados e do predicado meta, encontram-se os exemplos positivos do conceito. Esses exemplos positivos são separados dos exemplos negativos (contra-exemplos) pelo símbolo ";" numa única linha. O símbolo "." sozinho numa única 


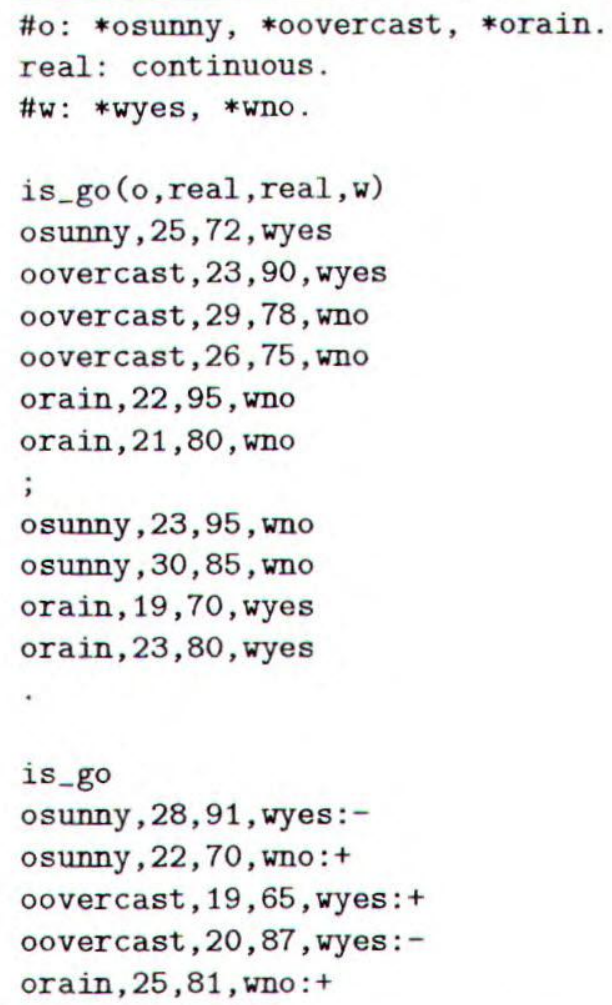

Figura 5.11: Arquivo FoIL "Proposicional" voyage.d

linha indica o final dos exemplos de treinamento a serem utilizados para induzir o conceito. Em seguida, encontram-se os exemplos de teste. Cada um desses exemplos de teste termina com a sequência ":+" ou ":-", indicando se o exemplo é positivo ou negativo, respectivamente.

Finalmente, o arquivo voyage.d gerado pelo c45_to_foil é o arquivo de entrada para as outras três ferramentas por nós implementados, i.e. foil2progol, foil2progolmb e foil2foilmb (Figura 5.1, página 45), descritas nas seções subsequentes.

\subsubsection{De FoIL "Proposicional" para PrOGOL "Proposicional"}

A ferramenta foil2progol (Figura 5.12) gera três arquivos de entrada para ProgoL, todos eles com extensão .pl, com os dados no formato por nós denominado "proposicional".

A fim de identificar cada um desses arquivos, foil2progol usa o nome do arquivo de dados (voyage no exemplo considerado) e concatena o nome, respectivamente, com _training, 


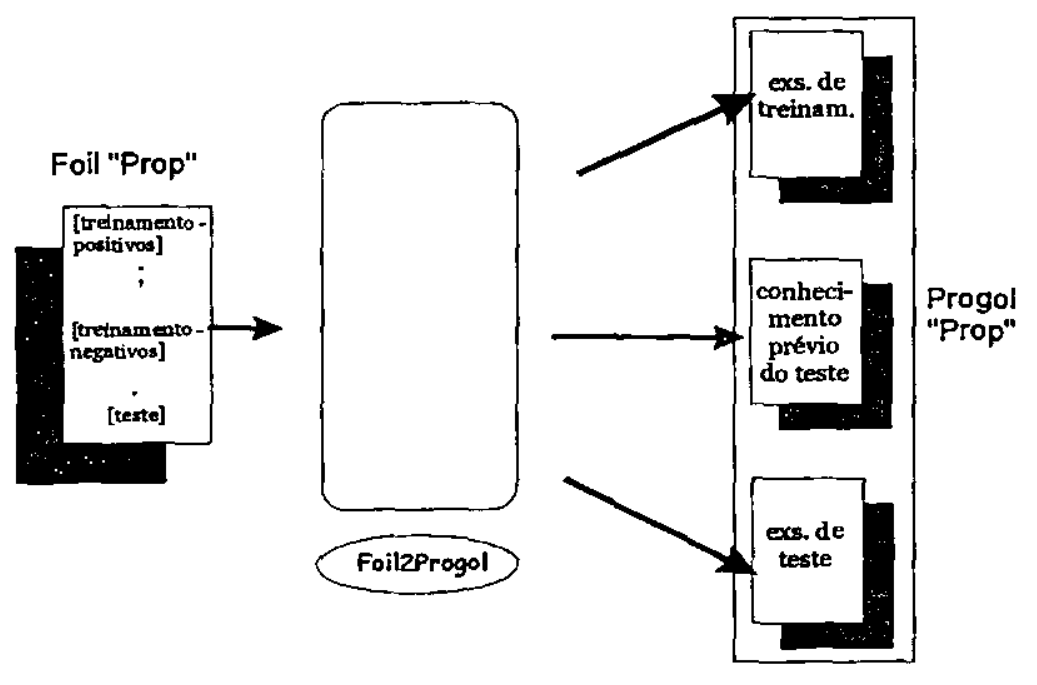

Figura 5.12: De Foll "Proposicional" para Progol "Proposicional"

_test e _extra_bg_test. Assim, os três arquivos gerados por foil2progol são:

1. voyage_training.pl (Figura 5.13);

2. voyage_test.pl (Figura 5.14);

3. voyage_extra_bg-test.pl (Figura 5.15).

$\mathrm{O}$ arquivo gerado voyage_training.pl (Figura 5.13) contém parâmetros configuráveis ${ }^{1}$, entre outras coisas. No Progol, esses parâmetros são setados através do predicado prédefinido set/2. foil2progol configura o parâmetro noise na primeira linha do arquivo utilizando esse predicado, de modo que cláusulas possam ser encontradas que cubram até $20 \%$ de exemplos negativos. Isso é necessário para manter a paridade com o Foll, que é ajustado por default para procurar cláusulas com no máximo $20 \%$ de erro.

\footnotetext{
${ }^{1}$ Deve ser observado que tanto os parâmetros configuráveis quanto outras informaçōes que devem ser explicitamente definidas para Progol, através de declaraçōes específicas, encontram-se implicitamente definidas em FoIL.
} 
Capítulo 5 - Ferramentas para Conversão de Dados no Formato Atributo-Valor para o Formato Relacional

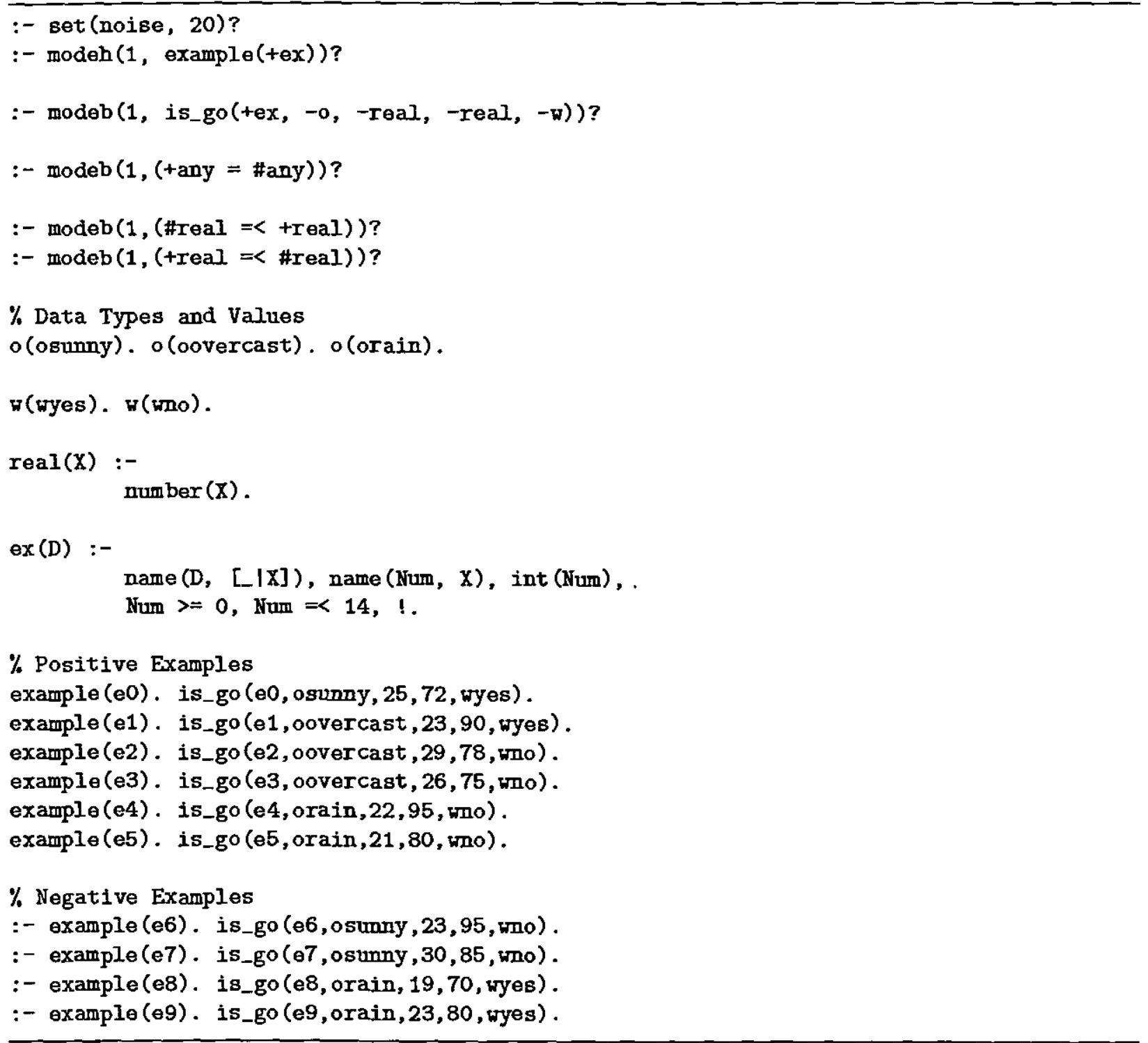

Figura 5.13: Arquivo Progol "Proposicional" voyage_training.pI 
Depois de configurar esse parâmetro, declaraçōes de modo dos predicados utilizados são escritas. Essas declarações indicam quais predicados farão parte da cabeça das cláusulas induzidas e quais farão parte do corpo. Para isso, se utiliza um predicado pré-definido modeh/2 no caso da cabeça e outro, modeb/2, para o corpo. Ambos predicados possuem os mesmos argumentos. O primeiro argumento indica o "recall", que limita o número de instanciações alternativas que podem ser consideradas para o predicado declarado no segundo argumento. $O$ "recall" 2 pode variar de 1 até infinito, sendo este último indicado por “*”. Na prática, “*” implica no máximo 100 instanciações. O segundo argumento é uma declaração de predicado que mostra o nome do predicado e os tipos de cada um de seus argumentos. Os argumentos de entrada são precedidos pelo símbolo "t" e os de saída pelo símbolo "-". Quando o argumento em questão deve assumir um valor constante, a declaração do tipo do argumento deve ser precedido pelo símbolo "\#”. Maiores informações podem ser encontradas em (Roberts, 1997) e (Muggleton e Firth, 1999).

A declaração da cabeça das cláusulas,:- $\operatorname{modeh}(1$, example(+ex))?, é a primeira feita no arquivo. Essa declaração indica que a cabeça será formada por um predicado example/1 com um argumento de entrada do tipo ex e "recall" igual a 1. O argumento desse predicado é um identificador utilizado para marcar os exemplos de forma única. Isso se tornou necessário pois Progol, ao contrário de Foll, não consegue induzir o conceito se ele estiver definido por um predicado que contém somente os atributos de cada exemplo. Em outras palavras, Progol necessita de conhecimento na forma de conhecimento de fundo para induzir o conceito. A fim de contornar este problema, foil2progol cria o predicado example/1, e declara-o como a cabeça das cláusulas a serem procuradas (i.e. o conceito a ser induzido) através de uma declaração de modo modeh/2. O conhecimento de fundo é definido de forma similar ao predicado meta do arquivo Forl contendo as instâncias dos valores dos atributos de cada exemplo, além de um argumento adicional (primeiro argumento) que identifica o exemplo, como mostra a primeira declaração modeb/2 na Figura 5.13 .

Depois de inserir essas declarações, definem-se algumas relaçōes já conhecidas porém de modo especial para melhorar o processo de indução. A primeira é a declaração da relação $=$ /2. Através da declaração :- $\operatorname{modeb}(1,(\operatorname{tany}=\#$ any $))$, argumentos de qualquer tipo declarados como variáveis, podem ser substituídas por valores constantes, caso sejam encontrados durante a indução. Para o caso de haver tipos de dados numéricos, outras duas declarações de modo modeb/2 são inclúdas. Ambas as declarações tratam da relação $=</ 2$

\footnotetext{
${ }^{2}$ Observar que o parâmetro "recall" não é o mesmo recall utilizado para definir precisão
} 
de modo a lidar com intervalos numéricos com limites superiores e inferiores. Para declarar o limite inferior $O$ argumento da esquerda na relação $a<$ deve ser uma constante, e $O$ da direita uma variável. No caso do limite superior, o argumento da direita é uma constante e o da esquerda uma variável.

Em seguida a essas declarações de modo, os tipos de dados utilizados são descritos. Os tipos de dados discretos são mostrados como fatos de um predicado cujo nome é o próprio tipo. No exemplo considerado (Figura 5.13), os tipos de dados discretos o e w são descritos, respectivamente, como \{o(osunny). o(oovercast). o(orain).\} e \{w(wyes). w(wno). \}. Quando há valores numéricos, inclui-se uma descrição intensional do predicado real/1 como sendo equivalente ao predicado pré-definido do PROGOL, number/1. O tipo de dado que expressa o argumento do identificador do exemplo, ex, é declarado através do predicado ex/1 como sendo composto por uma sequência de letras (no caso, a letra e) e terminando com um número no intervalo de 0 até $n-1$, onde $n$ é o número total de exemplos de treinamento e teste.

Depois das declarações de tipos de dados, os exemplos de treinamento são escritos, com seus identificadores e os valores dos atributos do respectivo exemplo. Exemplos negativos são indicados pelos símbolos ": - ", precedendo o identificador. Por exemplo, o primeiro exemplo positivo de treinamento no arquivo de Foll (Figura 5.11, página 51), escrito como is_go (osunny, 25,72 , wyes), é transformado em uma declaração com dois fatos: \{example $(e 0)$. is_go (e0, osunny, 25,72 , wyes) . $\}$, e assim sucessivamente. Da mesma forma, o primeiro exemplo negativo de treinamento no arquivo de FolL, escrito como $\{$ is_go $(e 6$, osunny $, 23,95$, wno $)\}$ pode ser transformado para uma declaração com os dois fatos $\{:-$ example $(e 6)$. is_go $(e 6$, osunny $, 23,95$, wno $)$.$\} , e analogamente para os ou-$ tros exemplos negativos.

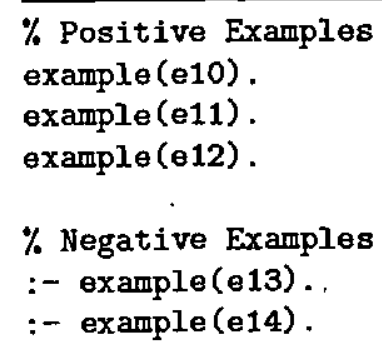

Figura 5.14: Arquivo PrOGOL "Proposicional" voyage_test.pl

O segundo arquivo, voyage_test.pI (Figura 5.14), contém os exemplos de teste, declarados 
Capítulo 5 - Ferramentas para Conversāo de Dados no Formato Atributo-Valor para o Formato Relacional

através do predicado example/1 e indicados como positivos ou negativos da mesma forma que no primeiro arquivo. Os valores dos atributos correspondentes a esses exemplos são colocados como conhecimento de fundo no terceiro arquivo gerado, voyage_extra_bg_test.pl (Figura 5.15).

\% Background for Positive Test Examples is_go (e10, osunny, 22,70 , wno).

is_go (e11, oovercast, 19,65 , wyes).

is_go (e12, orain, 25,81 , wno).

\% Background for Negative Test Examples

is_go (e13, osunny, 28,91, wyes).

is_go (e14, oovercast, 20,87 , wyes).

Figura 5.15: Arquivo Progol "Proposicional" voyage_extra_bg_test.pl

\subsubsection{De Foll "Proposicional" para Progol MB}

A ferramenta foil2progolmb (Figura 5.16) gera dois arquivos de entrada para Progol, através do método $\mathrm{MB}$, ambos com extensão .pl.

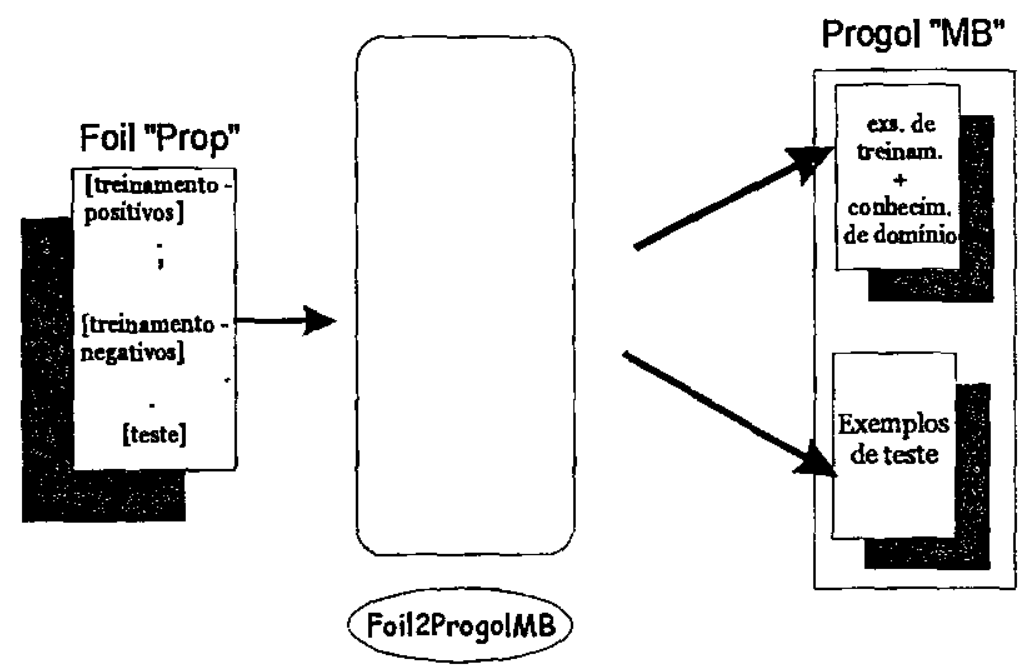

Figura 5.16: De Foll "Proposicional" para Progol MB

Esses arquivos são criados a partir do arquivo de Foll em formato "proposicional" gerado pela ferramenta c45_to_foil. Assim como na Subseção 5.4.3, a fim de identificar cada um 
desses dois arquivos, foil2progolmb usa o nome do arquivo de dados (voyage no exemplo considerado) e concatena, respectivamente, training_mb e test_mb a ele para formar o nome dos arquivos. A terminação _mb distingue esses arquivos daqueles criados pela ferramenta foil2progol, indicando que foram criados com base na proposta de Morik e Brockhausen explicada na Seção 5.3. Os dois arquivos gerados são:

1. voyage_training_mb.pI (Figura 5.17); e

2. voyage_test_mb.pI (Figura 5.18).

$\mathrm{O}$ arquivo gerado voyage_training mb.pI (Figura 5.17) contém os mesmos parâmetros configuráveis e declarações de modo que foram inseridos no arquivo voyage_training.pI com a ferramenta foil2progol, visto na Seção 5.4.3. A cabeça das cláusulas a serem buscadas é declarada através do predicado pré-definido modeh $/ 2$ e os predicados que podem formar o corpo das cláusulas são declaradas através do predicado pré-definido modeb/2. No entanto, onde foil2progol declara apenas um predicado como conhecimento de fundo, foil2progolmb declara vários.

Para isso, o predicado meta descrito no arquivo "proposicional" na sintaxe do Foll é decomposto em $n$ predicados binários, um para cada atributo que compõe o exemplo. Esses predicados são numerados de a0 até an - 1 e declarações de modo de corpo são inseridas para cada um desses novos predicados através do predicado pré-definido modeb/2. Os argumentos desses predicados são um identificador de exemplo, criado para cada exemplo, e o valor do atributo representado pelo predicado para o exemplo identificado.

Depois de inserir essas declarações, os tipos de dados utilizados também são declarados como da mesma forma que na ferramenta foil2progol. Os tipos de dados discretos são mostrados como fatos de um predicado cujo nome é o próprio tipo. No exemplo considerado (Figura 5.17), os tipos de dados discretos o e w são descritos, respectivamente, como $\{0$ (osunny). o(oovercast). o(orain). $\}$ e $\{w$ (wyes). w(wno). $\}$. Quando há valores numéricos, a ferramenta foil2progolmb inclui uma descrição intensional do predicado real/1 como sendo equivalente ao predicado pré-definido do PrOgOL, number/1. O tipo de dado que expressa o argumento do identificador do exemplo, ex, é declarado através do predicado ex/1 como sendo composto por uma sequência de letras (no caso, a letra 'e') e um número no intervalo de 0 até $n-1$, onde $n$ é o número total de exemplos de treinamento e teste. 


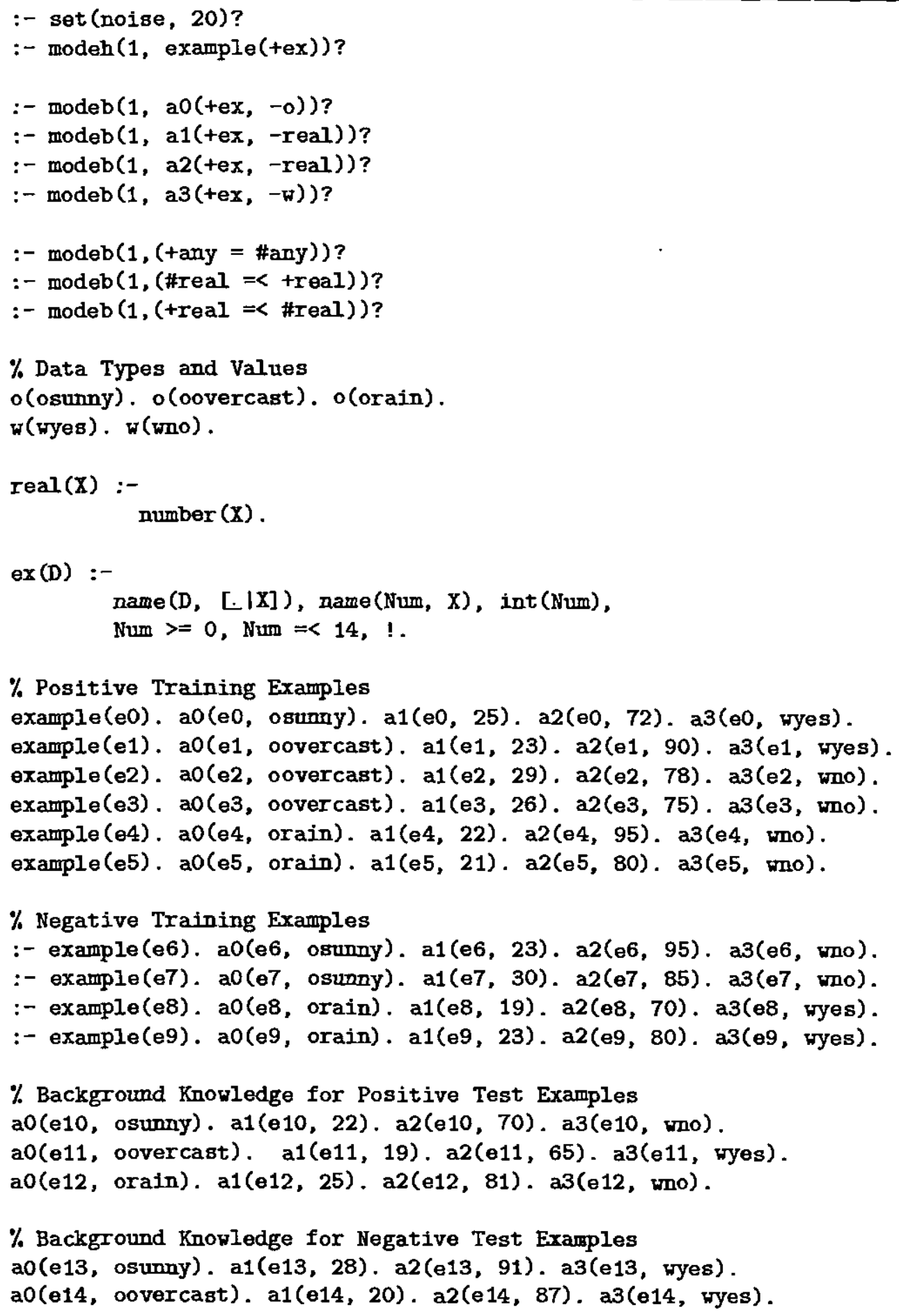

Figura 5.17: Arquivo Progol MB voyage_training_mb.pl 
\% Positive Test Examples

example (e10).

example (e11).

example (e12).

\% Negative Test Examples

:- example(e13).

:- example (e14).

Figura 5.18: Arquivo Progol MB voyage_test_mb.pl

Os exemplos de treinamento sāo então escritos no arquivo voyage_training_mb.pl. Para cada exemplo escreve-se um fato para o identificador do exemplo. Em seguida, utilizando os predicados de atributo definidos na parte de declaraçāo de modos, indica-se o valor para cada atributo. Cada exemplo positivo e negativo é descrito dessa forma. Os exemplos negativos são indicados por ' : -' antes dos fatos que descrevem seus identificadores. Por exemplo, o primeiro exemplo positivo de treinamento contido no arquivo de Foll "proposicional" (Figura 5.11, página 51), e equivalente a is_go (osunny, 25,72, wyes), seria transformado para $\{$ example $(e 0), a 0(e 0, o s u n n y), a 1(e 0,25), a 2(e 0,72), a 3(e 0$, wyes $)$,$\} , e assim$ sucessivamente. De forma semelhante, o primeiro exemplo negativo de treinamento de Forl "proposicional", equivalente a is_go (e6, osunny , 23, 95, wno) seria acrescentado de ':-' e transformado para $\{:-$ example $(e 6), a 0(e 6$, osunny). a0 $(e 6,23), a 0(e 6,95)$. $\mathrm{a} 0(e 6, \mathrm{wno})$.$\} , e analogamente para os outros exemplos negativos.$

Para manter a representação semelhante àquela da ferramenta foil2foilmb descrita na Subseção 5.4.5, os valores dos atributos para os exemplos de teste são inclúídos juntos com os dos exemplos de treinamento. Sendo assim, o segundo arquivo, voyage_test_mb.pl (Figura 5.18), contém os identificadores para os exemplos de teste, declarados como fatos do predicado example/1. Esse arquivo só pode conter instâncias do predicado de identificação, indicados como positivos ou negativos da mesma forma que no primeiro arquivo, voyage_training.mb.pl (Figura 5.17).

\subsubsection{De Foll "Proposicional" para Foll MB}

A ferramenta foil2foilmb (Figura 5.19) gera somente um arquivo, com os dados no formato MB, cuja extensão é .d.

O nome do arquivo é composto pelo nome do arquivo de dados e o sufixo _mb, para indicar 


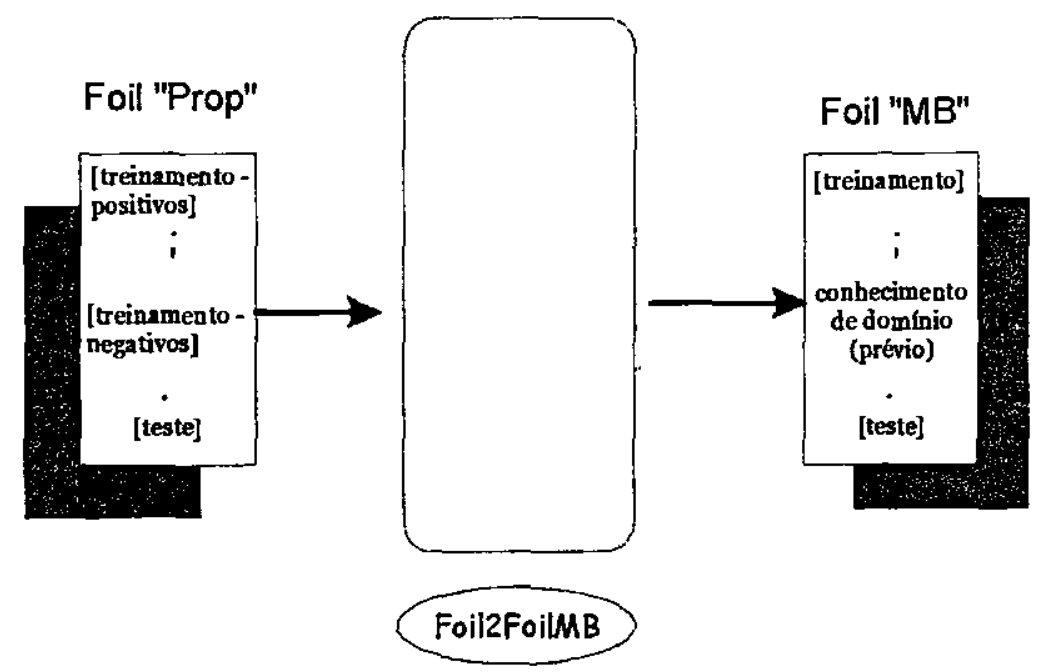

Figura 5.19: De Foll "Proposicional" para Foll MB

que foi criado com base na proposta de Morik e Brockhausen vista na Seção 5.3. Assim, o nome do arquivo para o exemplo corrente é voyage_mb. $d$, como pode ser visto na Tabela 5.4.

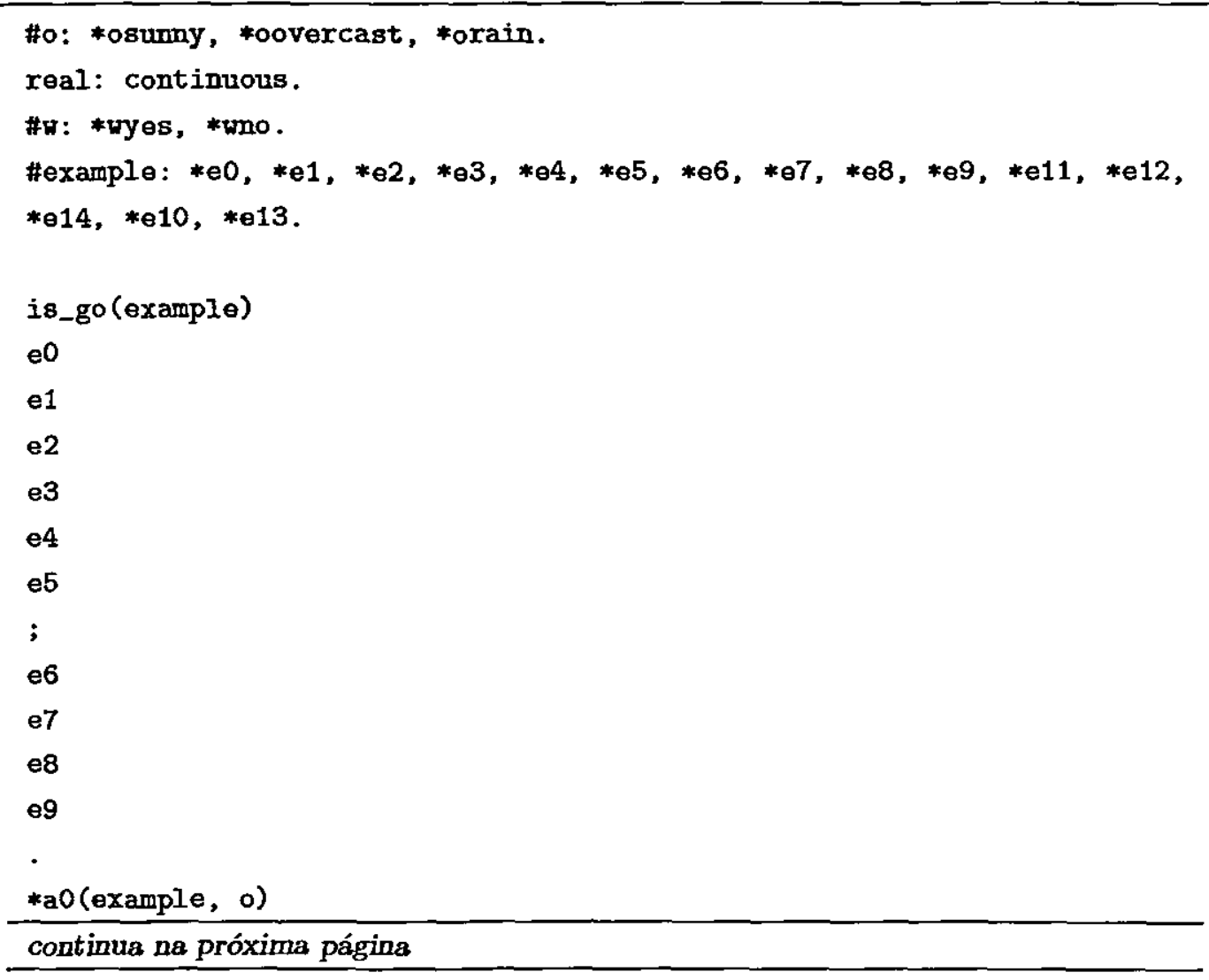


Capítulo 5 - Ferramentas para Conversão de Dados no Formato Atributo-Valor para o Formato Relacional

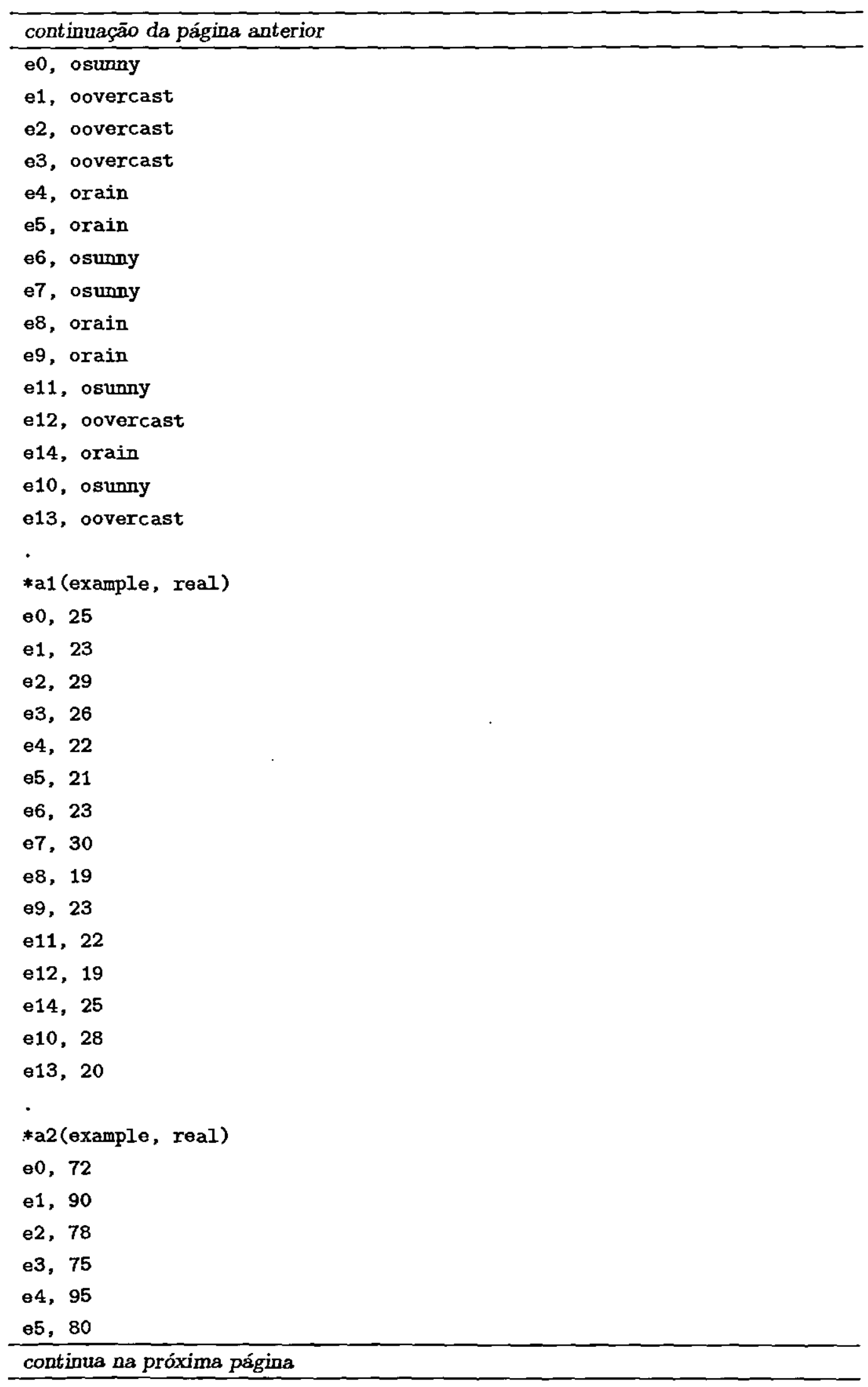


Capítulo 5 - Ferramentas para Conversāo de Dados no Formato Atributo-Valor para o Formato Relacional

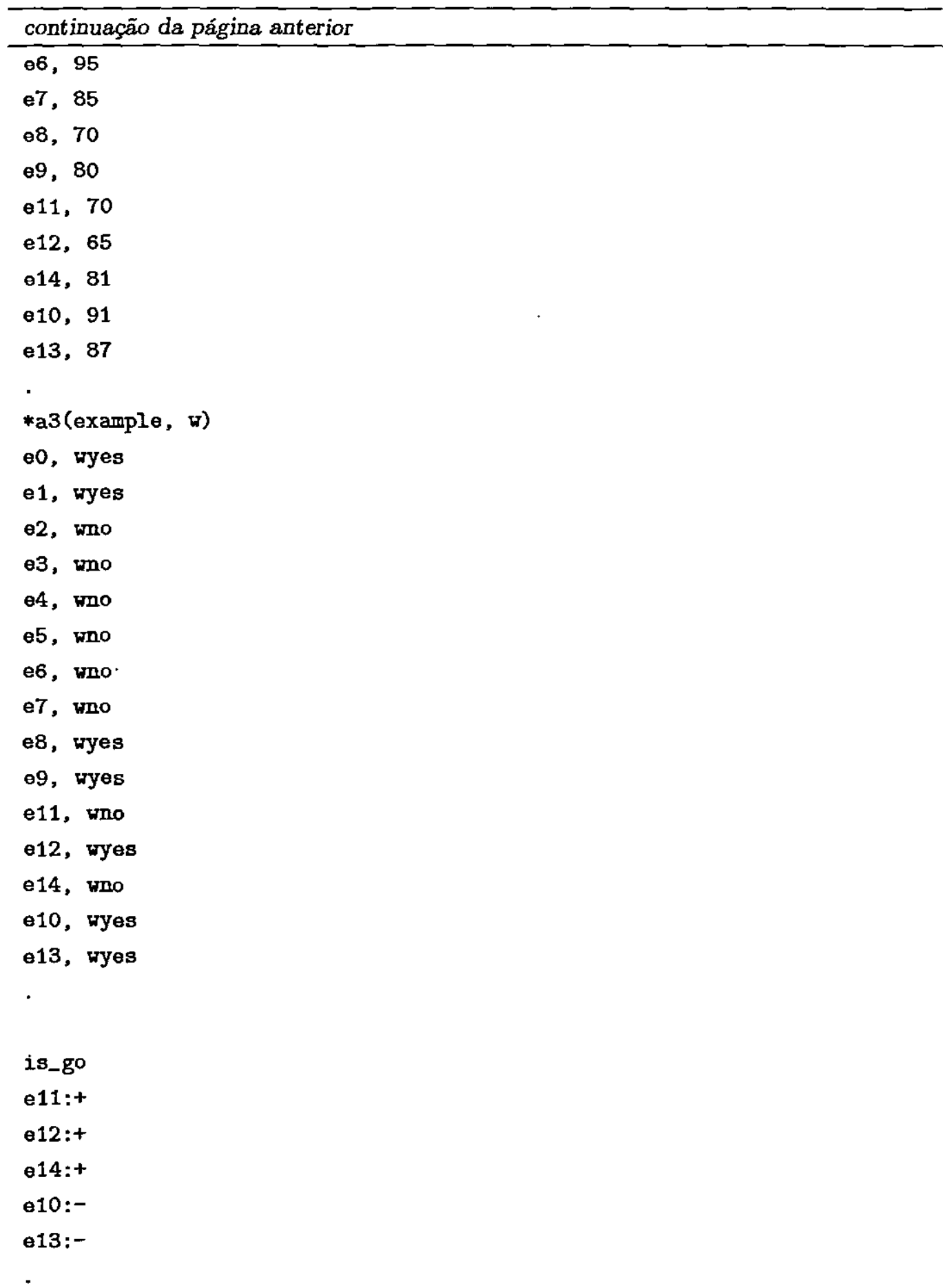

Tabela 5.4: Arquivo Foll MB voyage.mb.d 
No início do arquivo, são colocados os tipos de dados previamente declarados no arquivo FoIL "proposicional". Além desses, uma lista de identificadores é gerada representando os valores discretos do tipo de dados ex, para os identificadores de exemplos.

Depois dos tipos de dados, é descrito o predicado meta cujo nome é o mesmo do predicado meta do arquivo de FoIL "proposicional" (para o conjunto de dados considerado, is_go) e contém um único argumento que é o identificador do exemplo. Esse predicado será usado na cabeça das cláusulas encontradas.

Para cada um dos argumentos do predicado meta no arquivo de Foll "proposicional" são criados novos predicados binários. A declaração de cada um desses predicados é precedido de um * para indicar que não constitui um predicado meta e sim conhecimento de fundo que poderá ser incluído no corpo das cláusulas induzidas. O primeiro argumento é sempre o identificador do exemplo e o segundo é o valor, para aquele exemplo, do atributo representado pelo predicado binário. Assim, para o primeiro atributo é criado o predicado a0 com os argumentos de tipo ex e o, ou seja, $* \mathrm{a} 0(e x, 0)$, e assim por diante. O predicado novo para um determinado atributo é descrito e em seguida são listados os fatos sobre os valores daquele atributo para os exemplos. Um '.' sozinho em uma linha indica o fim da lista de fatos para o atributo. Esse processo se repete até que todos os atributos tenham sido listados.

Como Foll não possui uma interface para ler os exemplos de teste separadamente da geração da hipótese, facilidade esta disponível em ProGol, os valores dos atributos para os exemplos de teste devem ser colocados juntos com os de treinamento de modo que sejam carregados juntos na memória. Finalmente, é novamente escrito o nome do predicado meta (is_go) para indicar que os exemplos de teste serão listados. Somente os identificadores dos exemplos de teste são colocados, um em cada linha. A sequência ":+" ou ":-" no final da linha indica que o exemplo é positivo ou negativo, respectivamente, em relação ao conceito procurado. Um '.' sozinho em uma linha indica o fim da lista de exemplos de teste e do arquivo de dados.

\subsection{Considerações Finais}

Em princípio qualquer problema que possa ser aprendido com AM proposicional pode ser aprendido com AM relacional também. Para tanto, é necessário ter um processo para 
Capítulo 5 - Ferramentas para Conversão de Dados no Formato Atributo-Valor para o Formato Relacional

converter os dados em formato atributo-valor para o formato relacional. Através das ferramentas descritas neste capítulo, torna-se possível obter representações que possam ser utilizadas por sistemas de PLI, e de aprendizado relacional em geral. Essas ferramentas são utilizadas na comparação empírica realizada com FoIL e PrOGOL no capítulo seguinte e também no estudo de caso apresentado no Capítulo 7. 


\section{Capítulo 6}

\section{Comparação Empírica de FOIL e Progol Utilizando Dados no Formato Atributo-Valor}

\subsection{Considerações Iniciais}

Com algumas mudanças na especificação original de sistemas de aprendizado relacional, tornou-se possível definir variáveis contínuas que podem ser comparadas com um limite numérico. Através desse tratamento de valores numéricos, sistemas de PLI podem ser aplicados não só na busca de relações entre atributos, mas também a problemas de classificação atributo-valor convencionais. Assim, é interessante verificar o comportamento de sistemas de PLI nesse tipo de problema.

Neste capítulo, é descrita uma comparação do aprendizado de conceitos a partir de seis conjuntos de dados, utilizando FoIl e Progol para realizar a indução de relações. Inicialmente esses conjuntos estão no formato atributo-valor. As ferramentas descritas no Capítulo 5 são utilizadas para converter os dados no formato atributo-valor para os formatos "proposicional" e MB. Os dados sāo apresentados a FoIL e Progol tanto no formato "proposicional" quanto no formato MB, e o desempenho de ambos sistemas é medido em cada caso. 


\subsection{Conjuntos de Dados}

Os experimentos aqui descritos foram realizados com dados de vários domínios diferentes. Todos os conjuntos de dados são do UCI ML Repository (Blake et al., 1998), um repositório de dados, de domínio público, para aprendizado de máquina.

Para tornar as comparações mais interessantes, os conjuntos de dados foram escolhidos de modo que contivessem tipos de atributos bastante variados. Alguns conjuntos contem somente valores contínuos, enquanto outros combinam atributos discretos com atributos contínuos. Há ainda conjuntos contendo valores desconhecidos. Para melhor entendimento, uma descrição do conteúdo de cada conjunto, bem como as características gerais dos conjuntos, são apresentadas a seguir.

\subsubsection{Descrição Geral dos Conjuntos de Dados}

Bupa Contribuição de R. S. Forsyth à base UCI, consiste em dados que descrevem pacientes masculinos, através de vários exames de sangue e o volume de álcool consumido. Os pacientes dividem-se em "com problemas de fígado" - classe um - e "sem indícios de problemas" - classe dois.

Pima Doado por V. Sigillito do Laboratório de Física Aplicada da Universidade Johns Hopkins (EUA), trata-se de um subconjunto de uma base de dados maior mantida pelo Instituto Nacional de Diabete e Doenças Digestivas e de Rim, que descreve mulheres com pelo menos 21 anos, descendentes da tribo indígena Pima. O problema consiste em predizer se uma paciente irá testar como positiva - classe um - ou negativa - classe zero - em relação à diabete de acordo com os critérios da Organização Mundial da Saúde, a partir de resultados de exames médicos e medidas fisiológicas.

Breast Um de dois conjuntos de dados no repositório da UCI que tratam de câncer de mama. Divide-se em casos de recorrência - classe recurrence - de câncer e outros em que não houve recorrência - classe no_recurrence.

Hungaria Trata de doenças cardíacas em casos reunidos pelo Hungarian Institute of Cardiology. Divide-se em casos nos quais o paciente mostra a presença de uma doença classe presence - ou a ausência da mesma - classe absence. 
Credit Utilizado para aprovação de crédito a clientes, divide-se em casos de aceitação classe positive - e rejeição - classe negative - de crédito.

Hepatitis Reúne casos com características de pacientes com hepatite. Divide-se em casos de pacientes com esperança de vida -- classe live - e sem esperança de vida - classe die.

\subsubsection{Características dos Conjuntos de Dados}

A Tabela 6.1 mostra um resumo das características dos conjuntos de dados utilizados para realizar as comparações entre Foll e Progol. Mostra-se, para cada conjunto, o número de instâncias (\#Inst.), número e porcentagem de instâncias duplicadas (que aparecem mais de uma vez) e/ou conflitantes (mesmos valores dos atributos mas com classificações diferentes), número de atributos (\#Atrib.) contínuos e nominais, distribuição das classes, erro majoritário e se o conjunto de dados tem pelo menos um valor desconhecido (Valores Desconh. $)^{1}$.

\begin{tabular}{|c|c|c|c|c|c|c|c|}
\hline $\begin{array}{l}\text { Conj. } \\
\text { de Dados }\end{array}$ & \#Inst. & $\begin{array}{l}\text { \#Duplic. ou } \\
\text { Confitt. }(\%)\end{array}$ & $\begin{array}{c}\text { \#Atrib. } \\
\text { (cont.,nom.) }\end{array}$ & Classe & $\%$ Classe & $\begin{array}{c}\text { Erro } \\
\text { Majoritário }\end{array}$ & $\begin{array}{l}\text { Valores } \\
\text { Desconh. }\end{array}$ \\
\hline bupa & 345 & $4(1.16 \%)$ & $6(6,0)$ & $\begin{array}{l}\text { "1" } \\
\text { "2" }\end{array}$ & $\begin{array}{l}\mathbf{4 2 . 0 3 \%} \\
\mathbf{5 7 . 9 7 \%} \\
\end{array}$ & $\begin{array}{l}42.03 \% \\
\text { em " } 2 "\end{array}$ & $\mathbf{N}$ \\
\hline pirna & 769 & $1(0.13 \%)$ & $8(8,0)$ & "0" & $\begin{array}{l}65.02 \% \\
34.98 \%\end{array}$ & $\begin{array}{l}34.98 \% \\
\text { em " } 0 \text { " }\end{array}$ & $\bar{N}$ \\
\hline hungaria & 294 & $1(0.34 \%)$ & $13(13,0)$ & $\begin{array}{l}\text { "presence" } \\
\text { "absence" }\end{array}$ & $\begin{array}{l}36.05 \% \\
63.95 \%\end{array}$ & $\begin{array}{c}36.05 \% \\
\text { em "absence" }\end{array}$ & $\bar{Y}$ \\
\hline credit & 490 & $0(0 \%)$ & $15(6,9)$ & $\begin{array}{l}\text { "positive" } \\
\text { "negative" }\end{array}$ & $\begin{array}{l}44.29 \% \\
55.71 \% \\
\end{array}$ & $\begin{array}{r}44.29 \% \\
\text { em "negative" } \\
\end{array}$ & $Y$ \\
\hline hepatitis & 155 & $0(0 \%)$ & $19(6,13)$ & $\begin{array}{l}\text { "die" } \\
\text { "live" }\end{array}$ & $\begin{array}{l}20.65 \% \\
79.35 \%\end{array}$ & $\begin{array}{c}20.65 \% \\
\text { em "live" }\end{array}$ & $\bar{Y}$ \\
\hline
\end{tabular}

Tabela 6.1: Resumo de Características dos Conjuntos de Dados

Os conjuntos são apresentados em ordem crescente de acordo com o número de atributos, ordenação esta que será mantida na descrição dos resultados. A Figura 6.1 mostra a dimensionalidade dos conjuntos de dados, isto é, o número de atributos e instâncias em cada conjunto. Deve ser observado que devido à grande variação, o número de instâncias

\footnotetext{
${ }^{1}$ Estas informações foram obtidas utilizando a ferramenta info contida no $\mathcal{M C C}++$.
} 
é representado na figura como $\log _{10}$ (\#Instâncias).

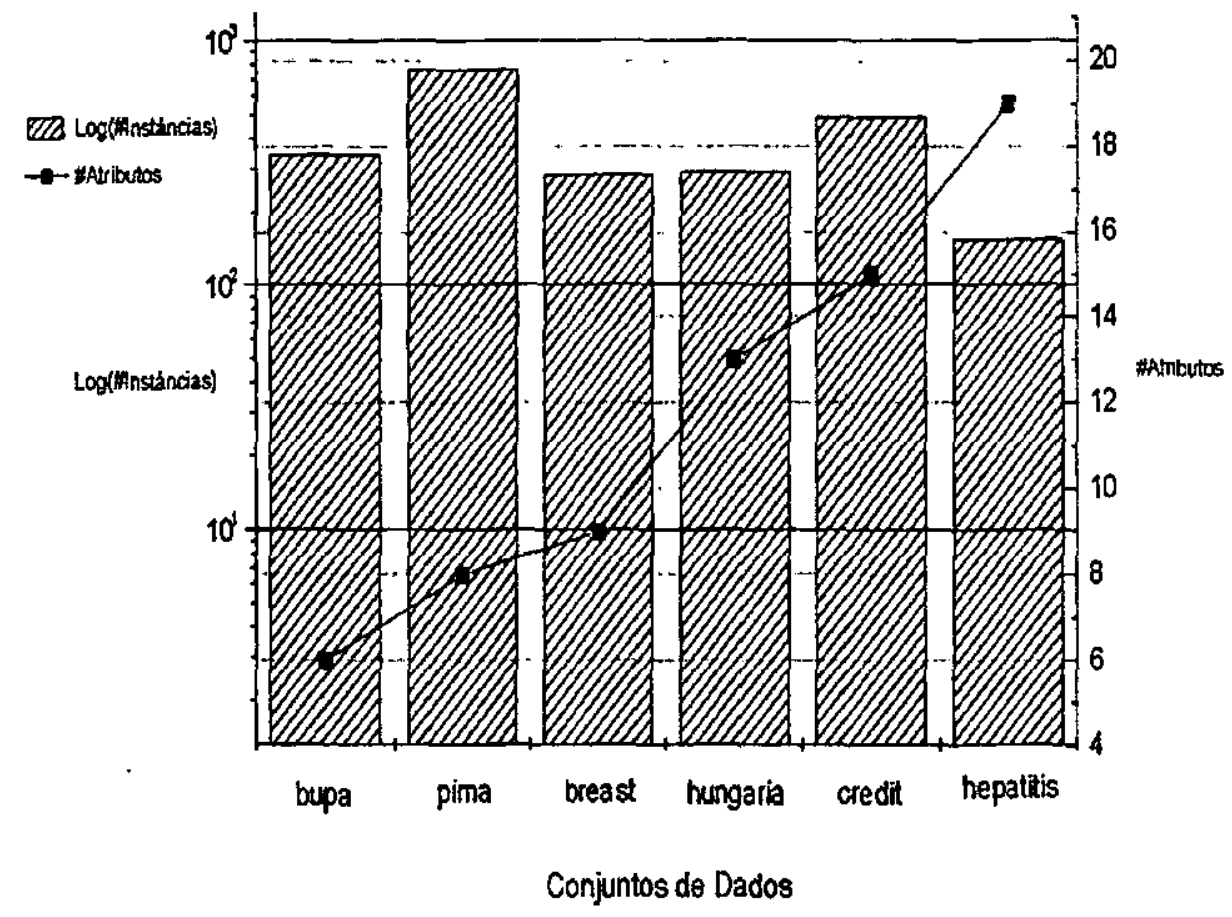

Figura 6.1: Dimensionalidade dos Conjuntos de Dados

\subsection{Descrição dos Experimentos}

Os sistemas de PLI aqui tratados aprendem um conceito que diferencia entre duas classes, induzindo uma hipótese que cobre os exemplos de uma das classes - classe positiva de modo que qualquer exemplo pertencente à outra classe -- classe negativa - não seja coberto. Para que os sistemas aprendam tanto o conceito referente à primeira classe $(X)$ quanto o conceito referente à segunda classe $(Y)$, é necessário executá-los duas vezes. Inicialmente, os exemplos da classe $X$ são fornecidos como exemplos positivos e os exemplos da classe $Y$ são fornecidos como exemplos negativos desse conceito. Na execução seguinte é feito o processo contrário, fornecendo os exemplos da classe $Y$ como exemplos positivos e os exemplos da classe $X$ como exemplos negativos. Neste trabalho ambos conceitos foram induzidos.

Os sistemas de aprendizado FoIl e PROGOL foram executados com os parâmetros padrões. 
A única alteração feita foi no sentido de alterar o parâmetro de erro permitido no ProGOL para um máximo de $20 \%$ de erro nas regras geradas. Isto foi feito com a finalidade de equipará-las com as regras geradas por Foll, já que a taxa de erro padrão para as regras deste último é de $20 \%$. Vale ressaltar ainda que todos os atributos numéricos (contínuos) foram considerados como sendo do mesmo tipo "real", e todos os atributos booleanos, ou seja, que tivessem valores "yes" ou "no", foram marcados como sendo do tipo "boolean".

Para estimar a taxa de erro verdadeira, foi escolhido o método de "resampling" chamado "10-fold cross validation". Este método é aconselhável para conjuntos de exemplos de tamanho médio como os utilizados neste trabalho, pois é capaz de combinar eficiencia computacional e boa precisão para estimar a taxa de erro verdadeira.

Os conjuntos de exemplos foram embaralhados e divididos em 10 partições mutuamente exclusivas, utilizando as ferramentas para particionamento de exemplos presentes no ambiente AMPSAM (Batista, 1997). Posteriormente, foram construídos os conjuntos de treinamento e teste segundo o método "10-fold cross validation". Um aspecto importante a ser destacado nos experimentos realizados, é que exatamente as mesmas partições foram utilizadas para medir ambos algoritmos. Ou seja, para cada conjunto de exemplos, os sistemas foram medidos utilizando os mesmos 10 conjuntos de treinamento e teste. Este procedimento pode, eventualmente, auxiliar em uma análise mais minuciosa para entender as possíveis diferenças de performance entre os dois sistemas de aprendizado. Após a construção dos conjuntos de treinamento e teste, foram aplicados os conversores sintáticos, descritos no Capítulo 5, para o formato de Foll e Progol, colocando os dados no formato atributo-valor, ou "proposicional", e também no formato relacional através do método MB.

\subsection{Medidas Consideradas}

A matriz de confusão oferece uma medida da eficiência do modelo de classificação, i.e. a hipótese $h$ induzida, mostrando o número de classificações corretas versus as classificações preditas para cada classe. Para exemplificar, considera-se um problema de classificação com duas classes, rotuladas como "+" e "-". Os dois tipos de erro possíveis são chamados de falso positivo e falso negativo. A Tabela 6.2 ilustra a matriz de confusão correspondente onde $T_{P}$ é o número de exemplos positivos classificados corretamente, ou verdadeiros positivos, $F_{N}$ é o número de instâncias positivas classificadas de forma errada, ou falsos negativos, $F_{P}$ é o número de exemplos negativos classificados de forma errada, ou falsos po- 
sitivos, e $T_{N}$ é o número de instâncias negativas classificadas corretamente, ou verdadeiros negativos, em um total de $n=\left(T_{P}+F_{N}+F_{P}+T_{N}\right)$ instâncias.

\begin{tabular}{c|cc|cc}
\hline \hline Rótulo da classe & predito como $C_{+}$ & predito como $C_{-}$ & Taxa de Erro da Classe & Taxa de erro total \\
\hline & Verd. positivos & Falsos negativos & $\frac{F_{N}}{T_{P}+F_{N}}$ & \\
verd. $C_{+}$ & $T_{P}$ & $F_{N}$ & & $\frac{F_{P}+F_{N}}{n}$ \\
& & & & \\
& Falsos positivos & Verd. negativos & $F_{P}$ & \\
verd. $C_{-}$ & $F_{P}$ & $T_{N}$ & $\frac{F_{P}+T_{N}}{2}$ \\
\hline
\end{tabular}

Tabela 6.2: Desempenho de Classificação para Duas Classes

A taxa de erro é uma métrica bastante utilizada para avaliar o desempenho de sistemas de aprendizado. Dentre as possíveis taxas, as utilizadas neste trabalho são:

1. a taxa de erro relativo à classe positiva - Equaçāo 6.1;

2. a taxa de erro relativo à classe negativa - Equação 6.2;

3. o erro total, onde $n=\left(T_{P}+F_{N}+F_{P}+T_{N}\right)$ é o número total de instâncias - Equação $6.3 ; \mathrm{e}$

4. a média G, uma variação da média geométrica a qual é apropriada para situaçōes nas quais o número de exemplos em cada uma das classes $X$ e $Y$ está muito desbalanceado - Equação 6.4 .

$$
\begin{aligned}
\text { Erro em } C_{+} & =\frac{F_{N}}{T_{P}+F_{N}} \\
\text { Erro em } C_{-} & =\frac{F_{P}}{F_{P}+T_{N}} \\
\text { Erro total } & =\frac{F_{P}+F_{N}}{n} \\
\text { Média } G & =\sqrt{\frac{F_{N}}{T_{P}+F_{N}} \frac{F_{P}}{F_{P}+T_{N}}}
\end{aligned}
$$


Considerando ainda a Tabela 6.2, quatro situaçōes podem ocorrer, ilustradas na Figura 6.2 para a $<$ classe $=C_{+}>$e descritas em seguida.

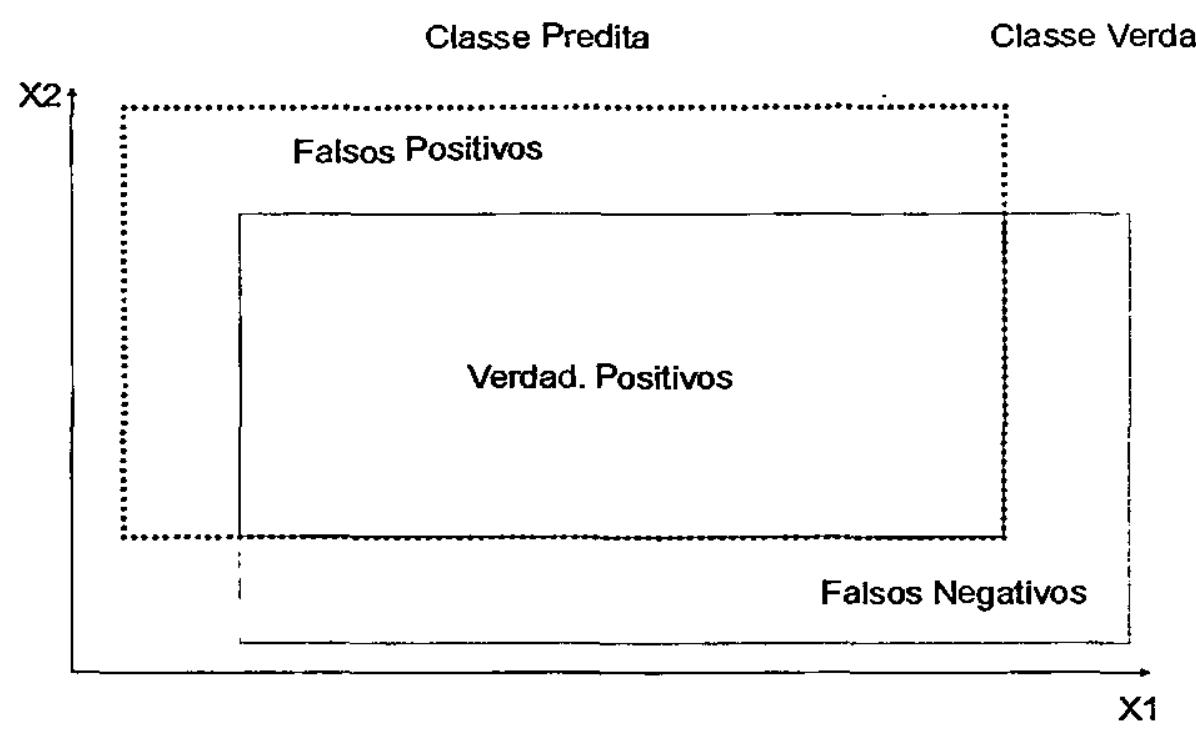

Figura 6.2: Verdadeiros Positivos, Falsos Positivos e Falsos Negativos

1. a instância pertence à classe $C_{+} \mathrm{e}$ é predito pelo classificador como sendo da classe $C_{+}$. Nesse caso, essa instância é um verdadeiro positivo.

2. a instância pertence à classe $C_{-}$e é predito pelo classificador como sendo da classe $C_{-}$. Nesse caso, essa instância é um verdadeiro negativo.

3. a instância pertence à classe $C_{-}$e é predito pelo classificador como sendo da classe $C_{+}$. Nesse caso, essa instância é um falso positivo.

4. a instância pertence à classe $C_{+}$e é predito pelo classificador como sendo da classe $C_{-}$. Nesse caso, essa instância é um falso negativo.

Outra medida utilizada é a diferença em desvios-padrão do erro. Suponha que se queira comparar dois algoritmos com taxas de erro iguais a $9,0 \pm 1,0$ e 7,5 $\pm 0,8$. Será que um deles é melhor que o outro? i.e., que existe uma diferença significativa de um para o outro com relação às taxas de erro apresentadas por eles, com nível de confiança de $95 \%$ ? Para responder essa pergunta, assume-se o caso geral para determinar se a diferença de um algoritmo para outro - por exemplo $A_{1}$ e $A_{2}$ - é significativa ou não. Para tanto, 
a média e o desvio padrão combinados são calculados de acordo com as Equações 6.5 e 6.6, respectivamente. A diferença absoluta em desvios-padrão é calculada através da Equação 6.7 (Weiss e Indurkhya, 1998).

$$
\begin{aligned}
\operatorname{mean}\left(A_{2}-A_{1}\right) & =\operatorname{mean}\left(A_{2}\right)-\operatorname{mean}\left(A_{1}\right) \\
\operatorname{sd}\left(A_{2}-A_{1}\right) & =\sqrt{\frac{\operatorname{sd}\left(A_{2}\right)^{2}+\operatorname{sd}\left(A_{1}\right)^{2}}{2}} \\
\operatorname{ad}\left(A_{2}-A_{1}\right) & =\frac{\operatorname{mean}\left(A_{2}-A_{1}\right)}{\operatorname{sd}\left(A_{2}-A_{1}\right)}
\end{aligned}
$$

Se ad $\left(A_{2}-A_{1}\right)>0$, pode-se dizer que $A_{1}$ tem um desempenho melhor que $A_{2}$. Se ad $\left(A_{2}-\right.$ $\left.A_{1}\right) \geq 2$ desvios-padrão, pode-se dizer que $A_{1}$ tem melhor desempenho que $A_{2}$ com nível de confiança de $95 \%$. Por outro lado, se ad $\left(A_{2}-A_{1}\right)<0$ diz-se que $A_{2}$ tem um desempenho melhor que $A_{1}$ e se ad $\left(A_{2}-A_{1}\right) \leq 2$ desvios-padrão então $A_{2}$ tem um desempenho melhor que $A_{1}$ com nível de confiança de $95 \%$.

\subsection{Resultados Experimentais}

Para cada conjunto de dados foram construídas várias tabelas que procuram detalhar os resultados experimentais obtidos. A fim de ilustrar a informação nessas tabelas, a seguir são apresentados somente os resultados obtidos com o conjunto de dados Breast. Deve ser ressaltado que os resultados detalhados obtidos com todos os conjuntos de dados encontram-se em (Caulkins e Monard, 2000a).

A primeira tabela - Tabela 6.3-- descreve cada atributo do conjunto de dados, através de um número, o nome do atributo e o tipo (discreto ou contínuo). Para atributos discretos, o número máximo de valores possíveis e o número de valores realmente atribuídos ao atributo no conjunto de dados, ambos calculados pela ferramenta info do $\mathcal{M L C + +}$, são mostrados. Deve ser observado que um número maior de valores encontrados em relação ao de valores possíveis indica que há valores faltando para aquele atributo, porém o contrário não é 
verdade.

\begin{tabular}{r|l|rrl}
\hline \hline \multirow{2}{*}{$\begin{array}{c}\text { Número } \\
\text { Atrib. }\end{array}$} & Nome & \multicolumn{3}{|c}{ \#Valores Distintos } \\
\cline { 2 - 5 }$\#$ Atrib. & Age & - & 44 & contínuo \\
$\# 1$ & Age-at-meno & - & 3 & discreto \\
$\# 2$ & Tumor-size & - & 23 & contínuo \\
$\# 3$ & Involved-nodes & - & 18 & contínuo \\
$\# 4$ & Node-capsule & 3 & 3 & discreto \\
$\# 5$ & Degree-of-malig & - & 3 & contínuo \\
$\# 6$ & Breast & - & 2 & discreto \\
$\# 7$ & Breast-Quadrant & 6 & 6 & discreto \\
$\# 8$ & Irradiation & - & 2 & discreto \\
\hline \hline
\end{tabular}

Tabela 6.3: Breast - Descrição dos Atributos

A segunda tabela - Tabela 6.4 - consiste de duas partes, sendo que os valores foram calculados para os experimentos realizados utilizando o método "proposicional" e "10-fold cross-validation". A parte (a) mostra o valor médio e desvio-padrão, para as taxas de erro relativo à classe positiva e à classe negativa, o erro total e o erro baseado na média G. Além disso, são mostradas matrizes de confusão onde cada posição contém o valor médio para os 10 "folds".

A parte (b) dessa tabela mostra o número médio de regras geradas (cláusulas com corpo) e o número médio do total de cláusulas (com corpo e sem) para se ter uma idéia do tamanho das hipóteses induzidas e da cobertura das regras. Na quarta coluna está indicado o tempo médio de execução e seu desvio-padrão. O tempo de CPU nas tabelas refere-se à execução de Progol em um Pentium II com clock de $233 \mathrm{MHz}$, rodando Linux como sistema operacional, e à execução de FoIL em uma estação de trabalho Sun Ultra1 com clock de $140 \mathrm{MHz}$, rodando o Solaris como sistema operacional.

A terceira tabela - Tabela 6.5 - mostra os mesmos números que a segunda tabela - Tabela 6.4 - mas para os experimentos realizados utilizando o método MB para representar os dados.

A quarta tabela - Tabela 6.6 - mostra a diferença em desvios-padrão de FoIL para PROGOL quando o método "proposicional" foi utilizado.

A quinta tabela - Tabela 6.7 - mostra a diferença em desvios-padrão de FoIL para PROGOL quando o método MB foi utilizado.

A sexta tabela - Tabela 6.8 - mostra as taxas de erro aparente relativo à classe posi- 
Capítulo 6 - Comparação Empírica de Foll e Progol Utilizando Dados no Formato Atributo-Valor

\begin{tabular}{|c|rr|c|c|c|c|}
\hline \hline Algoritmo & \multicolumn{2}{|c|}{ Matriz } & $\frac{F_{N}}{T_{P}+F_{N}}$ & $\frac{F_{P}}{P_{P}+T_{N}}$ & $\frac{F_{P}+F_{N}}{n}$ & $\sqrt{\frac{F_{N}}{T_{P}+F_{N}} \frac{F_{P}}{F_{P}+T_{N}}}$ \\
\hline Foil(C1) & 4.0 & 4.4 & $52.1 \pm 9.0$ & $21.0 \pm 9.3$ & $30.2 \pm 7.4$ & $32.1 \pm 8.6$ \\
{$[$ max, min] } & 4.2 & 15.9 & {$[71.4,42.9]$} & {$[38.9,4.8]$} & {$[46.4,17.2]$} & {$[48.3,15.5]$} \\
\hline Progol(C1) & 2.1 & 6.3 & $75.9 \pm 13.9$ & $11.7 \pm 2.6$ & $30.7 \pm 4.8$ & $30.0 \pm 4.5$ \\
{$[$ max, min $]$} & 2.4 & 17.7 & {$[100.0,50.0]$} & {$[16.7,9.1]$} & {$[37.9,24.1]$} & {$[37.8,22.9]$} \\
\hline \hline Foil(C2) & 16.4 & 3.7 & $18.3 \pm 7.8$ & $49.1 \pm 19.2$ & $27.3 \pm 10.3$ & $29.7 \pm 11.7$ \\
{$[$ max, min] } & 4.1 & 4.3 & {$[31.8,9.5]$} & {$[85.7,25.0]$} & {$[46.4,13.8]$} & {$[52.2,15.4]$} \\
\hline Progol(C2) & 16.1 & 4.0 & $19.9 \pm 10.9$ & $54.5 \pm 19.6$ & $30.0 \pm 8.7$ & $31.0 \pm 9.3$ \\
{$[$ max, min] } & 4.5 & 3.9 & {$[40.9,4.8]$} & {$[85.7,25.0]$} & {$[44.8,13.8]$} & {$[48.4,13.4]$} \\
\hline \hline
\end{tabular}

(a)

\begin{tabular}{|r|r|r|r|}
\hline \hline Algoritmo & \# Cláusulas & \# Regras & Tempo Médio \\
\hline Foil(C1) & $26.8 \pm 3.4$ & $16.5 \pm 4.3$ & $0.7 \pm 4.3$ \\
\hline Progol(C1) & $44.3 \pm 3.5$ & $6.4 \pm 3.8$ & $106.7 \pm 15.5$ \\
\hline \hline Foll(C2) & $28.0 \pm 4.2$ & $24.4 \pm 4.2$ & $0.7 \pm 4.2$ \\
\hline Progol(C2) & $29.3 \pm 2.8$ & $8.3 \pm 3.4$ & $52.9 \pm 3.4$ \\
\hline \hline
\end{tabular}

(b)

Tabela 6.4: Médias para o Conjunto de Dados Breast e Método "Proposicional", $(\mathrm{C} 1=$ recurrence e $\mathrm{C} 2=$ no_recurrence)

\begin{tabular}{|c|c|c|c|c|c|c|}
\hline Algoritmo & \multicolumn{2}{|c|}{ Matriz } & $\frac{F_{N}}{T_{P}+F_{N}}$ & $\frac{F_{P}}{F_{P}+T_{N}}$ & $\frac{F_{p}+F_{N}}{n}$ & $\sqrt{\frac{F_{N}}{T_{P}+F_{N}} \frac{F_{P}}{F_{P}+T_{N}}}$ \\
\hline $\begin{array}{r}\text { Foil }(C 1) \\
{[\max , \min ]}\end{array}$ & $\begin{array}{l}3.0 \\
3.0\end{array}$ & $\begin{array}{r}5.4 \\
17.1\end{array}$ & $\begin{array}{l}65.2 \pm 11.7 \\
{[87.5,55.6]}\end{array}$ & $\begin{array}{l}14.8 \pm 9.8 \\
{[33.3,0.0]}\end{array}$ & $\begin{array}{l}29.5 \pm 7.8 \\
{[42.9,17.2]}\end{array}$ & $\begin{array}{c}29.4 \pm 11.8 \\
{[44.7,7.9]}\end{array}$ \\
\hline $\begin{array}{l}\text { Progol(C1) } \\
{[\max , \min ]}\end{array}$ & $\begin{array}{l}1.2 \\
1.6\end{array}$ & $\begin{array}{r}7.2 \\
18.5\end{array}$ & $\begin{array}{l}85.8 \pm 9.2 \\
{[100.0,71.4]}\end{array}$ & $\begin{array}{l}7.8 \pm 3.8 \\
{[14.3,0.0]}\end{array}$ & $\begin{array}{l}30.9 \pm 5.2 \\
{[37.9,21.4]}\end{array}$ & $\begin{array}{c}25.6 \pm 7.6 \\
{[37.8,9.3]}\end{array}$ \\
\hline $\begin{array}{r}\text { Foil(C2) } \\
{[\max , \min ]}\end{array}$ & $\begin{array}{r}14.7 \\
3.6\end{array}$ & $\begin{array}{l}5.4 \\
4.8\end{array}$ & $\begin{array}{l}26.7 \pm 8.5 \\
{[40.9,16.7]}\end{array}$ & $\begin{array}{l}41.7 \pm 19.5 \\
{[77.8,14.3]}\end{array}$ & $\begin{array}{l}31.6 \pm 9.8 \\
{[50.0,17.9]}\end{array}$ & $\begin{array}{l}32.6 \pm 10.4 \\
{[53.5,16.5]}\end{array}$ \\
\hline $\begin{array}{l}\text { Progol(C2) } \\
{[\max , \min ]}\end{array}$ & $\begin{array}{r}14.4 \\
4.5\end{array}$ & $\begin{array}{l}5.7 \\
3.9\end{array}$ & $\begin{array}{l}28.2 \pm 8.5 \\
{[38.1,9.5]}\end{array}$ & $\begin{array}{l}54.1 \pm 21.9 \\
{[85.7,22.2]}\end{array}$ & $\begin{array}{l}35.8 \pm 6.1 \\
{[44.8,24.1]}\end{array}$ & $\begin{array}{l}37.1 \pm 8.3 \\
{[51.0,24.4]}\end{array}$ \\
\hline
\end{tabular}

(a)

\begin{tabular}{|r|r|r|r|}
\hline \hline Algoritmo & \# Cláusulas & \# Regras & Tempo Médjo \\
\hline Foil(C1) & $60.8 \pm 0.8$ & $35.8 \pm 1.2$ & $50.9 \pm 6.8$ \\
\hline Progol(C1) & $55.5 \pm 7.9$ & $4.4 \pm 8.0$ & $156.1 \pm 34.0$ \\
\hline \hline Foil(C2) & $55.2 \pm 0.2$ & $33.9 \pm 1 . \overline{2}$ & $90.8 \pm 38.1$ \\
\hline Progol(C2) & $38.2 \pm 3.0$ & $7 . \overline{3} \pm 3.8$ & $71.8 \pm 3.9$ \\
\hline \hline
\end{tabular}

(b)

Tabela 6.5: Médias para o Conjunto de Dados Breast e Método $\mathrm{MB},(\mathrm{C} 1=$ recurrence e $\mathrm{C} 2=$ no_recurrence)

\begin{tabular}{|l|r|r|r|r|}
\hline \hline Conceito & Erro Neg. & Erro Pos. & Erro Total & Erro G \\
\hline C1 & -2.0 & +1.4 & -0.1 & +0.3 \\
C2 & -0.2 & -0.3 & -0.3 & -0.1 \\
\hline
\end{tabular}

Tabela 6.6: Diferença em Desvios-Padrão dos Erros de Forl para Progol com Método "Proposicional"

\begin{tabular}{|l|r|r|r|r|}
\hline \hline Conceito & Erro Neg. & Erro Pos. & Erro Total & Erro G \\
\hline C1 & -2.0 & +0.9 & $-0 . \overline{2}$ & +0.4 \\
C2 & -0.2 & -0.6 & -0.5 & -0.5 \\
\hline
\end{tabular}

Tabela 6.7: Diferença em Desvios-Padrão dos Erros de Forl para Progol com Método $\mathrm{MB}$ 
tiva e à classe negativa, e o erro total, obtidos quando regras são induzidas sobre todo o conjunto de dados. Da segunda à quinta coluna os resultados utilizando a representação "proposicional" são indicados e as quatro colunas seguintes mostram os resultados obtidos com a representação $\mathrm{MB}$.

\begin{tabular}{|c|c|c|c|c|c|c|c|c|c|c|}
\hline & \multicolumn{5}{|c|}{ Método Prop } & \multicolumn{5}{|c|}{ Método MB } \\
\hline Algoritmo & Mat & onf. & $\frac{F N}{T p+F N}$ & $\frac{F_{P}}{F_{P}+T_{N}}$ & $\frac{F_{P}+F_{N}}{n}$ & Mat & onf. & $=\frac{F_{N}}{T_{P}+F_{N}}$ & $\frac{F_{P}}{F_{P}+T_{N}}$ & $\frac{F_{P}+F_{N}}{n}$ \\
\hline Foll (C1) & $\begin{array}{r}76 \\
0\end{array}$ & $\begin{array}{r}8 \\
201\end{array}$ & 0.10 & 0.00 & 0.03 & $\begin{array}{r}84 \\
0\end{array}$ & $\begin{array}{r}0 \\
201\end{array}$ & 0.00 & $0 . \overline{00}$ & 0.00 \\
\hline Progol (C1) & $\begin{array}{r}84 \\
4\end{array}$ & $\begin{array}{r}0 \\
197\end{array}$ & $0 . \overline{00}$ & $\overline{0.02}$ & $\overline{0.01}$ & $\begin{array}{r}84 \\
5\end{array}$ & $\begin{array}{r}0 \\
196\end{array}$ & 0.00 & $0 . \overline{02}$ & 0.02 \\
\hline Foll (C2) & $\begin{array}{r}201 \\
0\end{array}$ & $\begin{array}{r}0 \\
84\end{array}$ & 0.00 & 0.00 & 0.00 & $\begin{array}{r}201 \\
0\end{array}$ & $\begin{array}{r}0 \\
84\end{array}$ & 0.00 & $0 . \overline{00}$ & 0.00 \\
\hline PROGOL (C2) & $\begin{array}{r}201 \\
20\end{array}$ & $\begin{array}{r}0 \\
64\end{array}$ & $0 . \overline{00}$ & 0.24 & 0.07 & $\begin{array}{r}201 \\
0\end{array}$ & $\begin{array}{r}0 \\
84\end{array}$ & 0.00 & 0.00 & 0.00 \\
\hline
\end{tabular}

Tabela 6.8: Erro Aparente para o Conjunto de Dados Breast $(\mathrm{C} 1=$ recurrence e $\mathrm{C} 2=$ no_recurrence)

A última tabela - Tabela 6.9 - mostra o número total de cláusulas geradas quando regras são induzidas utilizando todo o conjunto de dados, o número de regras (cláusulas com corpo) induzidas, e o tempo de execução necessário para fazer a indução. Da segunda à quinta coluna os resultados são os obtidos utilizando a representação "proposicional", e as quatro colunas seguintes mostram resultados obtidos com a representação MB. Cada linha mostra o resultado de um dos sistemas, levando em consideração cada uma das duas classes como "positiva".

\begin{tabular}{|c|c|c|c|c|c|c|}
\hline & \multicolumn{3}{|c|}{ Método Prop } & \multicolumn{3}{|c|}{ Método MB } \\
\hline Álgoritmo & Total Cl. & Regras & Tempo de Exec. & Total Cl. & Regras & Tempo de Exec. \\
\hline FoIL (C1) & 27 & 18 & 0.7 & 52 & 13 & $3 \overline{35.3}$ \\
\hline PROGOL (C1) & 48 & 7 & 122.57 & 55 & 6 & 167.86 \\
\hline Foll (C2) & 31 & 26 & 0.9 & 64 & 18 & 63.9 \\
\hline PrOGOL (C2) & 34 & 11 & 63.97 & 123 & 13 & 403.58 \\
\hline
\end{tabular}

Tabela 6.9: Número de Cláusulas, Regras e Tempo de Execução Utilizando Todo o Conjunto de Dados Breast $(\mathrm{C} 1=$ recurrence e $\mathrm{C} 2=$ no_recurrence $)$

Deve ser observado que a diferença entre o número total de cláusulas e regras fornece o número de exemplos positivos não cobertos pelas regras induzidas, mas que são cobertos por uma cláusula sem corpo que simplesmente nomeia o exemplo. Pode ser observado que para este conjunto de dados, essa diferença é sempre maior para Progol. As oito figuras a seguir mostram as regras geradas em cada um dos casos descritos na Tabela 6.9. 


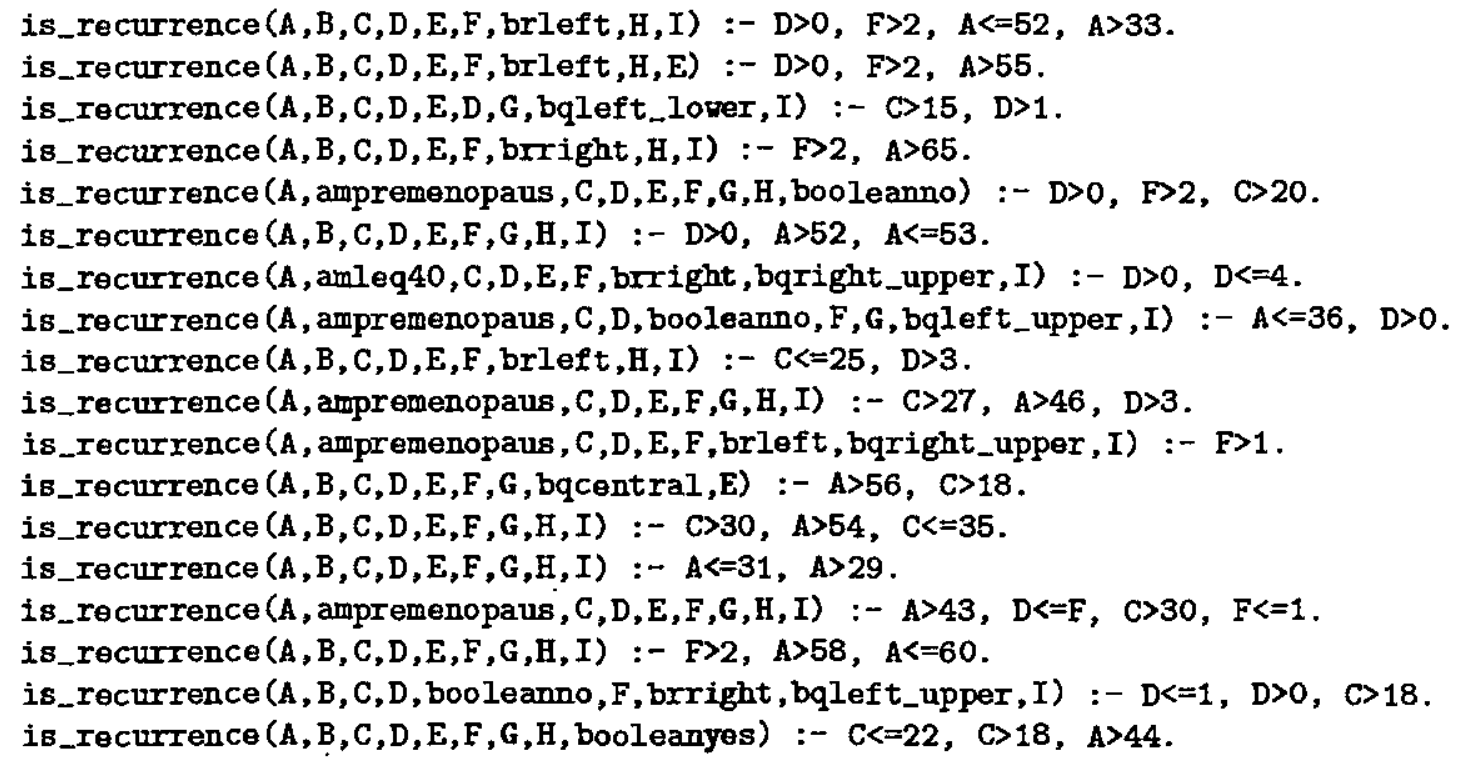

Figura 6.3: Regras Geradas por FoIL: Conjunto de Dados Breast e Método Prop, com C1 $=$ recurrence

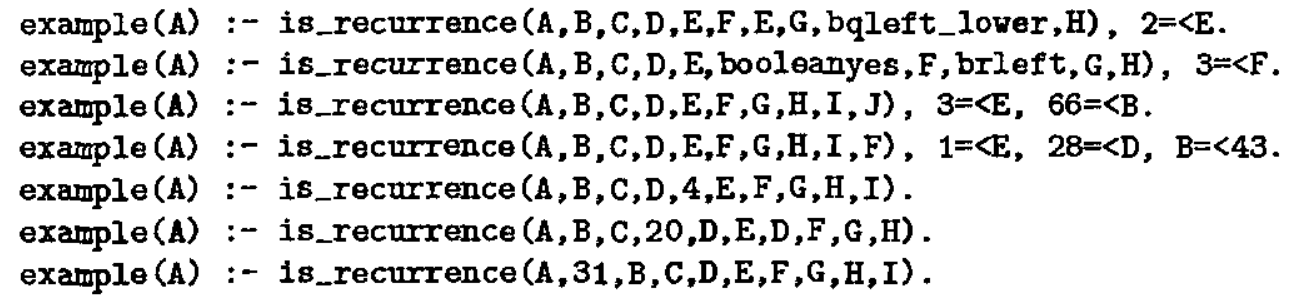

Figura 6.4: Regras Geradas por Progol: Conjunto de Dados Breast e Método Prop, com $\mathrm{C} 1=$ recurrence 
is_recurrence $(A):-a 6(A, b r l e f t), a 0(A, C), a 3(A, D), a 5(A, E), D>0, E>2, C<=52, C>33$. is_recurrence(A):- a4 (A,B), a6(A,brleft), a8 (A,B), a0 (A,D), a3 (A,E), a5 (A, F), E>0, $\mathrm{F}>2, \mathrm{D}>55$.

is_recurrence $(A):-a 7\left(A, b q l e f t \_l o w e r\right), a 2(A, C), a 3(A, D), a 5(A, D), C>15, D>1$. is_recurrence $(A):-a 6(A, b r r i g h t), a 0(A, C), a 5(A, D), D>2, C>65$.

is_recurrence $(A):-a 8(A, b o o l e a n n o), a 1(A$, ampremenopaus), a2 (A,D), a3 (A,E), a5 (A,F), $\mathrm{E}>0, \mathrm{~F}>2, \mathrm{D}>20$.

is_recurrence $(A):-a 0(A, B), a 3(A, C), C>0, B>52, B<=53$.

is_recurrence(A) :- a6 (A,brright), a1 (A, amleq40), a7 (A,bqright_upper), a3(A,E), $\mathrm{E}>0, \mathrm{E}<=4$.

is_recurrence (A) :- a4 (A,booleanno), a1 (A,ampremenopaus), a7 (A,bqleft_upper), $\mathrm{a} 0(\mathrm{~A}, \mathrm{E}), \mathrm{a} 3(\mathrm{~A}, \mathrm{~F}), \mathrm{E}<=36, \mathrm{~F}>0$.

is_recurrence $(A):-a 6(A, b r l e f t), a 2(A, C), a 3(A, D), C<=25, D>3$.

is_recurrence(A) :- $a 0(A, B), a 5(A, C), C>2, B>58, B<=60$.

is_recurrence (A) :- a6 (A,brleft), a1 (A,ampremenopaus), a7 (A,bqright_upper), a5 $(A, E), E>1$.

is_recurrence (A) :- a0 (A,B), a2 $(A, C), a 5(A, D), B>56, B<=58, D<=2, C>15, D>1$.

is_recurrence (A) :- $a 0(A, B), B<=31, B>29$.

Figura 6.5: Regras Geradas por Foll: Conjunto de Dados Breast e Método MB, com C1 $=$ recurrence

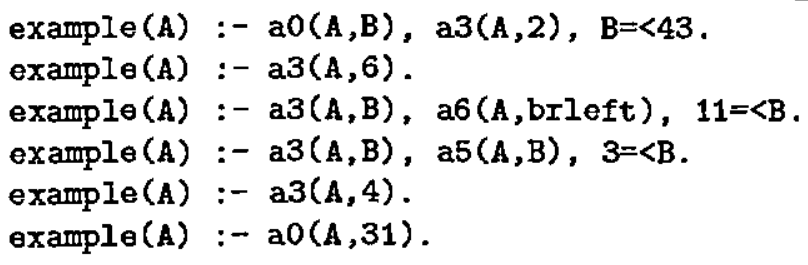

Figura 6.6: Regras Geradas por Progol: Conjunto de Dados Breast e Método MB, com $\mathrm{C} 1=$ recurrence 
is_no_recurrence ( $A, B, C, D$, booleanno, $F, G, H, I):-A>46, C<=18$. is_no_recurrence $(A, B, C, D, E, F, G, H, I):-D<=0, F<=1, A>51$.

is_no_recurrence $(A, B, C, D, E, F, G, H, I):-D<=0, A<=43, A>31, F<=2$.

is_no_recurrence $(A, B, C, D, E, F, G, H, I):-F<=2, A>44, A<=56, F>1, D<=2, C>25$.

is_no_recurrence $(A, B, C, D, E, F, G, b q l e f t$ upper., $I):-D<=0, F>2$.

is_no_recurrence $(A$, amle $440, C, D, E, F, G, H, I):-F<=2, A<=56, A>46$.

is_no_recurrence $(A, B, C, D, E, F, G, H, I):-F<=2, A>36, A<=41$.

is_no_recurrence (A, ampremenopaus, $C, D, E, F, G, H, E):-A>44, A<=50, C<=25, C>22$.

is_no_recurrence (A, ampremenopaus, $C, D$, booleanno, $F, G, H, I):-A>44, C<=20$.

is_no_recurrence $(A, B, C, D, E, F, G, b q l e f t$ lower, $I):-D<=0, F>2$.

is_no_recurrence $(A, B, C, D, E, F, G, H, I):-F<=2, A>58, D<=0, C<=30$.

is_no_recurrence $(A$, amleq $40, C, D, E, F, G, H, I):-F<=2, D>F, A<=63$.

is_no_recurrence $(A, B, C, D$, booleanyes, $F$, brright, $H$, booleanyes) :- $A<=46$.

is_no_recurrence $(A, B, C, D, E, F, G, b q l e f t$ _lower, $I):-A>43, C>24, F<=2, C<=30$.

is_no_recurrence $(A, B, C, D$, booleanno, $F, G, H, I):-A<=55, A>53$.

is_no_recurrence ( $A, B, C, D, E, F$, brright, $H$, booleanyes) :- $A<=46, C<=27$.

is_no_recurrence $(A, B, C, D, E, F, G, H$, booleanno) :- $D>1, A>49, D<=3$.

is_no_recurrence $(A, B, C, D$, booleanno, $F$, brleft,$H$, booleanno $):-C<=35, F<=1$.

is_no_recurrence $(A, B, C, D, E, F, G, H, b o o l e a n n o):-D>6, A>54$.

is_no_recurrence $(A, B, C, D, E, F, G, b q r i g h t$ upper, $I):-A<=35$.

is_no_recurrence (A, B, C,D,E, F, G,bqleft_lower,booleanno) :- $C>40$.

is_no_recurrence $(A, B, C, D, E, F, G, b q r i g h t$ upper, $I):-A<=51, F>2, A>47$.

is_no_recurrence $(A$, amleq $40, C, D, E, F, G$, bqleft_upper, $I):-D>4, C>13$.

is_no_recurrence ( $A, B, C, D, E, F, G, b q l e f t$ lower, $I):-C<=10$.

is_no_recurrence (A, ampremenopaus, $C, D$, booleanno, $F, G, H$, booleanno) :- $C>28, A>40, A<=46$.

is_no_recurrence $(A, B, C, D, E, F, G, b q$ left_lower, I) :- $A>56, A<=63, C<=30$.

Figura 6.7: Regras Geradas por Foll: Conjunto de Dados Breast e Método Prop, com C2 $=$ no_recurrence

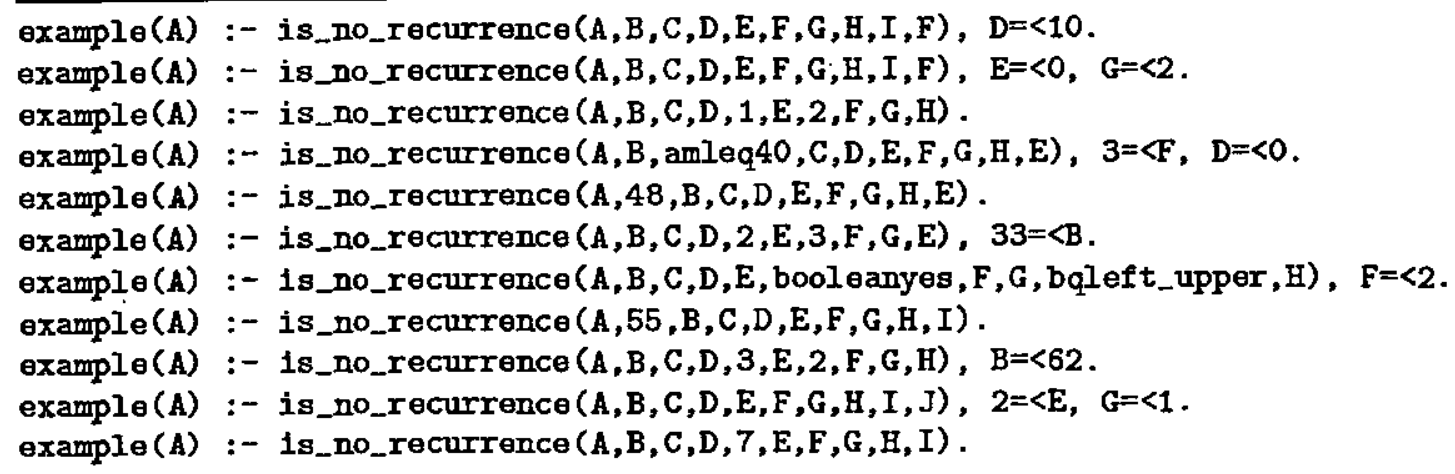

Figura 6.8: Regras Geradas por Progol: Conjunto de Dados Breast e Método Prop, com $\mathrm{C} 2=$ no_recurrence 


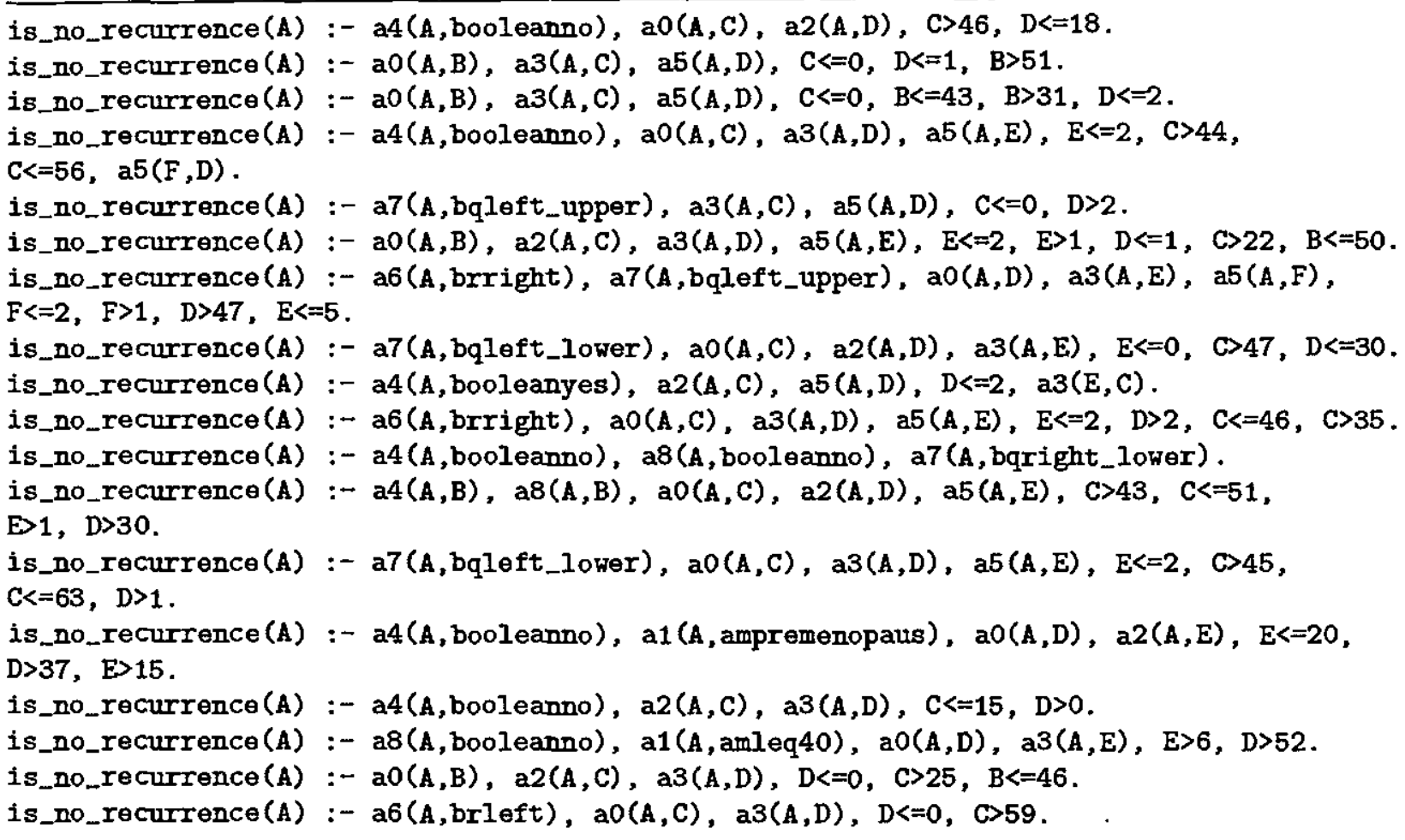

Figura 6.9: Regras Geradas por Foll: Conjunto de Dados Breast e Método MB, com C2 $=$ no.recurrence

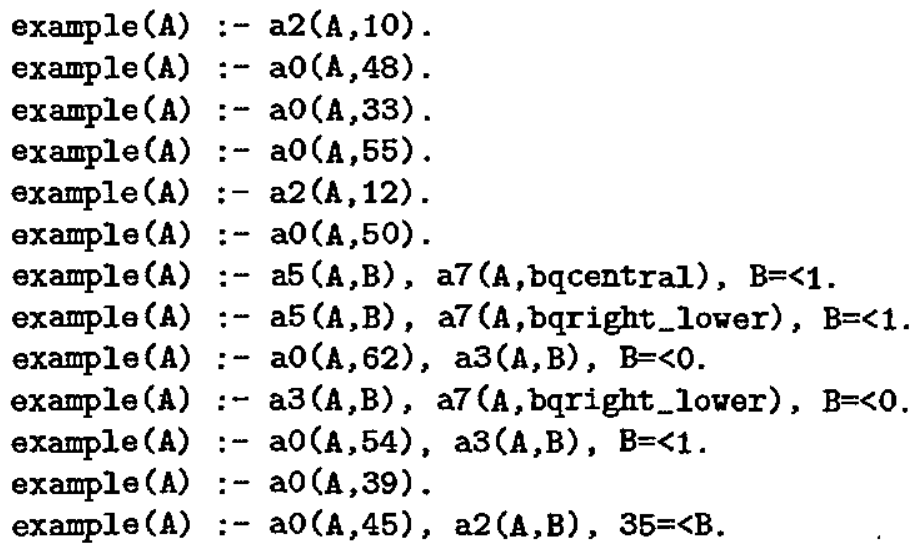

Figura 6.10: Regras Geradas por Progol: Conjunto de Dados Breast e Método MB, com $\mathrm{C} 2$ = no.recurrence 
Com relação ao tempo de execução, deve ser observado que Progol mostrou-se muito lento quando comparado com Foll. Como já mencionado, nestes experimentos Foll foi executado em um computador mais lento que aquele onde foi executado Progol. Ainda assim, o tempo de execução de Progol é, na grande maioria dos casos, muito maior que o tempo de execução de Foll.

A Tabela 6.10 mostra, para todos os conjuntos de dados, o erro total ${ }^{2}$ e o número de cláusulas (com corpo e sem) e regras que participam da hipótese induzida. Com relação ao número médio de cláusulas, pode-se observar que, no caso de FoIL, esse número é sempre maior quando são utilizados os dados no formato MB. O mesmo acontece com o número médio de regras. Porém, isso não se verifica no caso de Progol. Considerando o número médio de cláusulas, algumas vezes esse valor é inferior quando o formato MB é utilizado, por exemplo para o conjunto de dados Hepatitis.

\begin{tabular}{|c|c|c|c|c|c|c|c|}
\hline $\begin{array}{l}\text { Conjunto de } \\
\text { Dados }\end{array}$ & Algoritmo & \multicolumn{2}{|c|}{$F_{P}+F_{N}$} & \multicolumn{2}{|c|}{ \# Cláusulas } & \multicolumn{2}{|c|}{ \# Regras } \\
\hline \multirow[t]{4}{*}{ Bupa } & Foil(C1) & $30.2 \pm 7.4$ & $29.5 \pm 7.8$ & $26.8 \pm 3.4$ & $60.8 \pm 0.8$ & $16.5 \pm 4.3$ & $35.8 \pm 1.2$ \\
\hline & Progol(C1) & $30.7 \pm 4.8$ & $30.9 \pm 5.2$ & $44.3 \pm 3.5$ & $55.5 \pm 7.9$ & $6.4 \pm 3.8$ & $4.4 \pm 8.0$ \\
\hline & & $27.3 \pm 10.3$ & $31.6 \pm 9.8$ & $28.0 \pm 4.2$ & $55.2 \pm 0.2$ & $24.4 \pm 4.2$ & $33.9 \pm 1.2$ \\
\hline & Progol(C2) & $30.0 \pm 8.7$ & $35.8 \pm 6.1$ & $29.3 \pm 2.8$ & $38.2 \pm 3.0$ & $8.3 \pm 3.4$ & $7.3 \pm 3.8$ \\
\hline \multirow[t]{8}{*}{ Pima } & Foil(CI) & $32.4 \pm 5.0$ & $30.0 \pm 3.0$ & $42.8 \pm 6.5$ & $95.3 \pm 3.9$ & $37.0 \pm 8.4$ & $60.3 \pm 4.3$ \\
\hline & Progol(C1) & $30.6 \pm 3.9$ & $32.0 \pm 4.4$ & $92.2 \pm 17.1$ & $119.9 \pm 31.5$ & $24.6 \pm 17.1$ & $22.3 \pm 33.3$ \\
\hline & Foil(C2) & $30.1 \pm 5.8$ & $27.9 \pm 5.8$ & $48.0 \pm 6.3$ & $159.7 \pm 18.7$ & $30.6 \pm 7.4$ & $87.1 \pm 20.1$ \\
\hline & Progol(C2) & $26.4 \pm 5.9$ & $26.1 \pm 6.4$ & $103.2 \pm 4.4$ & $128.7 \pm 2.4$ & $19.6 \pm 4.7$ & $10.3 \pm 3.0$ \\
\hline & Foil(C1) & $30.2 \pm 7.4$ & $29.5 \pm 7.8$ & $26.8 \pm 3.4$ & $60.8 \pm 0.8$ & $16.5 \pm 4.3$ & $35.8 \pm 1.2$ \\
\hline & Progol(C1) & $30.7 \pm 4.8$ & $30.9 \pm 5.2$ & $44.3 \pm 3.5$ & $55.5 \pm 7.9$ & $6.4 \pm 3.8$ & $4.4 \pm 8.0$ \\
\hline & Foil $(C 2)$ & $27.3 \pm 10.3$ & $31.6 \pm 9.8$ & $28.0 \pm 4.2$ & $55.2 \pm 0.2$ & $24.4 \pm 4.2$ & $33.9 \pm 1.2$ \\
\hline & rol(C2) & $30.0 \pm 8.7$ & $35.8 \pm 6.1$ & $29.3 \pm 2.8$ & $38.2 \pm 3.0$ & $8.3 \pm 3.4$ & $7.3 \pm 3.8$ \\
\hline \multirow[t]{4}{*}{ Breast } & Foil(C1) & $19.3 \pm 9.9$ & $22.2 \pm 6.5$ & $20.9 \pm 6.2$ & $44.3 \pm 7.1$ & $13.5 \pm 6.4$ & $26.5 \pm 7.5$ \\
\hline & Progol(C1) & $19.8 \pm 6.9$ & $21.6 \pm 7.4$ & $46.4 \pm 3.8$ & $37.9 \pm 9.6$ & $4.0 \pm 4.3$ & $2.5 \pm 10.3$ \\
\hline & Foil(C2) & $24.8 \pm 9.5$ & $20.1 \pm 6.3$ & $19.5 \pm 1.6$ & $41.9 \pm 0.1$ & $17.1 \pm 4.4$ & $26.6 \pm 0.4$ \\
\hline & Progol(C2) & $28.4 \pm 9.6$ & $25.5 \pm 6.0$ & $45.5 \pm 3.7$ & $44.3 \pm 12.3$ & $13.2 \pm 3.8$ & $4.5 \pm 12.3$ \\
\hline \multirow[t]{4}{*}{ Hungaria } & Foil(C1) & $19.3 \pm \overline{9} .9$ & $22.2 \pm 6.5$ & $20.9 \pm 6.2$ & $44.3 \pm 7.1$ & $13.5 \pm 6.4$ & $26.5 \pm 7.5$ \\
\hline & Progol(C1) & $19.8 \pm 6.9$ & $21.6 \pm 7.4$ & $46.4 \pm 3.8$ & $37.9 \pm 9.6$ & $4.0 \pm 4.3$ & $2.5 \pm 10.3$ \\
\hline & Foil(C2) & $24.8 \pm 9.5$ & $20.1 \pm 6.3$ & $19.5 \pm 1.6$ & $41.9 \pm 0.1$ & $17.1 \pm 4.4$ & $26.6 \pm \quad 0.4$ \\
\hline & Progol(C2) & $28.4 \pm 9.6$ & $25.5 \pm 6.0$ & $45.5 \pm 3.7$ & $44.3 \pm 12.3$ & $13.2 \pm 3.8$ & $4.5 \pm 12.3$ \\
\hline \multirow[t]{4}{*}{ Credit } & Foil(C1) & $19.0 \pm 6.4$ & $14.4 \pm 4.1$ & $21.8 \pm 0.8$ & $52.8 \pm 6.1$ & $19 . \overline{5} \pm 1.0$ & $30.8 \pm 6.4$ \\
\hline & Progol(C1) & $16.7 \pm 5.7$ & $18.5 \pm 4.5$ & $47.0 \pm 2.1$ & $63.6 \pm 22.6$ & $10.1 \pm 2.3$ & $5.0 \pm 22.7$ \\
\hline & Foil(C2) & $20.9 \pm 3.9$ & $15.0 \pm 6.2$ & $23.0 \pm 1.1$ & $62.1 \pm 5.2$ & $20.9 \pm 1.6$ & $35.5 \pm 5.8$ \\
\hline & Progol(C2) & $14.8 \pm 5.2$ & $13.2 \pm 4.6$ & $38.9 \pm 1.2$ & $40.5 \pm 2.6$ & $11.9 \pm 1.5$ & $2.8 \pm 2.6$ \\
\hline \multirow[t]{4}{*}{ Hepatitis } & Foil(C1) & $25.1 \pm 10.5$ & $19.9 \pm 7.4$ & $9.5 \pm 0.5$ & $21.2 \pm 2.3$ & $6.4 \pm 0.7$ & $11.9 \pm 2.5$ \\
\hline & Progol(C1) & $20.4 \pm 10.5$ & $21.1 \pm 9.0$ & $28.8 \pm 1.9$ & $20.1 \pm 1.2$ & $0.0 \pm 1.9$ & $2.4 \pm 1.2$ \\
\hline & Foil(C2) & $23.2 \pm 13.1$ & $23.9 \pm 12.3$ & $9.6 \pm 2.7$ & $14.7 \pm 5.0$ & $8.8 \pm 3.3$ & $9.9 \pm 5.8$ \\
\hline & Progol(C2) & - & $26.3 \pm 8.6$ & - & $15.5 \pm 2.6$ & - & $4.0 \pm 3.4$ \\
\hline
\end{tabular}

Tabela 6.10: Taxas Médias de Erro e Número Médio de Cláusulas e Regras

Com relação ao número médio de regras, Foll também gera um número maior quando os dados estão no formato MB, exceto para o conjunto de dados Hepatitis. Para esse

\footnotetext{
${ }^{2}$ Não foi possível executar Progol (C2) com o conjunto de dados Hepatitis e formato "proposicional", pois Progol entrou em "loop".
} 
conjunto de dados não é possível tirar alguma conclusão, devido ao elevado desvio padrão. Entretanto, isso não acontece com Progol que mostra uma clara tendência a gerar um pequeno número de regras utilizando esse formato. Na realidade, os dados no for mato MB mostram-se mais apropriados para serem usados com PROGOL.

A Tabela 6.11 mostra a diferença em desvios-padrão de Foll para Progol para o método "proposicional" e MB. Ou seja, valores negativos indicam que o erro cometido por Foll é menor que o cometido por Progol, enquanto que valores positivos indicam que o erro cometido por Progol é menor que o cometido por Foll. Como pode ser observado, em nenhum dos casos considerados esse valor é maior que 2 ou menor que -2 . Portanto, nenhum dos sistemas mostrou, para esses conjuntos de dados, um desempenho melhor que o outro com nível de confiança de $95 \%$.

\begin{tabular}{|l|l|r|r|}
\hline \hline Conjunto de & \multirow{2}{*}{ Conceito } & \multicolumn{2}{|c|}{ Erro Total } \\
\cline { 3 - 4 } Dados & Prop & MB \\
\hline Bupa & C1 = um & $-0,3$ & $+0,1$ \\
& C2 = dois & $-0,8$ & $-1,0$ \\
\hline Pima & C1 = zero & $+0,4$ & $-0,5$ \\
& C2 = um & $+0,6$ & $+0,3$ \\
\hline Breast & C1 = recurrence & $-0,1$ & $-0,2$ \\
& C2 = no_recurrence & $-0,3$ & $-0,5$ \\
\hline Hungaria & C1 = presence & $-0,1$ & $+0,1$ \\
& C2 = absence & $-0,4$ & $-0,9$ \\
\hline Credit & C1 = negative & $+0,4$ & $-1,0$ \\
& $\mathrm{C} 2=$ positive & $+1,3$ & $+0,3$ \\
\hline Hepatitis & $\mathrm{C} 1=$ die & $+0,4$ & $-0,1$ \\
& $\mathrm{C} 2=$ live & - & $-0,2$ \\
\hline \hline
\end{tabular}

Tabela 6.11: Diferenças em Desvios-Padrão dos Erros entre FoIL e Progol

\subsection{Considerações Finais}

Neste Capítulo foi analisado o desempenho dos sistemas de PLI FOIL e Progol a partir de seis conjuntos de dados, do tipo atributo-valor, com características diferentes, os quais foram transformados inicialmente para os formatos "proposicional" e MB, fazendo uso das ferramenitas por nós implementadas.

Os resultados mostram que ambos sistemas tem desempenho semelhante quando o erro do classificador por eles gerado é considerado. Com relação ao tipo de conhecimento induzido, é possível concluir, para os conjuntos de dados considerados, que o formato MB é mais apropriado para ser utilizado com PROGOL.

Finalmente, um aspecto que deve ser observado, é o tempo excessivo utilizado por ProGOL, 
Capítulo 6 - Comparação Empírica de Foll e Progol Utilizando Dados no Formato Atributo-Valor

na maioria dos casos, para induzir conhecimento. 


\section{Capítulo 7}

\section{Estudo de Caso com uma Base de Dados sobre Gado Nelore}

\subsection{Considerações Iniciais}

Neste capítulo é descrito um estudo de caso realizado utilizando uma base de dados do Programa de Melhoramento Genético da Raça Nelore - PMGRN. Esta base foi obtida em função de uma parceria entre o PMGRN e o Laboratório de Inteligência Computacional LABIC - da Universidade de São Paulo em São Carlos. Ela é composta de dados sobre os diversos animais bovinos cadastrados no PMGRN, permitindo obter informações sobre pesos e medidas importantes dos animais, além de suas linhagens paterna e materna. Essas linhagens representam relações de parentesco entre os animais que, em princípio, as tornam propícias para a aplicação de Programação Lógica Indutiva.

\subsection{Histórico do PMGRN}

O PMGRN foi criado em junho de 1988, a partir de uma iniciativa conjunta de criadores de gado Nelore e pesquisadores do Departamento de Genética da Faculdade de Medicina DGFM - da USP em Ribeirão Preto. Com o intuito de buscar tecnologias novas que pudessem ser aplicadas na pecuária, foi implantada a metodologia do Modelo Animal para avaliação de touros, matrizes e animais jovens (Lôbo et al., 1998). Esta metodologia permite determinar Diferenças Esperadas nas Progênies - DEPs - de características 
econômicas dos animais como peso e perímetro escrotal, conseguindo assim melhoras no processo de criaçāo desses animais.

O trabalho de campo do PMGRN foi iniciado em 1995 com a coleta de dados em algumas fazendas de criação do gado Nelore. A cada ano mais fazendas são incorporadas ao projeto, atualizando sempre que possível o histórico de todas elas. Atualmente o PMGRN é formado por 88 rebanhos localizados em 11 estados brasileiros com mais de 177.000 animais cadastrados.

A base de dados é composta de uma série de informações contendo, entre outras: registro genealógico do animal, data de nascimento, informações referentes ao pai (ou touro) e māe (ou matriz) do animal, manejo do animal, pesagens, DEPs, etc. Cada informaçāo é representada como um atributo dentro da base de dados, a qual possui mais de 80 atributos cadastrados para cada animal. Assim, se tem um material bastante rico para extrair conhecimento desses dados, com vários atributos relevantes para serem estudados separadamente.

Em 1997, o DGFM iniciou um projeto de pesquisa em parceria com o LABIC da USP - São Carlos para analisar as informações nas bases de dados do PMGRN, a fim de descobrir relações entre essas informações que pudessem auxiliar o trabalho do grupo de pesquisa. Um mestrando do LABIC realizou estudos sobre uma parte dessas bases utilizando Redes Bayesianas, contribuindo para a divulgação de resultados interessantes (Lôbo et al., 1999; da Rocha, 1999).

A partir desses resultados, gerou-se interesse em realizar outros estudos nas bases de dados. Um desses estudos envolve um novo atributo introduzido na base, chamado de MTDNA ou "tipo mitocondrial". Na seção seguinte, mostra-se a motivação da criação desse atributo e o interesse que tornou-o objeto de análise do estudo de caso por nós realizado.

\subsection{Contexto do Problema}

As raças bovinas domesticadas existentes no mundo hoje podem ser divididas, basicamente, em dois grupos ou sub-espécies: os taurinos, conhecidos cientificamente como Bos taurus, e os Zebu, conhecidos como Bos indicus. O segundo grupo é composto de três raças, a Gyr, a Brahma e a Nelore, sendo esta última objeto de pesquisa do PMGRN.

Os taurinos foram trazidos ao continente sul-americano no século XVI, importados da 
Espanha e de Portugal. Os animais Zebu, dentre os quais exemplares da raça Nelore, foram importados da Índia. A população Nelore brasileira é oriunda das importações de 1930 e, notadamente, das de 1960 e 1962. Embora estivessem inclusas algumas fêmeas nos lotes de Zebu importados no País, a maioria dos touros Zebu foram cruzados com fêmeas taurinas "nativas", descendentes dos animais originários da Espanha e de Portugal.

Com esses cruzamentos, ocorreu uma miscigenação das genes das duas sub-espécies, principalmente no núcleo de suas células. A célula animal pode ser dividida, a grosso modo, em duas partes: o núcleo e o citoplasma. Na Figura 7.1, a composição do núcleo é indicada pelos números 6,10 e 11 e o citoplasma é todo o resto da célula. No núcleo, a herança genética se dá por meio do pai e da mãe de um indivíduo. Já a herança citoplásmatica é controlada essencialmente através da expressão de genes contidas na mitocôndria, indicada pelo número 9 na Figura 7.1. Essas genes são herdadas, nos mamíferos, quase que exclusivamente pela linhagem materna. Com isso, um animal pode ter "tipo mitocondrial" Bos taurus ou Bos indicus, de acordo com o conteúdo da mitocôndria de suas células. É interessante observar que, de acordo com experimentos realizados na literatura, somente um terço da população considerada Nelore no País apresenta o tipo mitocondrial Bos indicus (Meirelles et al., 1999).

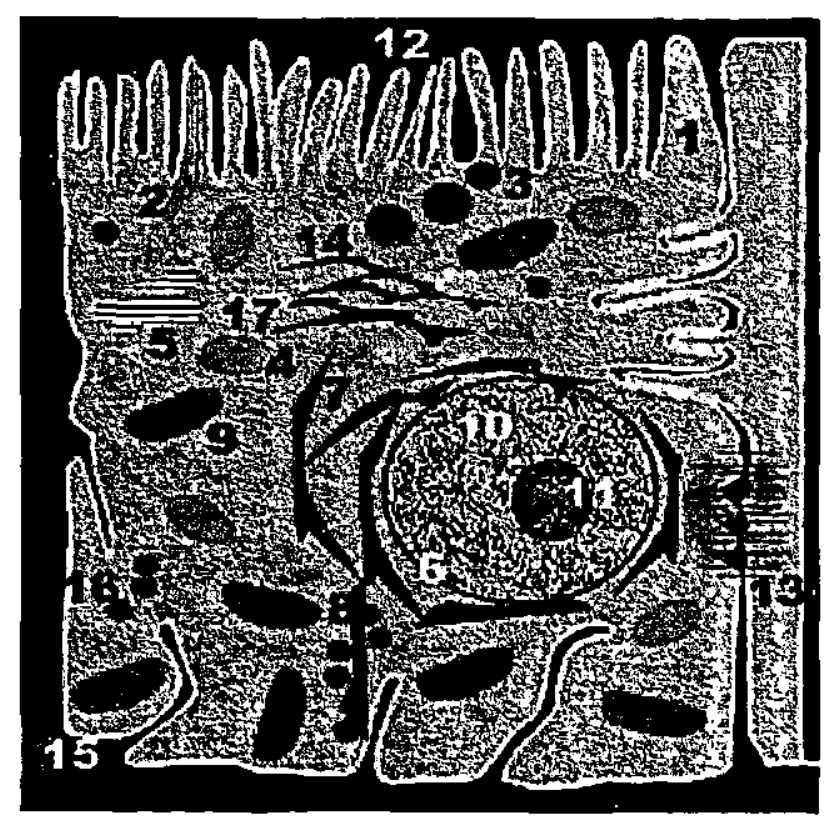

Figura 7.1: Célula Animal 
Já foi demonstrado que características bovinas de produção de carne e de leite variam em diferentes linhagens maternas. Dessa forma, evidencia-se a influência do Bos taurus nos cruzamentos do rebanho brasileiro, o que resultou num maior interesse por parte do PMGRN em pesquisar a influência que o tipo mitocondrial pode ter nas características citadas acima. Para representar o "tipo mitocondrial" criou-se um novo atributo, chamado MTDNA, na base de dados do PMGRN.

A identificação, ou tipagem, do animal é realizada em laboratório através de uma série de testes relativamente custosos, analisando o sêmen dos machos e os leucócitos das fêmeas. Tendo em vista esse custo, foi escolhido um grupo seleto de 212 tourinhos, ou bezerros, advindos de duas fazendas do PMGRN, para formar um grupo inicial de tipagem. A partir desses testes, 179 bezerros foram identificados como Bos taurus e 33 como Bos indicus, informação essa que foi inserida na base de dados.

Com esses dados, e baseando-se na informação fornecida pelo especialista de que o material genético da mitocôndria é totalmente herdado pela linhagem materna, é possível descobrir o tipo mitocondrial de vários animais e gerações dentro da base do PMGRN. O tipo de uma matriz pode ser conhecido através de um dos bezerros tipados em laboratório, ou o tipo de um animal pode ser conhecido desde que na sua árvore genealógica haja uma matriz em comum na árvore genealógica de algum dos bezerros já tipados. Para tanto, é necessário também conhecer a matriz dos animais cadastrados. Analisando os 177.379 registros de animais da base de dados, constatou-se que 32.753 não possuem essa informação, de modo que foram eliminados da base a ser tratada. Assim, restou um total de 144.626 registros de animais para os quais existe a possibilidade de deduzir seu tipo.

Para ampliar o número de animais com tipo conhecido, sem recorrer aos testes em laboratório, foi por nós implementado um programa, chamado de Tipagem, na linguagem de programação lógica Prolog (Bratko, 1990; Malpas, 1987). Nesse programa, a informação obtida a partir dos 212 bezerros tipados em laboratório é propagada através das linhagens maternas dos outros 144.414 registros de animais. Como resultado dessa computação foi possivel tipar 3.299 novos animais, os quais, junto com os 212 bezerros tipados em laboratório, totalizam uma base de 3.511 registros de animais tipados. Desses 3.511 animais, 1.404 foram tipados como Bos indicus e 2.107 como Bos taurus. Essa base compöe o subconjunto inicial de dados utilizado nesse estudo de caso.

A seguir é apresentado o processo genérico de aquisição de conhecimento baseado em dados, o qual serviu como base para a realização do estudo. 


\subsection{Processo para Aquisição de Conhecimento}

Um processo de aquisição de conhecimento pode ser dividido em quatro passos básicos, ilustrados na Figura 7.2. Esse processo se baseia no processo de Descoberta de Conhecimento em Bases de Dados, ou processo KDD, descrito em (Fayyad, 1996).

1. Definiçāo do problema;

2. Coleta, preparação e limpeza dos dados;

3. Aquisição de conhecimento e

4. Análise dos resultados.

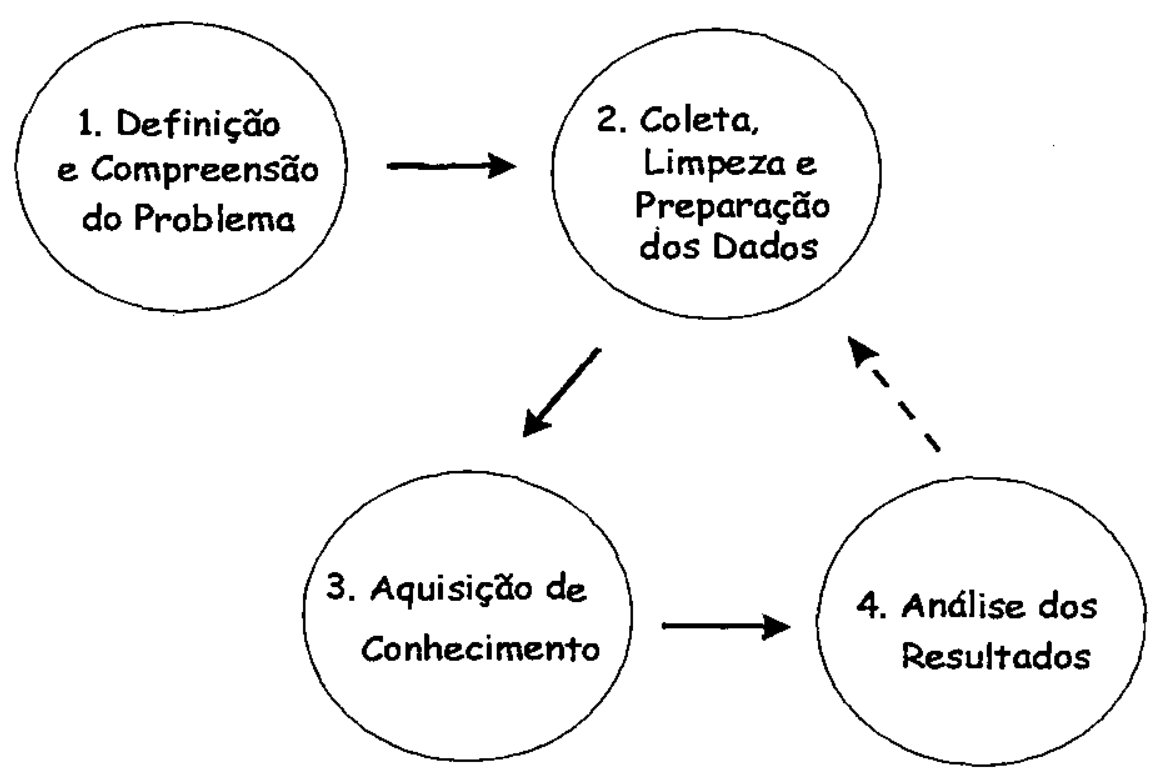

Figura 7.2: Passos do Processo de Aquisição de Conhecimento

O processo se inicia com a definição do problema (passo 1) em entrevista com o especialista do domínio, buscando compreender melhor o domínio do problema a ser tratado. A partir das infor mações fornecidas pelo especialista, os dados são coletados, limpados e preparados (passo 2) de modo que possam ser fornecidos a um sistema de aprendizado. Em seguida, os dados são apresentados a um ou mais sistemas de aprendizado de modo a realizar a aquisição de conhecimento propriamente dita (passo 3). O resultado dessa aquisição é um 
conhecimento que deve ser analisado em conjunto com o especialista (passo 4). Se a análise mostrar que os resultados não foram satisfatórios, geralmente retoma-se o processo a partir do passo 2. Pode ser que seja necessário realizar esse ciclo várias vezes até que se obtenha um conhecimento que seja de proveito para o especialista.

\subsubsection{Definição do Problema}

Em conversas com o Prof. Raysildo Lôbo, coordenador do PMGRN, e o analista de sistemas Luiz Bezerra, responsável pela administração de toda a base de dados do PMGRN, foi levantada a possibilidade da influência do tipo mitocondrial na Diferença Esperada na Progênie - DEP - para efeito materno aos 120 dias, ou DMPP120. Essa DEP prediz a diferença esperada em peso dos produtos, ou filhotes, das filhas do animal avaliado, devido às diferenças na habilidade maternal apresentadas por elas. Sendo assim, decidiuse por representar dois problemas para serem analisados: um problema de verificar se existe a influência do tipo mitocondrial na DMPP120, e um outro problema relacionado à influência que a DMPP120 possa ter no tipo mitocondrial. Em ambos os casos, consideramse informações sobre o animal e de seus progenitores.

\subsubsection{Coleta, Limpeza e Preparação dos Dados}

A base de dados inicial para este estudo de caso, como já mencionado, possui 3.511 animais tipados e mais de 80 atributos. Entre esses registros há casos onde um atributo possui um valor inválido e outros onde ele não possui um valor, isto é, o valor é desconhecido. Para manter a base completa, esses registros foram eliminados. Assim, foram retirados da base em torno de 400 registros que possuíam MGT com o valor inválido -9.99 , utilizado pelos analistas do PMGRN para indicar que não foi possível calcular alguma das DEPs para um determinado animal. Foram removidos ainda alguns registros para os quais o pai não estava registrado no atributo G_PAI (valor desconhecido). Com isso, a base de dados inicial foi reduzida a um total de 3.079 registros.

Também foram selecionados alguns atributos considerados mais relevantes. Tendo por base as indicaçōes dos especialistas, foram selecionados os seguintes atributos: G_ANIM, G_PAI, G_MAE, SX, MGT, DMPP120 e MTDNA. Esses atributos são descritos na Tabela 7.1, mostrando os valores possíveis e encontrados, tanto para a base de dados inicial de 3.511 animais quanto para a base de dados reduzida de 3.079 animais. 


\begin{tabular}{|c|c|c|c|c|c|c|}
\hline & & & \multicolumn{4}{|c|}{ \#Valores Distintos } \\
\hline \multirow{2}{*}{$\begin{array}{l}\text { Nome do } \\
\text { Atributo }\end{array}$} & \multirow{2}{*}{$\begin{array}{l}\text { Descriçäo } \\
\text { do Atributo }\end{array}$} & \multirow{2}{*}{$\begin{array}{l}\text { Tipo } \\
\text { do Atributo }\end{array}$} & \multicolumn{2}{|c|}{$\overline{\mathrm{B}} \mathrm{D}$ Inicial } & \multicolumn{2}{|c|}{ BD Reduzida } \\
\hline & & & possiveis & encontr. & possiveis & encontr. \\
\hline G_ANIM & Código do animal & discreto & 3511 & 3511 & 3079 & $\mathbf{3 0 7 9}$ \\
\hline G_PAI & Código do pai do animal & discreto & 393 & 394 & 362 & 362 \\
\hline G.MAE & Código da māe do animal & discreto & 1140 & 1140 & 1125 & 1125 \\
\hline $\mathbf{S X}$ & $\begin{array}{l}\text { Sexo: } 0 \text { - indefinido (morto ao nascer), } \\
1 \text { - macho, } 2 \text { - femea }\end{array}$ & discreto & 3 & 4 & 3 & 2 \\
\hline MGT & $\begin{array}{l}\text { Mérito Genético Total do animal: soma } \\
\text { ponderada das DEPs mais importantes }\end{array}$ & contínuo & - & 262 & - & 261 \\
\hline DMPP120 & DEP para efeito materno aos 120 dias & contínuo & - & 482 & - & 482 \\
\hline MTDNA & $\begin{array}{l}\text { Tipo Mitocondrial: i - Bos indicus, } \\
t \text { - Bos taurus }\end{array}$ & discreto & 2 & 2 & 2 & 2 \\
\hline
\end{tabular}

Tabela 7.1: Base de Dados Inicial e Reduzida: Descrição dos Atributos Considerados

Com esta base de dados reduzida, torna-se possível extrair conhecimento utilizando algum algoritmo de aprendizado de máquina proposicional e outro relacional, e analisar, em igualdade de condições, o conhecimento induzido por ambos os algoritmos. Considerando as indicaçōes dos especialistas, foram analisados dois atributos da Tabela 7.1 pará serem utilizados como classe:

1. MTDNA, ou Tipo Mitocondrial, e

2. DMPP120, ou DEP de Efeito Materno aos.120 dias.

No primeiro caso, o atributo MTDNA, que pode assumir somente dois valores (i e t), é considerado como atributo-classe. No segundo caso, o atributo considerado, DMPP120, é contínuo e necessita ser discretizado. Seguindo as indicações dos especialistas, esse atributo, quando utilizado como classe, pode separar os casos em aqueles com valor DMPP120 >0 (classe maioq0) e DMPP120 $\leq 0$ (classe menoq0). Assim, tem-se dois problemas diferentes, um quando o tipo mitocondrial é utilizado para classificar os dados, o qual é denominado TipoMT, e o outro quando a DEP do efeito materno é utilizado para esse fim, o qual é denominado de EfMat, como descrito na Tabela 7.2.

\begin{tabular}{|c|c|c|c|c|c|c|c|}
\hline $\begin{array}{l}\text { Conjunto } \\
\text { de Dados }\end{array}$ & \#Instâncias & $\begin{array}{l}\text { \#Duplicados ou } \\
\text { Conflitantes (\%) }\end{array}$ & $\begin{array}{l}\text { \#Atributos } \\
\text { (cont.,discr.) }\end{array}$ & Classe & $\%$ Classe & $\begin{array}{c}\text { Erro } \\
\text { Majoritário }\end{array}$ & $\begin{array}{c}\text { Valores } \\
\text { Desconhecidos }\end{array}$ \\
\hline TipoMt & 3.079 & $0(0 \%)$ & $6(2,4)$ & $\begin{array}{l}\mathrm{i} \\
\mathrm{t}\end{array}$ & $\begin{array}{l}39,79 \% \\
60.21 \% \\
\end{array}$ & $\begin{array}{c}39,79 \% \\
\text { em t } \\
\end{array}$ & Não \\
\hline EfMat & 3.079 & $0(0 \%)$ & $6(1,5)$ & $\begin{array}{l}\text { menoq0 } \\
\text { maioq0 }\end{array}$ & $\begin{array}{l}35,08 \% \\
64,92 \%\end{array}$ & $\begin{array}{c}35,08 \% \\
\text { em maioq0 }\end{array}$ & Nâo \\
\hline
\end{tabular}

Tabela 7.2: Características do Conjunto de Dados para os Dois Problemas Tratados 
Nessa tabela, descreve-se o número de instâncias, ou registros, consideradas em cada problema, e quantas são duplicadas ou conflitantes. Além disso, mostra-se quantos dos atributos utilizados são contínuos e quantos são discretos. Para o problema TipoMt, são dois atributos contínuos, pois o DMPP120 é considerado como contínuo quando o atributo MTDNA é utilizado como classe. No problema EfMat há apenas um atributo contínuo, o MGT, pois o atributo DMPP120 está discretizado e é considerado como classe.

\subsubsection{Aquisição de Conhecimento}

Tendo definido os dados a serem utilizados nos dois problemas, necessita-se delimitar os experimentos a serem realizados com sistemas de aprendizado de modo a extrair conhecimento desses dados. Com relação aos sistemas de aprendizado, decidiu-se utilizar um sistema proposicional e outro relacional, a fim de mostrar as limitações de aprendizado relacional utilizando estes dados. Especificamente foram utilizados os seguintes sistemas nos dois conjuntos de dados da Tabela 7.2:

1. o sistema de aprendizado proposicional See5 (Rulequest-Research, 1999), e

2. o sistema de Programação Lógica Indutiva Progol (Muggleton, 1995).

Com relação ao sistema $\mathrm{PrOGOL}$, decidiu-se realizar dois tipos de experimentos utilizando cada conjunto de dados. No primeiro experimento, denominado experimento P1, ProgoL é utilizado em ambos conjuntos de dados sem inserir informação adicional como conhecimento de fundo. Ou seja, somente os dados correspondentes a cada um dos dois conjuntos de dados são fornecidos ao Progol.

No segundo experimento, denominado experimento P2, além do conhecimento de fundo utilizado no experimento $\mathrm{P} 1$, decidiu-se fornecer ao Progol conhecimento de fundo extra, na forma intensional. Especificamente, o conhecimento de fundo extra consiste das seguintes duas relações:

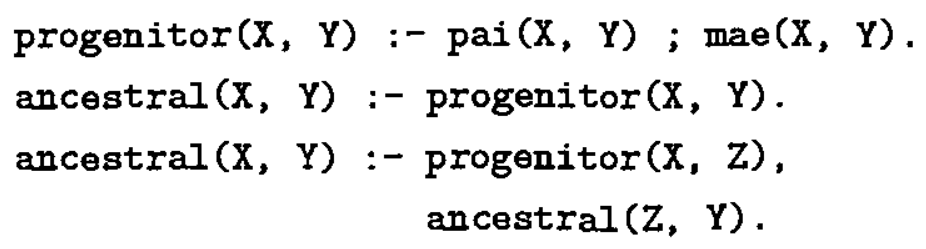


A introdução desse conhecimento de fundo extra tem como objetivo verificar se PROGOL consegue induzir relações não somente com os progenitores do animal, como no experimento P1, mas também considerando outros ancestrais.

\subsection{Experimentos Realizados e Resultados}

Nesta seção são melhor detalhados cada um dos experimentos realizados e os resultados obtidos utilizando os dois conjuntos de dados da Tabela 7.2.

\subsubsection{See5}

Como já mencionado, decidiu-se utilizar como sistema de aprendizado proposicional o $\mathcal{S}$ ee5, pois consideramos que é um dos melhores sistemas para induzir regras de decisão. $\mathrm{Na}$ realidade, $\mathcal{S}$ ee5 é um produto comercial que inclui melhorias dos algoritmos $\mathcal{C} 4.5$ e C4.5-rules (Quinlan, 1993), os quais induzem árvores e regras de decisão, respectivamente (Baranauskas e Monard, 2000b).

Primeiramente, os conjuntos de dados. TipoMt e EfMat - Tabela 7.2 - armazenados no Microsoft Access ${ }^{T M}$ foram transformados para o formato requerido por See5. Isto é realizado diretamente via um comando disponível no Microsoft Access ${ }^{T M}$. See5 foi executado, obtendo um conjunto de regras de conhecimento para cada experimento, aos quais denominamos:

1. TipoMt_See5 para o conjunto de dados TipoMt, e

2. EfMat_See5 para o conjunto de dados EfMat.

A Tabela 7.3 mostra os resultados desses experimentos, onde o erro aparente refere-se ao erro obtido utilizando todos os 3.079 exemplos como conjunto de treinamento e conjunto de teste. O erro verdadeiro refere-se ao erro obtido através de 10 -fold cross validation. $O$ \# de regras refere-se ao número de regras induzidas utilizando todos 3.079 exemplos e o tempo de execução (tempo de CPU) refere-se ao tempo utilizado para executar o experimento em um microcomputador Pentium II de $300 \mathrm{MHz}$, com o sistema operacional Windows $\mathrm{NT}^{T M}$. É interessante observar que no experimento TipoMt_See5, no qual a classe é a tipagem do animal, See5 induziu uma regra para cada uma das 1.125 matrizes na base de dados, 


\begin{tabular}{||c|r|r|r|r|}
\hline Experimento & $\begin{array}{r}\text { Erro } \\
\text { Aparente (\%) }\end{array}$ & $\begin{array}{r}\text { Erro (10 CV) } \\
\text { Verdadeiro (\%) }\end{array}$ & $\begin{array}{r}\text { \# de } \\
\text { Regras }\end{array}$ & $\begin{array}{r}\text { Tempo de } \\
\text { Execuçāo }\end{array}$ \\
\hline \hline TjpoMt_See5 & 0,0 & $4,5 \pm 0,5$ & 1.125 & 4,3 seg. \\
\hline EfMat_See5 & 10,3 & $16,6 \pm 0,6$ & 220 & 2,5 seg. \\
\hline
\end{tabular}

Tabela 7.3: Resumo dos Resultados Obtidos com See5

onde cada regra induzida consiste somente de um antecedente, que é a matriz. A Figura 7.3 mostra o número de progênie gerada pelas matrizes mais produtivas enquanto na Figura 7.4 são mostradas algumas regras geradas por See5. Por exemplo, a primeira regra na Figura 7.4, Rule 1, simplesmente especifica que

$$
\text { Se G_MAE }=56402 \text { então class }=i
$$

com um fator de confiança de 0.960 cobrindo 23 exemplos, que são os 23 exemplos referentes à progênie gerada por essa matriz, como mostra a Figura 7.3. Em outras palavras, See5 descobriu o óbvio, que a tipagem da matriz determina a tipagem do animal por ela gerado.

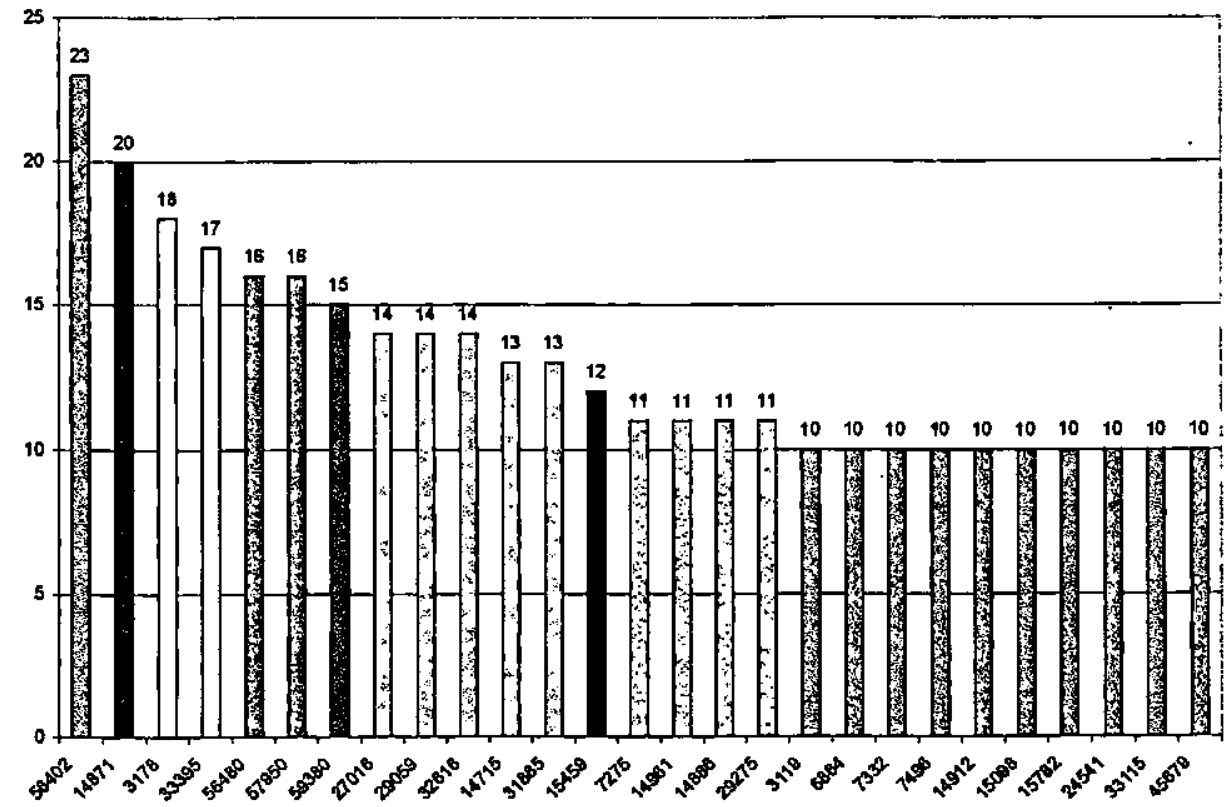

Figura 7.3: Quantidade de Progênie Gerada pelas Matrizes Mais Produtivas

No experimento EfMat_See5, no qual a classe está relacionada com o efeito materno aos 120 dias, foram geradas 220 regras, cinco vezes menos que no experimento anterior, com um erro verdadeiro aproximadamente quatro vezes maior - Tabela 7.3. Ainda assim, o erro verdadeiro, $16,6 \pm 0,6$, é bem menor que o erro majoritário de 35,08\% —- Tabela 7.2. 


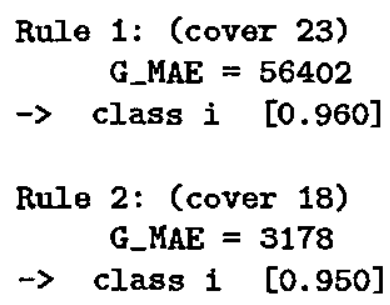

Figura 7.4: Algumas Regras Geradas no Experimento TipoMt_See5

A Tabela 7.4 mostra os atributos considerados nas regras induzidas por See5, bem como o número de regras onde esses atributos aparecem no antecedente das regras. Como pode ser observado, a mãe do animal é considerada irrelevante para classificar esses animais nas classes menoq0 e maioq0. Analisando as 220 regras induzidas por $\mathcal{S}$ ee 5 foi possível observar que:

- Em todas as regras induzidas, o atributo G_PAI aparece, exceto na seguinte regra

$$
\begin{aligned}
& \text { Rule 120: (cover 374) } \\
& \text { MGT }<=-0.34 \\
& \rightarrow \text { class menoq0 [0.665] }
\end{aligned}
$$

\begin{tabular}{|c|c|c|c|c|c|c|}
\hline \multicolumn{4}{|c|}{ Atributo Presente na Regra } & \multirow{2}{*}{$\begin{array}{r}\text { Número de } \\
\text { Regras }\end{array}$} & \multicolumn{2}{|c|}{ Regras por Classe } \\
\hline G.PAI & SX & MGT & MTDNA & & menog 0 & maioq0 \\
\hline$\cdot$ & & & & $\begin{array}{r}168 \\
2\end{array}$ & $\begin{array}{r}104 \\
1\end{array}$ & $\begin{array}{r}64 \\
1\end{array}$ \\
\hline$\bullet$ & & - & & 44 & 29 & 15 \\
\hline - & $\bullet$ & & & 2 & I & 1 \\
\hline$\bullet$ & - & $?$ & $\bullet$ & 1 & $\overline{1}$ & 1 \\
\hline$\bullet$ & & - & •• & 1 & 1 & _. \\
\hline - & - & - & - & 1 & 1 & - \\
\hline & Nún & ro Tota & de Regras & 220 & 138 & 82 \\
\hline
\end{tabular}

Deve ser observado que ainda que o fator de confiança dessa regra não seja muito alto, 0.665 , ela cobre 374 animais.

Tabela 7.4: EfMat_See5 - Quantidade de Regras por Classe e Atributos Considerados nessas Regras

- Existem 107 touros cuja progênie é toda da classe menoq0 e 64 cuja progênie é toda da classe maioq0, independentemente de outros fatores. Como exemplo dessas regras, são mostradas na Figura 7.5 duas da classe menoq0. 
Rule 1: (cover 70)

G_PAI $=2993$

$\rightarrow$ class menoqo [0.972]
Rule 2: (cover 22)

G_PAI $=7434$

$\rightarrow$ class menoqo [0.958]

Figura 7.5: Alguns Touros que Determinam a Classe menoq0 na Sua Progênie

Elas estabelecem que toda a progênie do G_PAI = 2993 e G_PAI = 7434 são da classe menoq0, como pode ser confirmado considerando o número total de progênie desses dois animais na Figura 7.6.

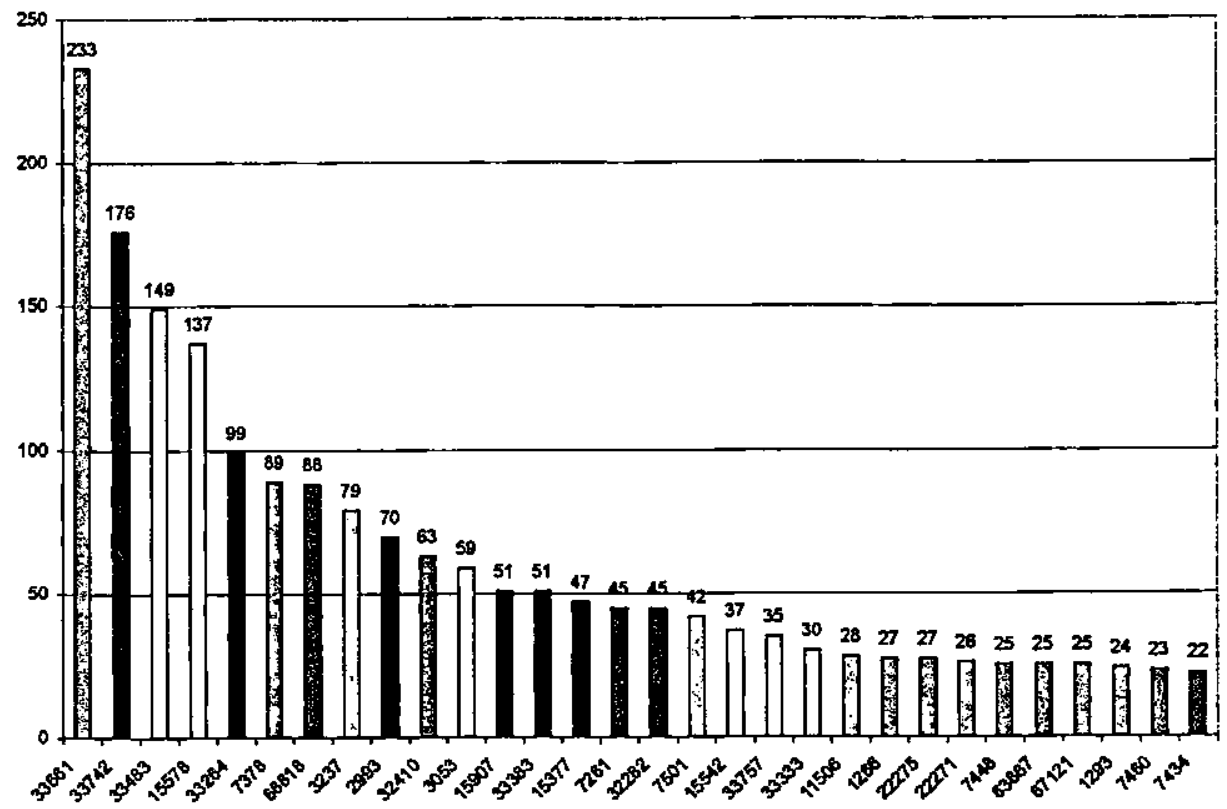

Figura 7.6: Quantidade de Progênie Gerada pelos Touros Mais Produtivos

Entretanto, a base de dados por nós considerada neste estudo de caso consiste de 3.079 registros de animais. Ou seja, menos de $2 \%$ da base de dados completa do PMGRN que tem 177.379 registros. Por exemplo, para esse dois touros, na base de dados completa do PMGRN tem-se o número total de progênie mostrado na Tabela 7.5. Pode ser observado que nessa base, a cobertura para a classe menoq0 não é de $100 \%$ para esses dois animais, mas cobre mais de $90 \%$ em ambos os casos.

Os melhores reprodutores são aqueles que somente geram animais da classe maioq0 e See5 induziu 64 regras para touros diferentes, independentemente de outros fatores. A Figura 7.7 mostra regras que identificam alguns desses animais, pois cobrem toda a progênie deles, como pode ser verificado através da Figura 7.6. O número total de 
proposicional e aquele obtido com um sistema de aprendizado relacional. Nas próximas seçōes são descritos os dois experimentos realizados utiliżando Progol.

\subsubsection{Transformação dos Dados de $\mathcal{S}$ ee5 para ProgoL}

Primeiramente, os dados utilizados com See5 devem ser transformados para o formato requerido por Progol. Deve ser ressaltado que os arquivos de definição de tipos e de dados de $\mathcal{S}$ ee5 são praticamente os mesmos que os utilizados por $\mathcal{C} 4.5$, de modo que os dados podem ser convertidos para os arquivos de Progol fazendo-se uso das ferramentas de conversão por nós implementadas e descritas no Capítulo 5. Colocando os dados no formato MB, a extração de regras pode ser realizada utilizando Progol. Primeiramente, os conjuntos de dados TipoMt e EfMat (Tabela 7.2), no formato requerido por See5, foram transformados para o formato MB através das ferramentas de conversão, obtendo assim os dados para realizar o experimento $\mathrm{P} 1$. Segundo o método utilizado nas ferramentas de conversão, para cada atributo é criado um predicado. Como nos dois problemas tratados há seis atributos sendo considerados, são criados seis nomes de predicado de a0 até a5, todos de aridade 2. Em todos esses predicados, o primeiro argumento representa um número (\#id) que identifica o exemplo considerado. Como segundo argumento de cada predicado é utilizado o valor de cada um dos atributos correspondentes. A Tabela 7.7 descreve esses predicados para os dois conjuntos de dados considerados.

\begin{tabular}{|l|l|}
\hline TipoMt & EfMat \\
\hline \hline a0(\#id, <G_ANIM> & a0(\#id, <G_ANIM> \\
a1(\#id, <G_PAI $>$ & a1(\#id, <G_PAI > \\
a2(\#id, <G_MAE> & a2(\#id, <G_MAE > \\
a3(\#id, <SX> & a3(\#id, <SX> \\
aA(\#id, <DMPP120> & aA(\#id, <MTDNA> \\
a5(\#id, <MGT> & a5(\#id, <MGT> \\
\hline
\end{tabular}

Tabela 7.7: Predicados Criados pelo Método $\mathrm{MB}$ e os Atributos Correspondentes para Cada Problema

Para realizar o experimento P2, como já mencionado, foi adicionado ao conhecimento de fundo do experimento $P 1$ somente as relações progenitor $/ 2$ e ancestral/2 definidas na Seção 7.4.3, página 90. Progol foi executado, obtendo um conjunto de regras de conhecimento para os dois experimentos aos quais denominamos

1. TipoMt_Progol_X, para o conjunto de dados TipoMt e

2. EfMat_Progol_X, para o conjunto de dados EfMat 
onde $\mathrm{X}=\mathrm{P} 1$ indica o experimento $\mathrm{P} 1$ e $\mathrm{X}=\mathrm{P} 2$ indica o experimento P2. Cada experimento foi executado duas vezes: primeiro considerando os exemplos da classe majoritária como classe positiva e a classe minoritária como classe negativa. Em seguida, a classe minoritária foi apresentada como classe positiva e a classe majoritária como classe negativa. Dessa forma, se tem uma noção mais precisa da classificação como um todo, pois PrOGOL encontra regras para apenas uma das classes.

Os resultados desses experimentos são descritos nas próximas seçōes, onde os erros aparente e verdadeiro foram obtidos para cada uma das execuçōes através do utilitário test/1 do Progol. O tempo de execução (tempo de CPU) refere-se ao tempo, em segundos, utilizado para executar o experimento num microcomputador Pentium II de $300 \mathrm{MHz}$, rodando o sistema operacional Linux.

\subsubsection{Progol - Experimento P1}

A Tabela 7.8 mostra os resultados do experimento P1. Deve ser observado que o número de regras e tempo de execuçāo, dado em segundos, se referem aos valores obtidos executando PROGOL com todos os dados disponíveis.

\begin{tabular}{|l|l|r|r|r|r||}
\hline Experimento & $\begin{array}{l}\text { Classe } \\
\text { Positjva }\end{array}$ & $\begin{array}{r}\text { Erro } \\
\text { Aparente (\%) }\end{array}$ & $\begin{array}{r}\text { Erro } \\
\text { Verdadeiro (\%) }\end{array}$ & $\begin{array}{r}\text { No. de } \\
\text { Regras }\end{array}$ & $\begin{array}{r}\text { Tempo } \\
\text { de Execução }\end{array}$ \\
\hline \hline TipoMt_ProGoL & t & 17,2 & $42,3 \pm 1,3$ & 238 & $134131.49 \mathrm{~s}$ \\
\hline TipoMt_PROGoL & $\mathrm{i}$ & 8,1 & $24,3 \pm 1,1$ & 171 & $45824.00 \mathrm{~s}$ \\
\hline EfMat_ProGOL & maioq0 & 17,9 & $27,8 \pm 1,1$ & 69 & $24919.23 \mathrm{~s}$ \\
\hline EfMat_ProGoL & menoq0 & 15,8 & $23,0 \pm 1,1$ & 65 & $39817.47 \mathrm{~s}$ \\
\hline
\end{tabular}

Tabela 7.8: Resumo dos Resultados Obtidos com Progol sem Conhecimento de Fundo Adicional

Para cada cláusula encontrada por Progol, quatro medidas são calculadas:

- $p$ - o número de exemplos positivos cobertos pela cláusula

- $n$ - o número de exemplos negativos cobertos pela cláusula e

- $h$ - o número de átomos necessários para completar a cláusula. Esse número é calculado inspecionando as variáveis de saída da cláusula e determinando se já foram definidas. Por exemplo, para um predicado $s(A, B)$ com declaração de modo $\operatorname{modeh}(1, s$ (+tipo_a, -tipo_b)), $h$ seria 3 , se fossem necessários, no mínimo, três átomos no corpo de uma cláusula para ligar A a B. Nos experimentos realizados, a relação a ser aprendida é de aridade 1, portanto o valor de $h$ é sempre 0 . 
- $f$ - uma medida do poder preditivo e da compressão da cláusula dada pela equação 7.1

$$
f=P(p-(n+c+h)) / p
$$

onde $c$ é o comprimento da cláusula, $P$ é o número total de exemplos positivos e $p$, $n$ e $h$ são os mesmos números calculados anteriormente.

Com essas medidas, Progol escolhe a cláusula a ser retornada como sendo aquela que tem o maior valor para $f$, desde que a sua cobertura de exemplos negativos não seja maior que a permitida pelo parâmetro noise, definido como $20 \%$. Se houver mais de uma cláusula com o maior valor, é retornada a primeira que for encontrada.

O experimento TipoMt_Progol utilizando como classe positiva t, foi o mais demorado consumindo mais de 37 horas de tempo de CPU. Este experimento mostra um caso típico de "não aprendizado", considerando o excessivo número de regras induzidas, 238, quando todos os dados disponíveis foram utilizados, e o erro verdadeiro de $42,3 \pm 1,3$. Esse erro é maior que o erro majoritário de $39,79 \%$ - Tabela 7.2, página 89 .

O experimento TipoMt_Progol utilizando como classe positiva i, também gera um número grande de regras, ainda que o erro verdadeiro é inferior ao erro majoritário. Entretanto, analisando as regras geradas, a grande maioria delas, exatamente 168, identifica os exemplos positivos simplesmente utilizando o identificador da mãe do animal, analogamente a $\mathcal{S}$ ee5. As outras três regras geradas são descritas a seguir, onde, para um melhor entendimento, foi utilizada a correspondência indicada com os nomes dos atributos originais descritos na Tabela 7.7.

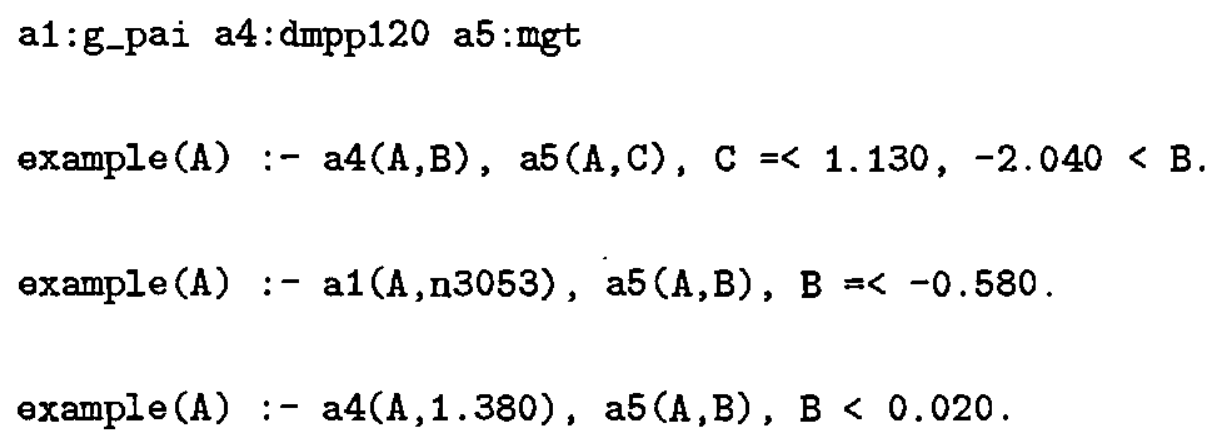

A primeira regra cobre 9 exemplos positivos e dois negativos, a segunda cobre 8 exemplos positivos e nenhum negativo enquanto que a terceira cobre 16 exemplos positivos e um negativo. 
O experimento EfMat_Progol utilizando como classe positiva maioq0, gerou um número bem menor de regras, 69, com erro verdadeiro menor que o erro majoritário. Entretanto, a grande maioria das regras também identifica os exemplos positivos utilizando somente o identificador da mãe ou do pai do animal. Segue uma descrição de algumas das outras regras geradas nas quais participam outros atributos, e que merecem maior atenção.

a3: sexo a5:mgt

example(A) :- a3 $(A, \operatorname{sexo} 2), a 5(A, B), 0.300=<B$.

example (A) :- a3 (A, sexo1), a5 (A,B), $0.910=<B$.

A primeira regra cobre 610 exemplos positivos e 126 negativos enquanto que a segunda cobre 66 exemplos positivos e 4 negativos. A primeira regra diz que o animal é da classe maioq0 se é uma vaca (sexo2) e seu mgt é maior ou igual a 0.300 . A segunda regra diz que o animal é da classe maioq0 se é um touro (sexo1) e seu mgt é maior ou igual a 0.910 .

O experimento EfMat_Progol utilizando como classe positiva menoq0, gerou o menor número de regras com o menor número de regras com o menor erro verdadeiro neste experimento P1. Analogamente ao experimento anterior, a grande maioria das regras identifica os exemplos positivos utilizando somente o identificador da mãe ou do pai $\vec{r}$ animal. Outras regras geradas são descritas a seguir.

a1:pai a3:sexo a5:mgt

example (A) :- a3 $(A$, sexo2), $a 5(A, B), B=<-0.600$.

example(A) :- a1 $(A, n 33661), a 5(A, B), B=<0.620$.

\subsubsection{PRogol - Experimento P2}

Nesse experimento P2, como já foi mencionado, acrescentou-se o conceito ancestral ao conhecimento de fundo, definido em função de um predicado progenitor e de si mesmo. Com isso, Progol poderia, eventualmente, incluir este conceito no corpo das cláusulas por ele descobertas. Entretanto, esse não foi o caso. Após uma análise cuidadosa, foi possível 
observar que o problema para Progol considerar o conhecimento de fundo ancestral/2, deve-se ao fato de ter o número do identificador do exemplo, gerado pela ferramenta de conversão do formato de dados para o formato MB. A fim de facilitar a tarefa de PrOGOL para utilizar ese novo conhecimento de fundo, seria melhor utilizar a identificação única de cada animal na base, suprimindo a identificação de cada exemplo. Esta nova experiência já foi iniciada como trabalho futuro.

\subsection{Considerações Finais}

Deve ser observado que o tempo de execução, como esperado, é muito maior nos experimentos realizados com Progol que naqueles feitos com $S$ ee5, o que pode ser explicado pelo tamanho do espaço de busca sendo considerado. Este é um dos problemas ainda não resolvidos pelos sistemas de aprendizado de máquina relacional.

Uma possível solução é utilizar um número mais limitado de exemplos de treinamento, e refinar o conhecimento obtido passo a passo, generalizando e especializando as relações induzidas automaticamente pelos sistemas relacionais. 


\section{Capítulo 8}

\section{Conclusões}

Aprendizado de Máquina - AM - objetiva desenvolver ferramentas, métodos e técnicas para construir máquinas inteligentes que tenham a capacidade de aprender e se modificar de modo a realizar cada vez melhor suas tarefas. Dentre as várias formas de AM está o aprendizado indutivo, foco deste trabalho.

Um problema de indução pode ser formulado como uma tarefa de aprendizado de conceitos a partir de dados, ou aprendizado indutivo de conceitos, onde regras de classificação para um determinado conceito devem ser induzidas a partir de instâncias positivas e/ou negativas do mesmo.

Para a expressão de qualquer paradigma de aprendizado indutivo sã் necessárias, no mínimo, linguagens para descrever objetos, ou exemplos, assim como linguagens para descrever os conceitos aprendidos. Vários formalismos lógicos têm sido utilizados em sistemas de aprendizado indutivo para a representação de exemplos e conceitos. Dois tipos de descrição, a baseada em atributos ou proposicional e a descrição relacional, são em geral utilizadas.

Em AM proposicional linguagens de descrição baseada em atributos tem sido aplicadas em um número razoável de domínios com relativo sucesso. No entanto, são limitados pelo fato de não conseguirem aprender relações intrínsecas aos dados. Entretanto, essas relaçōes podem ser aprendidas quando uma linguagem de descrição relacional, como por exemplo uma linguagem baseada em lógica de primeira ordem, é adotada. A adoção dessa linguagem viabiliza o aprendizado de um conjunto muito maior de conceitos. Programação Lógica Indutiva - PLI - é uma abordagem de AM indutivo que utiliza uma linguagem de descrição 
de conceitos baseada em lógica de primeira ordem. Através da incorporação de teoria do domínio, busca contornar algumas das limitações de sistemas de AM proposicionais. No entanto, ela possui problemas relacionados à busca no espaço de hipóteses, uma vez que este é muito maior que no caso proposicional.

Esses problemas podem ser contornados impondo restriçōes às linguagens de descrição utilizadas no sistema. Para isso, são utilizadas técnicas de PLI, como generalização e especialização, para procurar por cláusulas na linguagem de hipóteses que sejam consistentes com os exemplos de treinamento. Para reduzir a busca, o espaço de cláusulas é estruturado por uma relação de generalidade entre cláusulas, chamada de relação $\theta-s u b s o m a$.

Atualmente existem muitos sistemas de Programação Lógica Indutiva disponíveis, para serem pesquisados e aproveitados, em projetos tanto do meio acadêmico quanto para fins comerciais. Existem diversas aplicações, com variados níveis de sucesso, espalhadas por inúmeras áreas. Em função dessas aplicações, há também interesse em avaliar os sistemas em conjuntos de dados naturais.

Em princípio qualquer problema que possa ser aprendido com AM proposicional pode ser aprendido com AM relacional também. Para tanto, é necessário ter um processo para converter os dados em formato atributo-valor para o formato relacional. Neste trabalho, através das ferramentas por nós implementadas, obtém-se representações que podem ser utilizadas por sistemas de PLI, e de aprendizado relacional em geral. Com essas representaçōes, torna-se possível comparar o desempenho de sistemas de aprendizado relacional utilizando dados no formato atributo-valor.

Neste trabalho foram apresentados diversos experimentos realizados com os sistemas de PLI FoIl e Progol em bases de dados naturais. As ferramentas de conversão foram utilizadas para transformar as bases de dados em dois formatos que podem ser utilizados pelos sistemas de aprendizado relacional: um consistindo em uma representação quase direta do formato atributo-valor, e um outro que representa efetivamente o formato relacional, chamado formato MB.

Os resultados desses experimentos mostram a viabilidade de usar esses formatos para aprendizado em bases de dados no formato atributo-valor, independente de qual dos dois sistemas é utilizado. As ferramentas de conversão devem ser inseridas futuramente em um ambiente computacional para realizar aquisição automática de conhecimento, o qual está sendo desenvolvido no Laboratório de Inteligência Computacional - LABIC. 
Como estudo de caso foi utilizada um subconjunto de uma base de dados obtida junto ao Programa de Melhoramento Genético da Raça Nelore - PMGRN - do Departamento de Genética da Faculdade de Medicina - DGFM - da USP em Ribeirão Preto. Esse subconjunto consiste em animais para os quais foi possível determinar seu tipo mitocondrial. Esse tipo, herdado geneticamente pelas mitocôndrias das células do animal, provavelmente influencia características bovinas de produção de carne e de leite. Procurou-se explorar a utilização das ferramentas de conversão para tentar descobrir novos conhecimentos na base, além de incluir conhecimento de fundo na forma intensional. A partir dos resultados foi verificada a necessidade de incluir outros conhecimentos para que se possa descobrir novos conhecimentos nessa base. Trabalhos futuros nesse sentido serão desenvolvidos.

Na comunidade de AM, existe uma discussão sobre a possibilidade de integrar os sistemas de PLI com o processo KDD (Fürnkranz e Pfahringer, 1998; Lavrač, 1999), no qual o processo de aquisição de conhecimento mostrado no estudo de caso se baseia. No entanto, em função dos tempos de execução obtidos nos experimentos, parece ser necessário mais pesquisa no sentido de tornar os sistemas mais rápidos, principalmente para lidar com grandes quantidades de dados de forma eficaz.

Como sugestões de trabalhos futuros, pretende-se usar PLI para extrair conhecimento de outras bases. Obtendo esse conhecimento, pretende-se refiná-lo e melhorá-lo através do istema de RLI MOBAL. Além disso, pretende-se estudar a possibilidade de desenvolver utras ferramentas para conversão de dados para outros sistemas de PLI. 


\section{Apêndice A}

\section{FOIL}

Foll é um programa que foi criado pelo Prof. J. Ross Quinlan da Universidade de New South Wales na Austrália. O programa lề especificações extensionais de um conjunto de relações e produz cláusulas de Horn que definem uma ou mais dessas relações. O formato de seu arquivo de entrada e os vários parâmetros configuráveis que possui são mostrados a seguir.

\section{A.1 Arquivo de Entrada}

A entrada do programa Foll consiste de três seções:

- a especificação de tipos

- definições extensionais de relações

- casos de teste para as definições aprendidas \{opcional\}

Existem três tipos discretos de dados:

1. tipos ordenados (nome do tipo é precedido por '*') As constantes têm uma ordem natural e aparecem em ordem crescente na definiçäo do tipo. 
2. tipos não-ordenados (nome do tipo é precedido por '\#')

As constantes não têm uma ordem natural.

3. tipos possivelmente ordenados

O sistema tenta descobrir uma ordenação para as constantes, a qual pode ser útil em definições recursivas.

Cada especificaçāo de tipo contínuo consiste do nome do tipo seguido por : continuous . em uma única linha. Constantes correspondentes a um tipo contínuo são números inteiros e reais.

Toda relação é definida em termos do conjunto de tuplas positivas de constantes para as quais a relação é verdadeira, e opcionalmente o conjunto de tuplas negativas de constantes para as quais a relação é falsa. Se somente tuplas positivas são dadas, todas as outras tuplas de constantes com os tipos corretos são consideradas negativas.

Cada relação é definida por um cabeçalho e um ou dois conjuntos de tuplas de constantes. O cabeçalho pode ser definido como segue:

nome(tipo, tipo, ..., tipo) chave/chave $/ \ldots$ /chave

Os cabeçalhos de todas as relações além das relações metas começam com '*'. Um cabeçalho consiste do nome da relação, tipos de argumento e chaves opcionais. Chaves limitam as maneiras que a relação pode ser usada e consistem de um caracter para cada tipo. O caracter '\#' indica que o argumento correspondente num literal deve ser limitado (bound); o caracter '-' indica que o argumento pode ou não ser limitado (bound ou unbound). Dessa forma, cada chave mostra as formas permitidas de acessar a relação. Se não houver chaves, todas as combinações possíveis (bound ou unbound) de argumentos são permitidas.

Depois da linha de cabeçalho vem uma série de linhas de tuplas de constantes:

tupla positiva

tupla positiva

$\cdots$

tupla negativa | parte é

tupla negativa | opcional 
Cada tupla consiste de constantes, separadas por vírgulas, e deve estar em uma única linha. O caracter ';' separa as tuplas positivas das tuplas negativas, as quais são opcionais.

\section{A.2 Parâmetros Configuráveis}

Foll possui diversos parâmetros que podem ser setados através de opções na linha de comando. Essas opçōes, junto com seus significado, são descritas a seguir:

-n Literais negativos não são considerados. Isto pode ser útil em domínios nos quais literais negados não fazem sentido, ou se as definições aprendidas devem ser cláusulas de Horn.

$-N$ Semelhante a ' $n$ ', mas permite literais de igualdade negados como 'A $\neq B$ ' e 'A $\neq$ constante'.

-vverb Indica o nível de verbosidade $(0,1,2,3$ ou 4). O programa produz uma saída para rastreamento um tanto quanto volumosa, a qual pode ser controlada através desta variável. $O$ valor 1 produz uma quantidade boa de detalhe; o valor 0 produz uma saída bem pequena; o valor 3 mostra passo-a-passo o que o sistema está fazendo; e o valor 4 dá detalhes sobre as tuplas nos conjuntos de treinamento, etc. $O$ default é 1 .

-Vvars Indica o número máximo de variáveis que podem ser utilizadas durante a busca por uma definição. O default é 52 .

-sfrac No caso de alguns predicados de aridade alta, assumir o mundo fechado pode gerar muitas tuplas negativas. Esta opçāo faz com que somente uma porcentagem das tuplas negativas, aleatoriamente selecionadas, seja utilizada. Deve ser observado que esta opção não tem efeito se as tuplas negativas são declaradas explicitamente.

-mmaxt Indica o número máximo de tuplas. Se o valor default resultar em avisos que liter ais estão sendo excluídos em função do limite de tuplas, expandir esse limite pode ser útil (mas o tempo de execução também vai aumentar). O default é 100000.

-ddepth Indica a profundidade máxima das variáveis. Isso limita a profundidade possível das variáveis nos literais. O default é 4 . 
-wwklts Limita o número máximo de literais "fracos" (com zero ganho) que podem aparecer em sequência. Um grupo de literais determinados conta como um literal nesse caso. O default é 4 .

-aaccur Impõe uma precisão mínima para qualquer cláusula. FoIL não aceita uma cláusula que tenha precisão menor que isto. O default é $80 \%$.

-lalter Indica o número máximo de alternativas para um literal qualquer. Isto limita o quanto o sistema retrocede num momento qualquer. O default é 5 .

-tchkpt Indica o número máximo de "checkpoints" possíveis num determinado momento. $O$ default é 20 .

-fgain Qualquer literal alternativo deve ter no mínimo um ganho de gain\% em relação ao melhor ganho de um literal. O default é $80 \%$.

-gmax Literais determinados são inclúdos automaticamente, a menos que haja um literal que tenha pelo menos max\% do máximo ganho possível. O máximo ganho possível é alcançado por um literal que é satisfeito por todas as tuplas positivas, e por nenhuma tupla negativa, no conjunto corrente de treinamento. Obviamente que se max é zero, nenhum literal determinado é inclú́do a menos que não haja outros literais.

O sistema Foll também fornece um programa escrito em $\mathrm{C}$ chamado c45_to_foil. Esse programa, utilizado no desenvolvimento deste trabalho, permite converter arquivos do formato utilizado por C4.5 para aquele utilizado por FOIL. 


\section{Apêndice B}

\section{PROGOL}

Progol foi criado pelo grupo de Aprendizado de Máquina da Universidade de Oxford como um interpretador de Prolog contendo capacidades indutivas. Cláusulas de Horn sem cabeça são usadas para representar exemplos negativos e restrições. Progol constrói cláusulas novas através da generalização dos exemplos na base de dados Prolog, utilizando um algoritmo de implicação inversa. De acordo com a teoria de ILP a busca realizada no espaço de generalizaçōes é admissível, garantindo que os exemplos possam ser inferidos com um conjunto de cláusulas que tenhá compressão máxima.

A seguir são mostrados o formato do arquivo de entrada do PROGOL, além de vários parâmetros que podem ser configurados dentro de seu ambiente e os comandos que ele possui.

\section{B.1 Arquivo de Entrada}

O arquivo de entrada para o Progol tem uma extensão '.pl', e pode ser descrito da seguinte forma:

- declarações de modo para os predicados, além dos tipos dos argumentos de cada um

- (linha em branco)

- listagem dos valores permitidos para cada tipo

- (linha em branco) 
- descrição intensional de conhecimento prévio do domínio

- (linha em branco)

- definições extensionais de relações

- (linha em branco)

Casos de teste para as definiçōes aprendidas devem ser colocados em um arquivo opcional, também com extensão '.pl'.

\section{B.2 Declarações de Modo}

Declarações de modo restringem a forma como predicados aparecem na cabeça e corpo das regras geradas (gerais). Por exemplo:

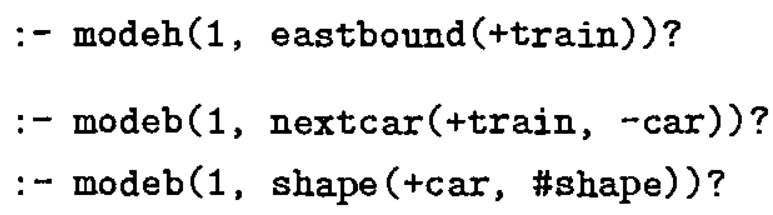

modeh indica qual predicado irá compor a cabeça das regras. No exemplo considerado, modeh informa que a cabeça das regras terá a forma eastbound $(X)$, 'onde $X$ é do tipo train. $O$ símbolo + que aparece antes do tipo indica que a posição de $X$ deve ser ocupada por uma variável. Assim a cabeça pode ter a forma eastbound(A), mas não a forma eastbound (train1). Para que Progol encontre cabeças da última forma, deve-se colocar uma \#, antes do tipo, na declaração de modo. Outra possibilidade é colocar um símbolo - na frente do tipo do argumento indicando que aquele argumento deve ser considerado como uma variável de entrada.

Há ainda outra restrição que pode ser colocada: o número de instanciações alternativas que um predicado pode ter. Indica-se que o número é desconhecido através de um asterisco $\left(^{*}\right)$, no lugar do primeiro argumento da declaração de modo. 


\section{B.3 Parâmetros Configuráveis}

Existem vários parâmetros do sistema que podem ser setados para controlar a maneira como Progol realiza o trabalho de indução. Alguns parâmetros podem receber valores inteiros. Esses estão marcados abaixo com (N) e são setados com o predicado do sistema set(Parameter, Value)?. Os outros parâmetros recebem como valor ou ON ou OFF. Eles podem ser "ligados" ou "desligados" através dos predicados de sistema set(Parameter)? e unset(Parameter)?. Os valores de todos os parâmetros configuráveis podem ser examinados com o comando settings?. Cada um deles é descrito a seguir.

c (N) seta o comprimento máximo do corpo das regras construídas por ProGol. Ou seja, se possui mais átomos do que o número estipulado por c, ignora-se a cláusula em questão. O default é 4 .

h (N) Progol aplica a regra de inferência de resolução para construir uma cláusula mais específica a partir de um exemplo. Com o parâmetro $h$, limita-se o número de aplicações dessa regra para derivar a cláusula mais específica. O default é 30.

i (N) Além de h, outra restrição que pode ser imposta às regras geradas é quanto à profundidade de suas variáveis. A profundidade $p(v)$ de uma variável $v$ em uma cláusula $C$ é definida como na eq. B.1

$$
\mathrm{p}(\mathrm{v})=\left\{\begin{array}{l}
0, \text { se } v \text { está na cabeça de } C \\
\left(\min _{u \in U_{v}} p(u)\right)+1, \text { caso contrário }
\end{array}\right.
$$

onde $U_{v}$ são as variáveis nos átomos do corpo de $C$ que contêm $v$.

Considere a seguinte cláusula:

eastbound (A):- nextcar(A, B), shape (B, C).

Nesta cláusula, a variável A tem profundidade 0, B tem profundidade 1 e $\mathrm{C}$ tem profundidade 2 . O default é 3 .

condition (ON/OFF) Este parâmetro é usado para aprender quando somente há dados positivos. Quando setado para ON, ProGol constrói a distribuição de probabilidade a partir dos exemplos. Quando setado para OFF, assume-se que os exemplos foram tirados de uma distribuição uniforme. O default é OFF. 
cover (ON/OFF) Se estiver em ON Progol utiliza busca por cobertura o que é essencial para aprender cláusulas recursivas. Quando em OFF a busca é feita por implicação, o que costuma ser mais rápido, embora deve ser observado que cláusulas recursivas não podem ser aprendidas. $O$ default é $\mathbf{O N}$.

inflate (N) Progol busca entre as combinações de predicados da cláusula mais específica aquela que, numa regra geral, irá comprimir melhor os dados, ou seja, que reduzirá mais o número de predicados. Nessa busca, um peso é dado aos dados ou aos predicados na regra geral. Este peso é conhecido como inflate e é expresso como uma porcentagem. Por exemplo, se Progol estivesse construindo uma regra a partir de 3 exemplos com inflate setado em $100 \%$, não se preocuparia em aprender uma regra de comprimento 3 pois isto não comprimiria os dados para uma forma menor. Agora, se estivesse setado em 101\%, Progol aprenderia uma regra dessas, pois os dados teria "tamanho" 3.03. O default é $100 \%$.

memoing (ON/OFF) Na busca por uma regra geral, Progol constrói várias combinações e calcula várias estatísticas para cada combinação. Em alguns momentos, o sistema pode precisar considerar uma mesma regra mais de uma vez. Obviamente, a busca será mais rápida se as estatísticas puderem ser lembradas. Isto pode ser facilitado setando memoing para $\mathrm{ON}$, mas deve ser lembrado que essa opção consome mais memória. $\mathrm{O}$ default é $\mathrm{ON}$.

nodes (N) O sistema pára de procurar por uma regra geral depois de ter realizada a busca em $N$ combinações sem sucesso. O default é 10000 .

noise (N) Em alguns casos, é interessante permitir que as regras encontradas não sejam perfeitas. Ou seja, permitir que as regras classifiquem ou predigam uma porcentagem dos exemplos negativos. Esta porcentagem pode ser setada com noise. O default é 0 .

posonly (ON/OFF) Quando setado em ON, ProGol pode aprender com exemplos positivos somente. $O$ default é OFF.

reductive (ON/OFF) A forma das regras geradas pode ser restringida através deste parâmetro. Quando setado para ON, os termos no corpo da regra aprendida devem ser menos complexos que os que estão na cabeça, sendo a complexidade do termo determinada pelo número de subtermos que ele contém. O default é OFF. 
searching (ON/OFF) É possível mudar o comportamento do ! com este parâmetro. Em geral o ! constrói a cláusula mais específica. No entanto, quando o parâmetro searching estiver setado para $\mathrm{ON}$, o ! tem o mesmo efeito que o comando generalise. O default é OFF.

verbose (N) Seta a quantidade de informação que ProGol oferece como saída; os valores de verbose são 0,1 e 2 . $O$ valor 0 quer dizer praticamente nenhuma saída, somente a resposta em si. O valor 2 também passa informaçōes, tais como estatísticas sobre o tempo de execução e outras. O default é 2 .

\section{B.4 Comandos Disponíveis}

Progol também possui facilidades e predicados de sistema, os quais estão listados a seguir:

\begin{tabular}{|c|c|c|c|}
\hline$=.$. & $=$ & advise/I & any $/ 1$ \\
\hline $\arg / 3$ & asserta/1 & bagof/3 & chisq $/ 4$ \\
\hline clause $/ 2$ & clause $/ 3$ & commutative/1 & commutatives \\
\hline constant/I & consult/1 & determination $/ 2$ & edit $/ 1$ \\
\hline element/2 & fixedseed & float/1 & functor $/ 3$ \\
\hline generalise/1 & help & help/1 & hypothesis/3 \\
\hline int $/ 1$ & is $/ 2$ & label/1 & label/2 \\
\hline leave/1 & length $/ 2$ & listing & listing/1 \\
\hline modeb $/ 2$ & $\operatorname{modeh} / 2$ & modes & name/2 \\
\hline nat/1 (arg no. natural) & nl & normal/3 & nospy \\
\hline not $/ 1$ & notrace & number $/ 1$ & op $/ 3$ \\
\hline ops & otherwise & quit & randomseed \\
\hline readI/1 (lê até Ctrl-Z) & $\mathrm{read} / 1$ & $\mathrm{read} / 2$ & record $/ 2$ (uso com bagof) \\
\hline reconsult/1 & reduce/1 & repeat & retract $/ 1$ \\
\hline sample/3 & set/1 (valor ON/OFF) & see/1 & seen \\
\hline set/2 (valor numérico) & setof $/ 3$ & settings & size (tam. em bytes) \\
\hline sort $/ 2$ & spies & spy $/ 1$ & stats \\
\hline $\mathrm{tab} / 1$ & uniform /3 ( $\mathrm{X}$ de distr. unif.) & tell $/ 1$ & told \\
\hline true & unset/1 (oposto set/1) & trace & $\operatorname{var} / 1$ \\
\hline
\end{tabular}




\section{Bibliografia}

Baranauskas, J. A. e Monard, M. C. (2000a). An Unified Overview of Six Supervised Symbolic Machine Learning Inducers. Technical Report 103, ICMC-USP. ftp://ftp.icmc.sc.usp.br/pub/BIBLIOTECA/rel_tec/Rt_.103.ps.zip.

Baranauskas, J. A. e Monard, M. C. (2000b). Reviewing some Machine Learning Concepts and Methods. Technical Report 102, ICMC - USP, São Carlos, SP. ftp://ftp.icmc.sc.usp.br/pub/BIBLIOTECA/rel_tec/Rt_.102.ps.

Batista, G. E. A. P. A. (1997). Um Ambiente de Avaliação de Algoritmos de Aprendizado de Máquina utilizando Exemplos. Master's thesis, ICMC-USP. Dissertação de mestrado.

Bergadano, F. e Gunetti, D. (1995). Inductive Logic Programming: From Machine Learning to Software Engineering. The MIT Press.

Blake, C., Keogh, E., e Merz, C. J. (1998). UCI Repository of Machine Learning Datasets. University of California, Department of Information and Computer Science, Irvine, CA. http://www.ics.uci.edu/ mlearn/MLRepository.html.

Boswell, T. (1990). Manual for CN2 version 4.1. The Turing Institute, TI/P2154/RAB/4/1.3 edition.

Bratko, I. (1990). Prolog Programming for Artificial Intelligence. Addison Wesley.

Buntine, W. (1988). Generalised Subsumption and Its Applications to Induction and Redundancy. Artificial Intelligence, 36(2):149-176.

Cameron-Jones, R. M. e Quinlan, J. R. (1993). First Order Learning, Zeroth Order Data. Technical Report 468, The University of Sydney. $15 \mathrm{pg}$.

Carbonell, J. G. (1989): Introduction: Paradigms for Machine Learning. Artificial Intelligence, $40(1-3): 1-9$. 
Caulkins, C. W. e Monard, M. C. (2000a). Comparação Empírica de Sistemas de Aprendizado de Máquina Relacional. Technical report, ICMC-USP. in print.

Caulkins, C. W. e Monard, M. C. (2000b). Ferramentas para Conversão de Dados de Entrada dos Algoritmos de Aprendizado de M Aprendizado de Máquina Relacional Foil e Progol. Technical Report 116, ICMC-USP.

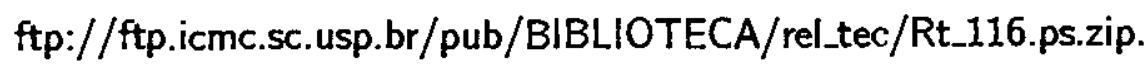

Cestnik, B., Kononenko, I., e Bratko, I. (1987). ASSISTANT 86: A Knowledge Elicitation Tool for Sophisticated Users. In Bratko, I. e Lavrač, N., editores, Progress in Machine Learning, páginas 31-45, Wilmslow, UK. Sigma Press.

Clark, P. e Boswell, R. (1991). Rule Induction with $\mathcal{C N} 2$ : Some Recent Improvements. In Kodratoff, Y., editor, Proceedings of the 5th European Conference (EWSL 91), páginas 151-163. Springer Verlag.

Clark, P. e Niblett, T. (1989). The CN2 Induction Algorithm. Machine Learning, 9(1):5794.

da Rocha, C. A. J. (1999). Redes Bayesianas para Extração de Conhecimento de Bases de Dados, Considerando a Incorporação de Conhecimento de Fundo e o Tratamento de Dados Incompletos. Master's thesis, ICMC-USP. Dissertação de Mestrado.

De Raedt, L. (1992). Interactive Theory Revision: An Inductive Logic Programming Approach. Academic Press, London, UK.

Džeroski, S. (1996). Inductive Logic Programming and Knowledge Discovery in Databases. In Fayyad, U., Piatetsky-Shapiro, G., Smyth, P., e Uthurusamy, R., editores, Advances in Knowledge Discovery and Data Mining, páginas 117-152, Cambridge, Massachusetts. The MIT Press.

Džeroski, S. e Bratko, I. (1992). Handling Noise in Inductive Logic Programming. In Proceedings of the Second International Workshop on Inductive Logic Programming, Tokyo. ICOT.

Džeroski, S., Todorovski, L., e Urbančic, T. (1995). Handling Real Numbers in ILP: a Step Towards Successful Behavioral Cloning. In Proceedings of the Eighth European Conference on Machine Learning, páginas 283-286, Berlin. Springer Verlag: 
Fayyad, U. M. (1996). Data Mining and Knowledge Discovery: Making Sense Out of Data. IEEE Expert, páginas 20-25.

Fürnkranz, J. e Pfahringer, B. (1998). Guest Editorial: First-Order Knowledge Discovery in Databases. Applied Artificial Intelligence, 12:345-361.

Lavrač, N. (1999). Challenges for Inductive Logic Programming. In Barahona, P. e Alferes, J. J., editores, Proceedings of the 9th Portuguese Conference on Artificial IntelligenceEPIA '99, páginas 16-33, Berlin. Springer Verlag. LNCS (LNAI) 1695.

Lavrač, N. e Džeroski, S. (1994). Inductive Logic Programming: Techniques and Applications. Ellis Horwood.

Lavrač, N., Džeroski, S., Pirnat, V., e Križman, V. (1993). The Utility of Background Knowledge in Learning Medical Diagnostic Rules. Applied Artificial Intelligence, $7: 273-293$.

Lloyd, J. (1987). Foundations of Logic Programming. Springer Verlag.

Lôbo, R. B., Bezerra, L. A. F., e de Oliveira, H. N. (1999). Avaliação Genética de Animais Jovens, Touros e Matrizes. GEMAC - Departamento de Gen Preto.

Lôbo, R. B., Bezerra, L. A. F., de Oliveira, H. N., e Reyes, A. (1998). Avaliação Genética de Animais Jovens, Touros e Matrizes, Sumário - 1998. PMGRN - FINEP, Ribeirão Preto, SP.

Malpas, J. (1987). ProLog - A Relational Language and its Applications. Prentice Hall.

Meirelles, F. V., Rosa, A. J. M., Lôbo, R. B., Garcia, J. M., Smith, L. C., e Duarte, F. A. M. (1999). Is the American Zebu Really Bos Indicus? Genetics and Molecular Biology, 22(4):543-546.

Michalski, R. S. (1980). Pattern Recognition as Rule-Guided Inductive Inference. IEEE Transactions on Pattern Analysis and Machine Intelligence, 2:349-361.

Michalski, R. S. (1983). A Theory and Methodology of Inductive Learning. In Michalski, R. S: ;Carbonell $;:$ J. G., e Mitchell, T. M., editores, Machine Learning: An Artificial Intelliğence Approach, volume I, páginas 83-184, Palo Alto, CA. Tioga.

Mitchell, T. M. (1982). Generalization as Search. Artificial Intelligence, 18(2):203-226. 
Monard, M. C., Caulkins, C. W., Baranauskas, J. A., Oliveira, R. B. T., e Rezende, S. O. (1998). Data Preparation, Reduction and Prediction in the Context of Data Mining: a Case Study with Insurance Policies. Technical Report 81, ICMC - USP, São Carlos, SP. ftp://ftp.icmc.sc.usp.br/pub/BIBLIOTECA/rel_tec/Rt_81.ps.zip.

Mooney, R. (1996). Inductive Logic Programming for Natural Language Processing. In Muggleton, S. H., editor, Proceedings of the Sixth International Workshop on Inductive Logic Programming, Stockholm, Sweden. Springer Verlag.

Morik, K. (1993). Balanced Cooperative modeling. Machine Learning, 11(2-3):217-236.

Morik, K. e Brockhausen, P. (1997). A Multistrategy Approach to Relational Knowledge Discovery in Databases. Machine Learning, 27:287-312.

Morik, K., Wrobel, S., Kietz, J.-U., e Emde, W. (1993). Knowledge Acquisition and Machine Learning. Academic Press.

Muggleton, S. (1995). Inverse Entailment and Progol. New Generation Computing, 13:245286.

Muggleton, S. (1997). Learning from Positive Data. In Proceedings of the Sixth International Workshop on Inductive Logic Programming, volume LNAI 1314. Springer Verlag.

Muggleton, S. e Firth, J. (1999). CProgol4.4: a tutorial introduction. University of York MLG Group. ftp://ftp.cs.york.ac.uk/pub/ML_GROUP/progol4.4/.

Muggleton, S. e Raedt, L. D. (1994). Inductive Logic Programming. The Journal of Logic Programming, 19-20:629-679.

Muggleton, S. H. (1991). Inductive Logic Programming. New Generation Computing, $8: 295-318$.

Muggleton, S. H. e Buntine, W. (1988). Machine Invention of First-Order Predicates by Inverting Resolution. In Proceedings of the Fifth International Conference on Machine Learning, páginas 339-352, San Mateo, California. Morgan Kaufmann Publishers.

Muggleton, S. H. e Feng, C. (1990). Efficient Induction of Logic Progtams.J In Proceedings of the First Conference on Algorithmic Learning Theory, páginas .368-381, . Tokyo. Ohmsha. 
Muggleton, S. H., King, R. D., e Sternberg, M. J. (1992). Protein Secondary Structure Prediction Using Logic-Based Machine Learning. Protein Engineering, 5:646-657.

Nicoletti, M. C. (1994):-Ampliando os Limites do Aprendizado Indutivo de Máquina através das Abordagens Construtiva Relacional. PhD thesis, IFQSC-USP. Disserta

Nicoletti, M. C: e.Monard, M. C. (1994). Learning Restricted Horn Clauses: Some Considerations on the ij-Determination Concept. Technical Report 009, Notas do ICMSC-USP, Série Compuțação. 16 pg.

Nicoletti, M. C. e Monard, M. C. (1995a). Constructing the Extensional Representation of an. Intepsional Domain Theory in Inductive Logic Programming. In Wainer, J. e Carvalho, A., editores, Advances in Artificial Intelligence, SBIA '95, páginas 171-180. Springer Verlag. Lecture Notes in Artificial Intelligence 991. is

Nicoletti, M. C. e Monard, M. C. (1995b). Inducing Logic Programs with the Learning System GOLEM. In Proceedings II International Congress and Exposition in Informatics, páginas 395-411.

Pazzani, M., Brunk, C., e Silverstein, G. (1991). A Knowledge-Intensive Approach to Learning Relational Concepts. In Proceedings of the Eighth International Workshop on Machine Learning, páginas 432-436, San Francisco. Morgan Kaufmann Publishers.

Pazzani, M. e Kibler, D. (1991). The Utility of Knowledge in Inductive Learning. Machine Learning, 8:295-318.

Plotkin, G. D. (1970). A Note on Inductive Generalization. In Meltzer, B. e Michie, D., editores, Machine Intelligence, volume 5, páginas 153-163. Edinburgh University Press.

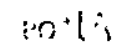

Plotkin, G. D. (1971). A Further Note on Inductive Generalization. In Meltzer, B. e Michie, D., editores, Machine Intelligence, volume 6, New York. Elsevier.

Pompe, U. e Kononenko, I. (1998). Effective Induction and Effective Use of First-Order s. Knowledge. Applied Artificial Intelligence, 12:421-453.

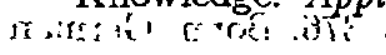

Quinlan, J. R. (1986). Induction of Decision Trees. Machine Learning, 1:81-106.

Quitilan, Jir R:s(1990)..:Jearning Logical Definitions from Relations. Machine Learning, $5(3): 239-266$. 
Quinlan, J. R. (1993). C4.5 Programs for Machine Learning. Morgan Kaufmann Publishers, San Mateo, California.

Quinlan, J. R. (1996). Learning First-Order Definitions of Functions. Journal of Artificial Intelligence Research, 5:139-161.

Quinlan, J. R. e Cameron-Jones, R. M. (1995). Induction of Logic P,rograms: FOIL and Related Systems. New Generation Computing, 13:287-312.

Roberts, S. (1997). An Introduction to Progol. ML-Group,' 'Univiversity of York. ftp://ftp.cs.york.ac.uk/pub/ML_GROUP/progol4.4/.

Robinson, J. (1965). A Machine-Oriented Logic Based on the Resolution Principle. Journal of the $A C M, 12(1): 23-41$.

Rulequest-Research (1999). Data Mining Tools See5 and C5.0. http://www.rulequest.com/see5-info.html.

Russell, S. J. e Norvig, P. (1995). Artificial Intelligence: A Modern Approach. Prentice Hall.

Sammut, C. A. (1993). The Origins of Inductive Logic Programming: A Prehistoric Tale. In Proceedings Third International Workshop on Inductive Logic Programming, páginas 127-147, Bled, Slovenia. Springer Verlag.

Sammut, C. A. (1998). Relations and Background Knowledge. http://www.cse.unsw.edu.au/ cs3411/notes/ml/07ilp/07ilp.html.

Sammut, C. A. e Banerji, R. B. (1986). Learning Concepts by Asking Questions. In Michalski, R. S., Carbonell, J. G., e Mitchell, T. M., editores, Machine Learning: An Artificial Intelligence Approach, volume 2, páginas 167-191, Los Altos, California. Morgan Kaufmann Publishers.

Shapiro, E. Y. (1983). Algorithmic Program Debugging. The MIT Press.

Siou, E. (1994). A Bidirectional Search for Clauses. In Proceedings of the Fourth International Workshop on Inductive Logic Programming, páginas 365-376, Bonn, Germany. GMD.

Sommer, E., Emde, W., Kietz, J.-U., e Wrobel, S. (1996). Moball4.1b9. Usert Gakide (ärafț). GMD, AI Research Division. ftp://ftp.gmd.de/mlt/Mobal/userguide!ps. $\& .: ., . ;$ 
Sommer, E., Morik, K., Andre, J., e Uszynski, M. (1994). What On-line Learning Can Do for Knowledge Acquisition. Knowledge Acquisition, 6:435-460.

Srinivasan, A., Muggleton, S., King, R., e Sternberg, M. (1994). Mutagenesis: ILP experiments in a non-determinate biological domain. In Proceedings of the Fourth Inductive Logic Programming Workshop.

Weiss, S. M. e Indurkhya, N. (1998). Predictive Data Mining: A Practical Guide. Morgan Kaufmann Publishers, San Francisco, CA.

Wrobel, S. (1994). Concept Formation and Knowledge Revision. Kluwer Academic Publishers. 